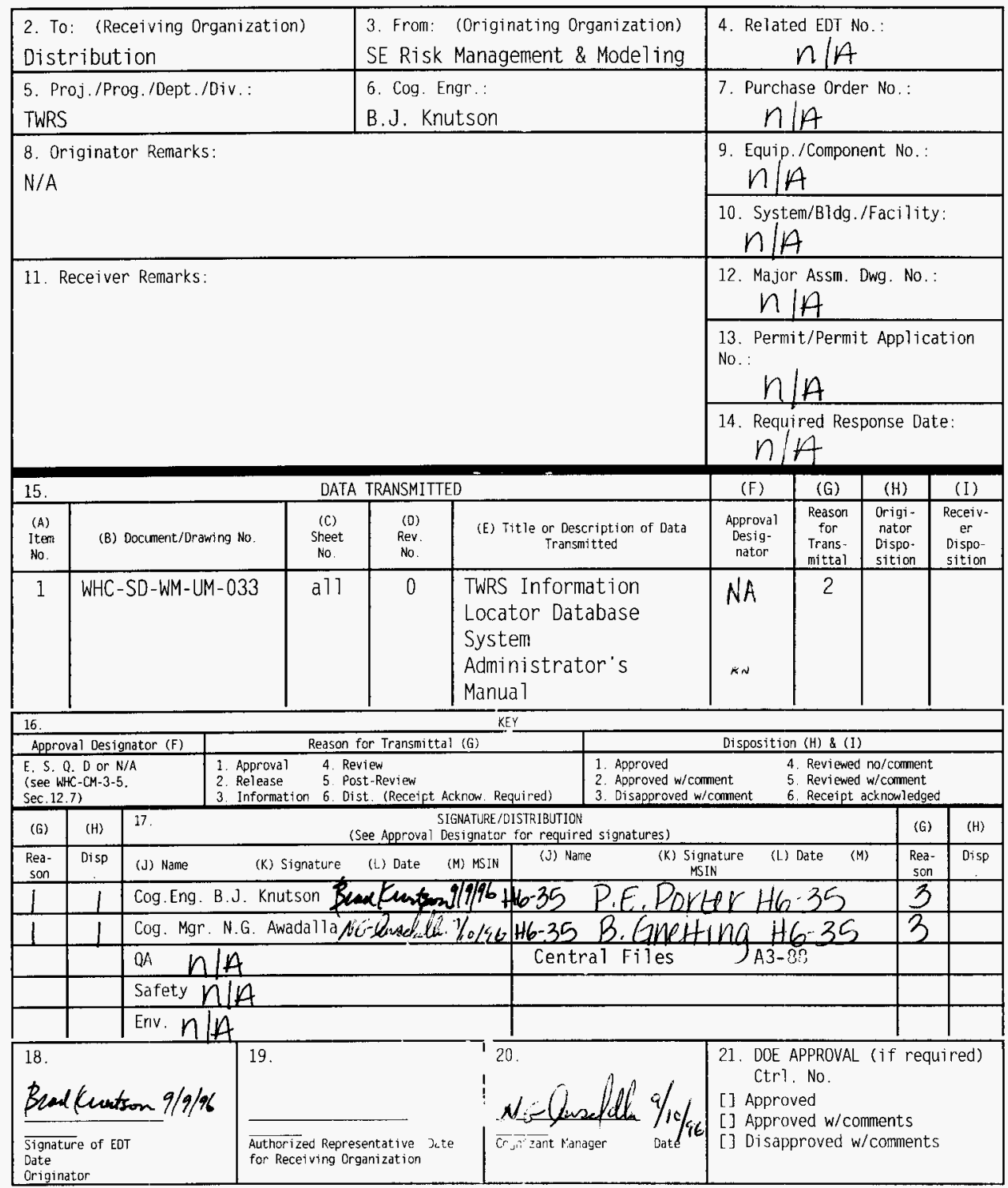




\section{TWRS Information Locator Database System Administrator's Manual}

B. J. Knutson

Westinghouse Hanford Company, Richland, WA 99352

U.S. Department of Energy Contract DE-AC06-87RL10930

C. E. O'Connor

D. J. Kain

Westech International, Richland, WA 99352

EDT/ECN: 613249 UC: 2030

Org Code: 74450

B\&R Code: EW3120075

Charge Code: D1N34

Total Pages: 113

Key Words: ILD, System Design

Abstract: This document is a guide for use by the Tank Waste Remediation System (TWRS) Information Locator Database (ILD) System Administrator. The TWRS ILD System is an inventory of information used in the TWRS Systems Engineering process to represent the TWRS Technical Baseline. The inventory is maintained in the form of a relational data base developed in Paradox 4.5.

TRADEMARK DISCLAIMER. Reference herein to any specific comercial product, process, or service by trade name, trademark, manufacturer, or otherwise, does not necessarily constitute or imply its endorsement, recommendation, or favoring by the United States Government or any agency thereof or its contractors or subcontractors.

Printed in the United States of America. To obtain copies of this document, contact: WHC/BCS Document Control Services, P.O. Box 1970, Mailstop H6-08, Richland WA 99352, Phone (509) 372-2420: Fax (509) $376-4989$.
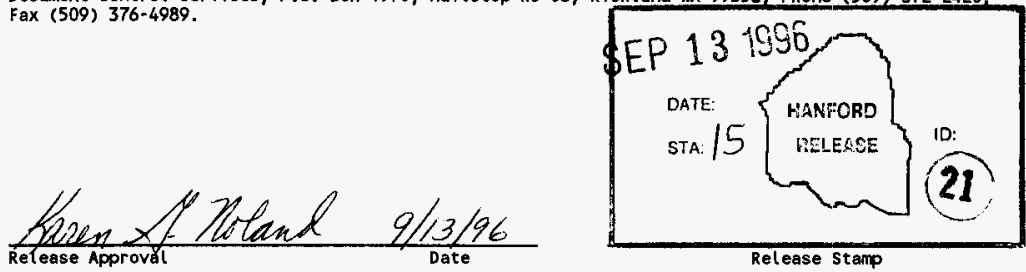
WHC-SD-WM-UM-033 Rev. 0

\section{TRADEMARKS}

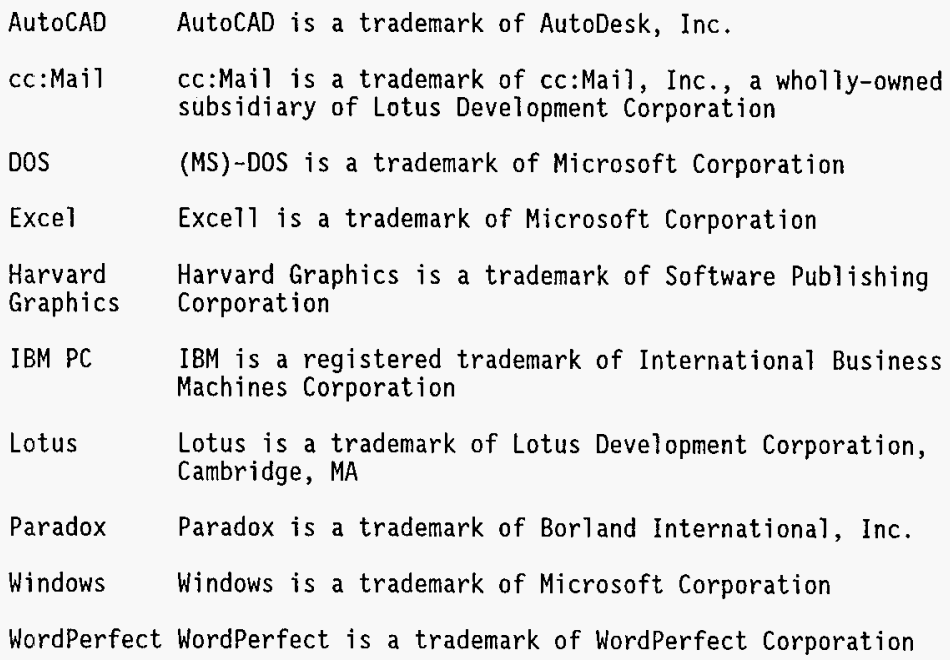




\section{TWRS Information Locator Database System Administrator's Manual}

Prepared for the U.S. Department of Energy Office of Environmental Restoration and Waste Management

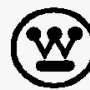

Westinghouse

Hanford Company Richland, Washington

Management and Operations Contractor for the

U.S. Department of Energy under Contract DE-AC06-87RL10930

Approved for Public Release 
WHC-SD-WM-UM-033, Rev. 0

LECAL DISCLAMER

This report was prepared as an account of work sponsored by an agency of the United Stetes Government. Neither the

United States Government nor any agency thereof, nor any of their employees, nor any of their contractors, subcontractors or their employees, makes any warranty, express or implied, or aseumes any legel liability or responsibility for the accuracy, completeness, or any third party's use or the results of such use of any information, apparatus, product, or process disclosed, or represents that its use would not infringe privately owned rights. Reference herein to any specific commerciel product, process, or service by trede name, tredemark, manufacturer, or otherwise, does not necesserily constitute or imply its endorement, recommendation, or favoring by the United States Government or any agency thereof or its contractors or subcontrectors. The views and opinions of authors expressed herein do not necessarily state or reflect those of the United States Government or any agency thereof.

This report has been reproduced from the best available copy.

Printed in the United States of America

DISCLM-2.CHP (1-91) 


\section{Table of Contents}

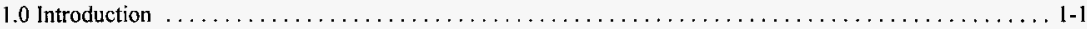

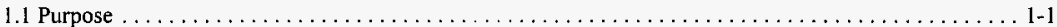

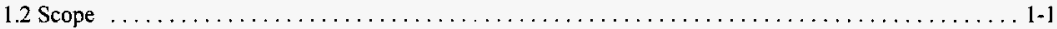

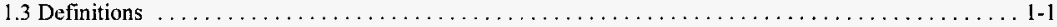

1.4 Overview $\ldots \ldots \ldots \ldots \ldots \ldots \ldots \ldots \ldots \ldots \ldots \ldots \ldots \ldots \ldots \ldots \ldots \ldots \ldots \ldots \ldots \ldots \ldots \ldots \ldots \ldots \ldots \ldots, 2$

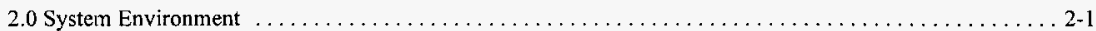

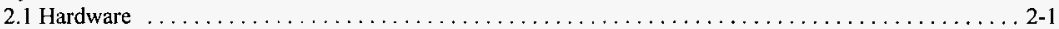

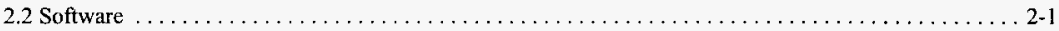

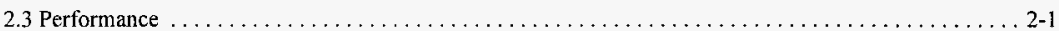

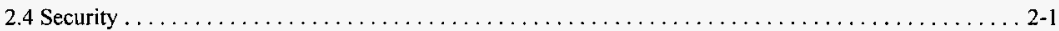

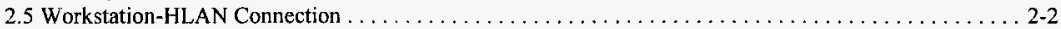

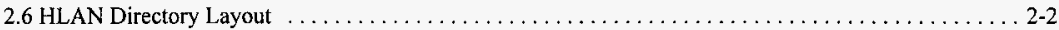

2.7 Function of the TWRSINV and WORKING Directories. $\ldots \ldots \ldots \ldots \ldots \ldots \ldots \ldots \ldots \ldots \ldots \ldots \ldots \ldots \ldots \ldots, 4$

3.0 System Operation $\ldots \ldots \ldots \ldots \ldots \ldots \ldots \ldots \ldots \ldots \ldots \ldots \ldots \ldots \ldots \ldots \ldots \ldots \ldots \ldots \ldots \ldots \ldots \ldots \ldots \ldots \ldots, 1$

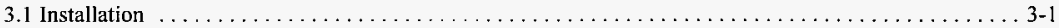

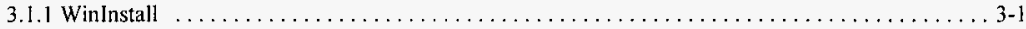

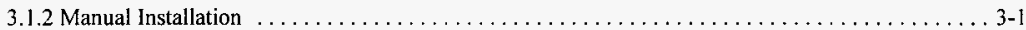

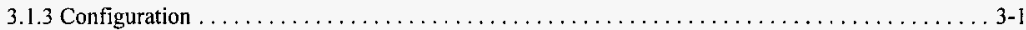

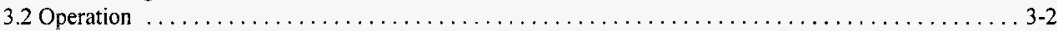

3.2.1 Starting the system $\ldots \ldots \ldots \ldots \ldots \ldots \ldots \ldots \ldots \ldots \ldots \ldots \ldots \ldots \ldots \ldots \ldots \ldots \ldots \ldots \ldots \ldots \ldots \ldots \ldots \ldots \ldots \ldots \ldots, 2$

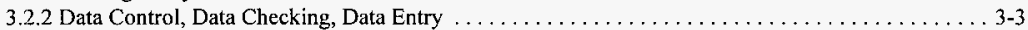

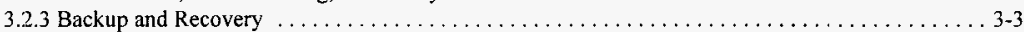

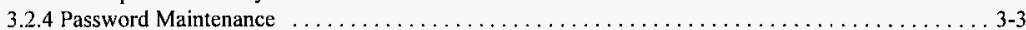

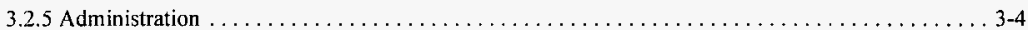

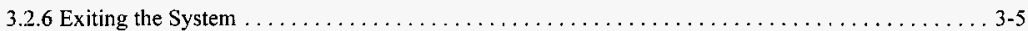

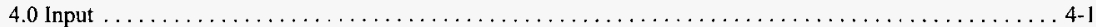

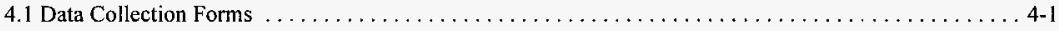

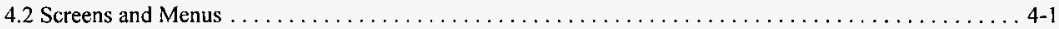

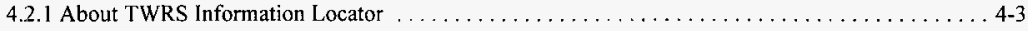

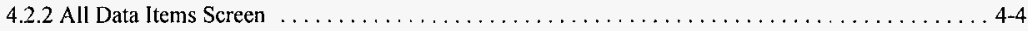

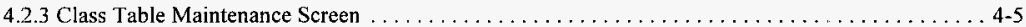

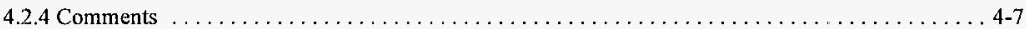

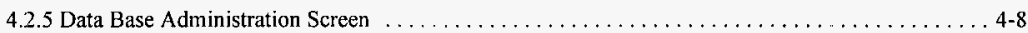

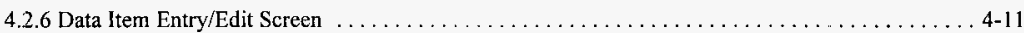

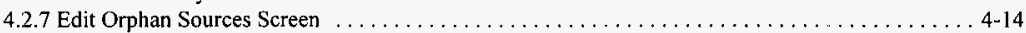

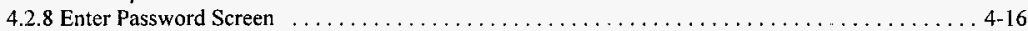

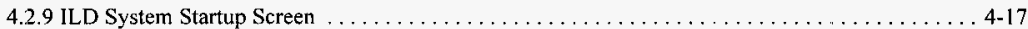

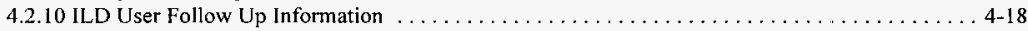

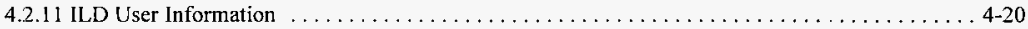


4.2.12 Map Data Items to New System Engineering Functions Screen $\ldots \ldots \ldots \ldots \ldots \ldots \ldots \ldots$. 4-22

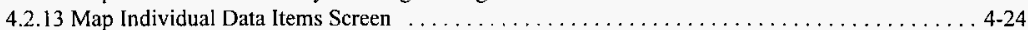

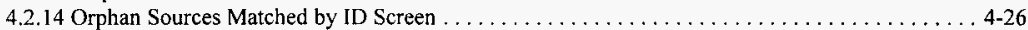

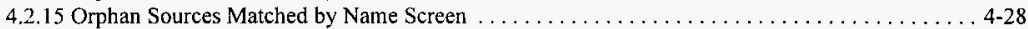

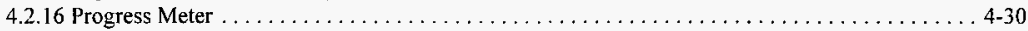

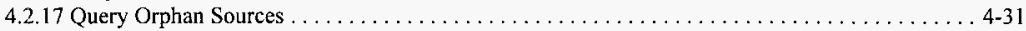

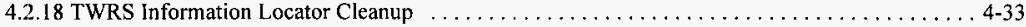

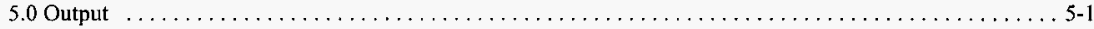

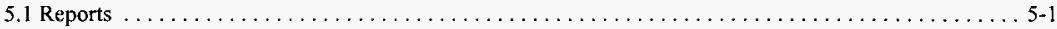

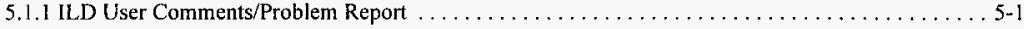

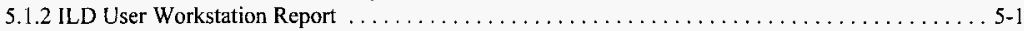

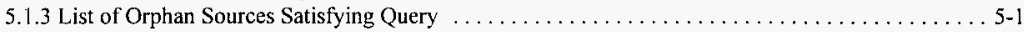

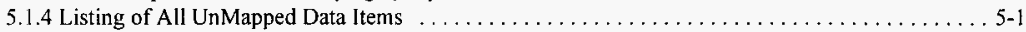

5.1.5 Listing of All UnMapped Data Items for Function $\ldots \ldots \ldots \ldots \ldots \ldots \ldots \ldots \ldots \ldots \ldots \ldots \ldots \ldots \ldots$

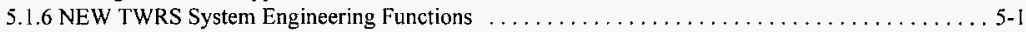

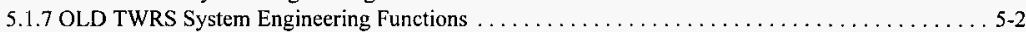

5.1.8 Parent Item, Orphan Source, and Data Base ID Match - Entire Report . . . . . . . . . . . . 5-2

5.1.9 Parent Item, Orphan Source, and Data Base ID Match - Mark Records Report . . . . . . . . . 5-2

5.1.10 Parent Item, Orphan Source, and Data Base Name Match - Entire Report . . . . . . . . . . 5-3

5.1.11 Parent Item, Orphan Source, and Data Base Name Match - Mark Records Report . . . . . . . . 5-3

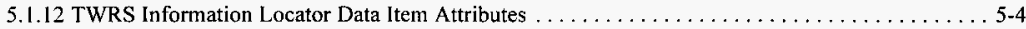

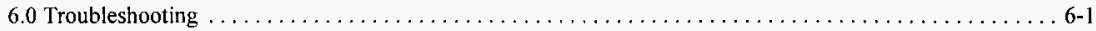

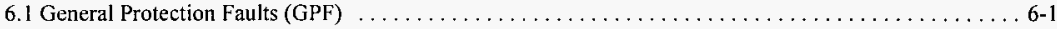

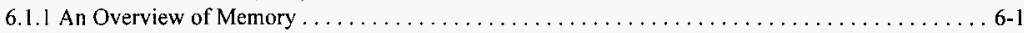

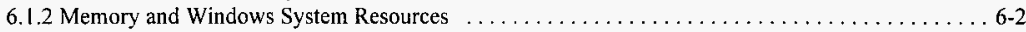

6.1 .3 Protection Faults $\ldots \ldots \ldots \ldots \ldots \ldots \ldots \ldots \ldots \ldots \ldots \ldots \ldots \ldots \ldots \ldots \ldots \ldots \ldots \ldots \ldots \ldots \ldots \ldots \ldots \ldots \ldots \ldots \ldots, 2$

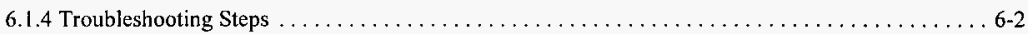

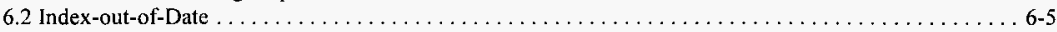

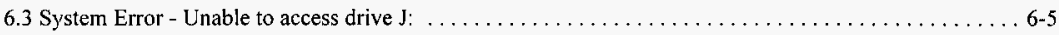

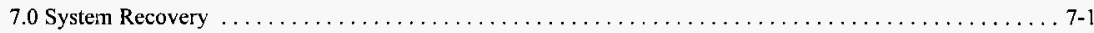

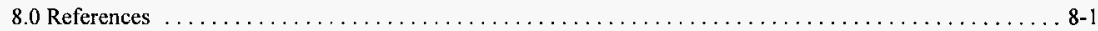

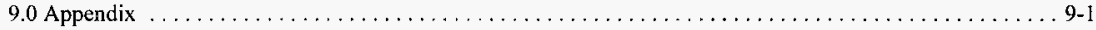

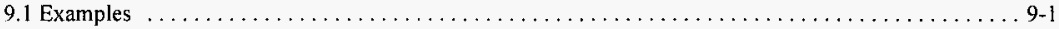

9.1.1 Starting ILD and Accessing System Administrator Functions $\ldots \ldots \ldots \ldots \ldots \ldots \ldots \ldots \ldots$ 9-1

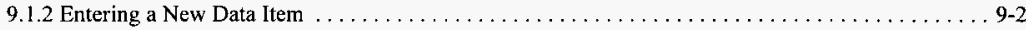

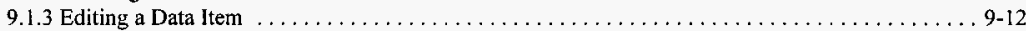

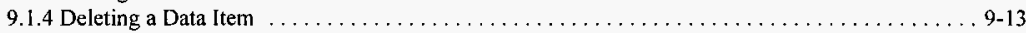

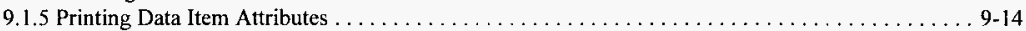

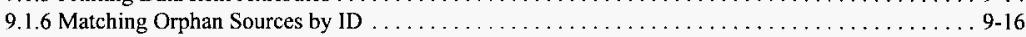

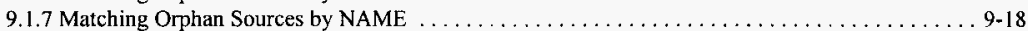

9.1 .8 Editing Orphan Sources . . . . . . . . . . . . . . . . . . . . . . . . . . . . . . 9-20

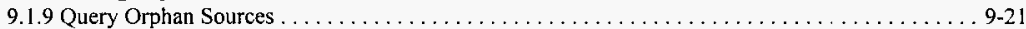

9.1.10 Mapping Data Items to New System Engineering Functions $\ldots \ldots \ldots \ldots \ldots \ldots \ldots \ldots .9 .22$

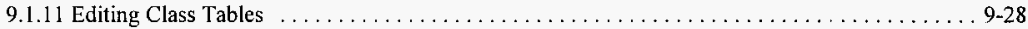

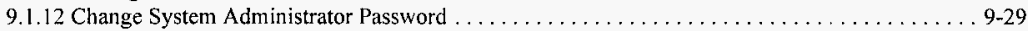

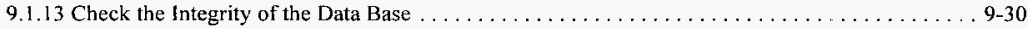




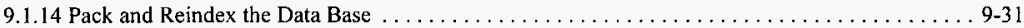

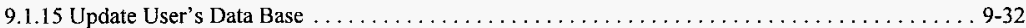

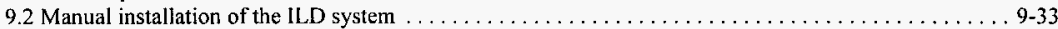

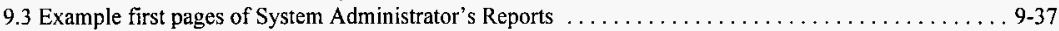

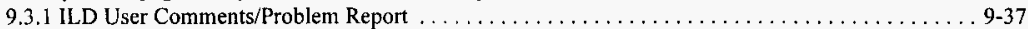

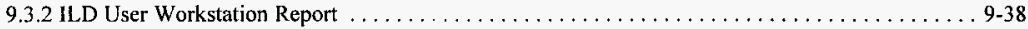

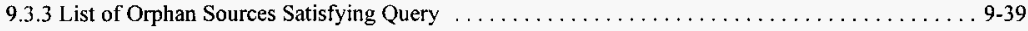

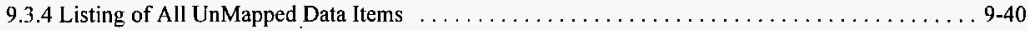

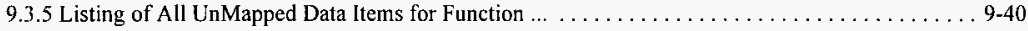

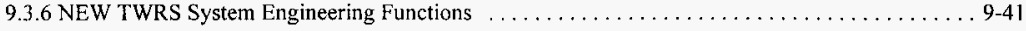

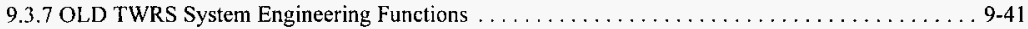

9.3.8 Parent Item, Orphan Source, and Data Base ID Match - Entire Report . . . . . . . . . . . 9-4I

9.3.9 Parent Item, Orphan Source, and Data Base ID Match - Mark Records Report . . . . . . . . 9-42

9.3.10 Parent Item, Orphan Source, and Data Base Name Match - Entire Report . . . . . . . . . . 9-42

9.3.11 Parent Item, Orphan Source, and Data Base Name Match - Mark Records Report . . . . . . . 9-42

9.3.12 TWRS Information Locator Data Item Info $\ldots \ldots \ldots \ldots \ldots \ldots \ldots \ldots \ldots \ldots \ldots \ldots . . . \ldots 2$

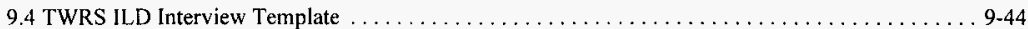




\section{List of Figures}

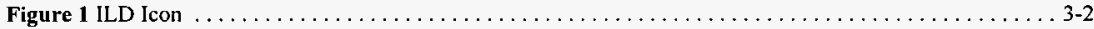

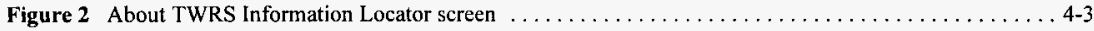

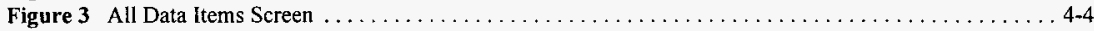

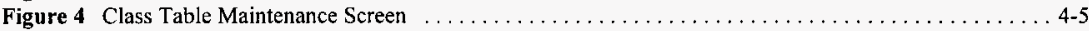

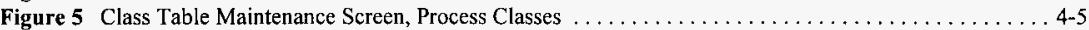

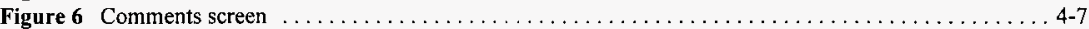

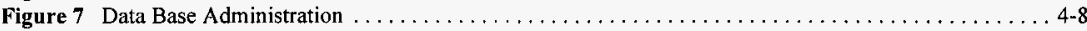

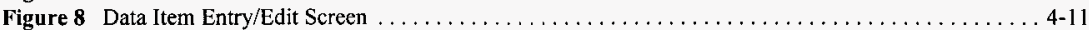

Figure 9 Data Item Entry/Edit, Application Software page. $\ldots \ldots \ldots \ldots \ldots \ldots \ldots \ldots$

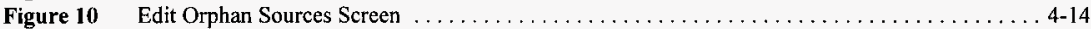

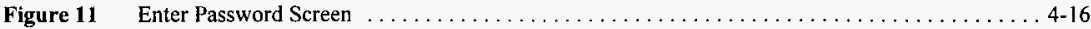

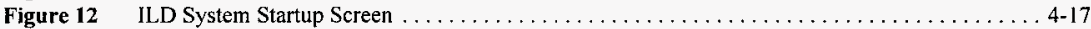

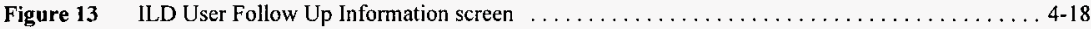

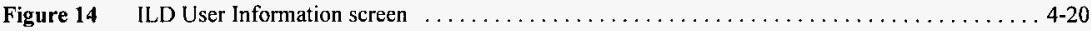

Figure 15 Map Data Items to New System Engineering Function Screen $\ldots \ldots \ldots \ldots \ldots \ldots$

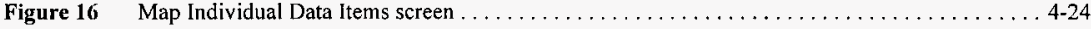

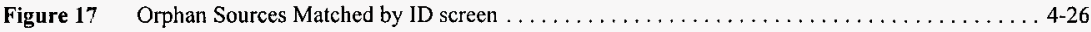

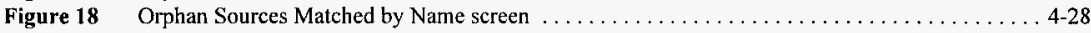

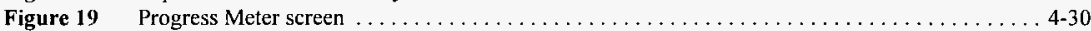

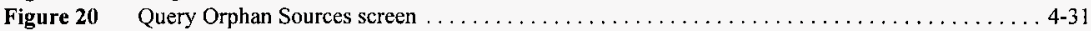

Figure $2 \| \quad$ TWRS Information Locator Cleanup screen $\ldots \ldots \ldots \ldots \ldots \ldots \ldots \ldots \ldots \ldots$

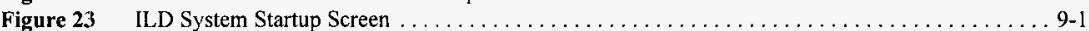

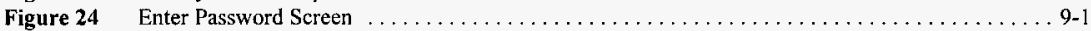

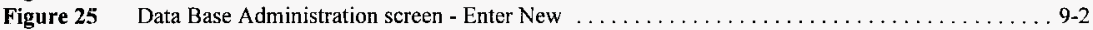

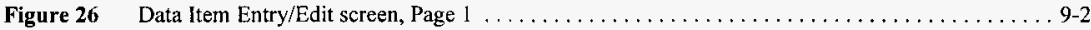

Figure $27 \quad$ Data Item Entry/Edit screen, page $2 \ldots \ldots \ldots \ldots \ldots \ldots \ldots \ldots \ldots \ldots$

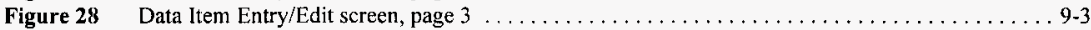

Figure 29 Data Item Entry/Edit screen, page 4 (Data Base type) $\ldots \ldots \ldots \ldots \ldots \ldots$

Figure 30 Data Item Entry/Edit screen, page 4 (Document, Image, etc.) $\ldots \ldots \ldots \ldots \ldots$

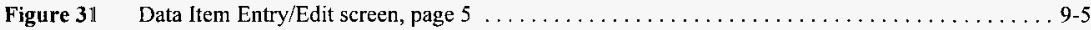

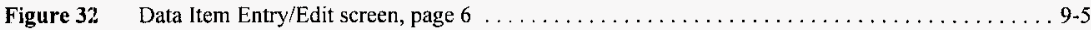

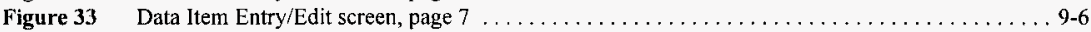

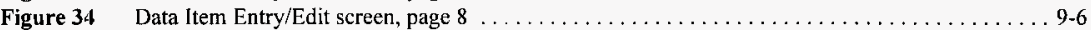

Figure 35 Data Item Entry/Edit screen, page $9 \ldots \ldots \ldots \ldots \ldots \ldots \ldots \ldots \ldots \ldots \ldots \ldots \ldots$

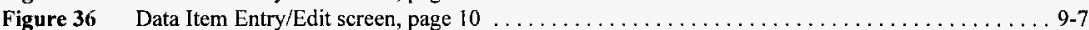

Figure $37 \quad$ Data Item Entry/Edit screen, page $11 \ldots \ldots \ldots \ldots \ldots \ldots \ldots \ldots \ldots$

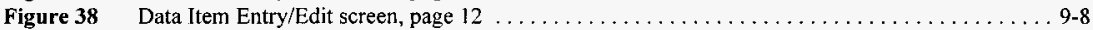

Figure $39 \quad$ Data Item Entry/Edit screen, page $13 \ldots \ldots \ldots \ldots \ldots \ldots \ldots \ldots \ldots \ldots$

Figure 40 Data Item Entry/Edit screen, page $14 \ldots \ldots \ldots \ldots \ldots \ldots \ldots \ldots \ldots \ldots$

Figure 41 Data Item Entry/Edit screen, page 15 (Non-Site standard) $\ldots \ldots \ldots \ldots \ldots \ldots$

Figure $42 \quad$ Data Item Entry/Edit screen, page 15 (Site Standard) $\ldots \ldots \ldots \ldots \ldots \ldots$

Figure $43 \quad$ Data Item Entry/Edit screen, page $16 \ldots \ldots \ldots \ldots \ldots \ldots \ldots \ldots \ldots \ldots$

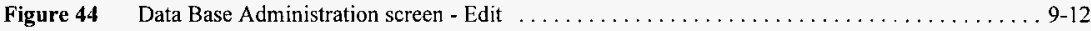

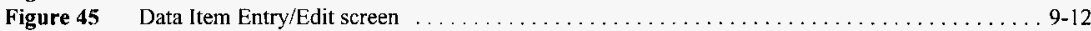

Figure 46 Data Base Administration screen - Delete $\ldots \ldots \ldots \ldots \ldots \ldots \ldots \ldots \ldots \ldots$

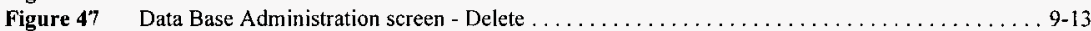

Figure 48 Data Base Administration screen - View/Print $\ldots \ldots \ldots \ldots \ldots \ldots \ldots \ldots \ldots \ldots \ldots \ldots$

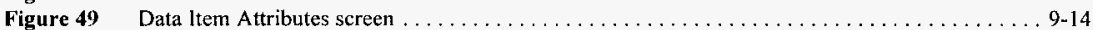

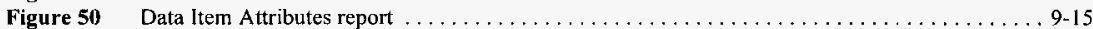


Figure 51 Data Base Administration screen - Orphan Match by ID . . . . . . . . . . . . . .

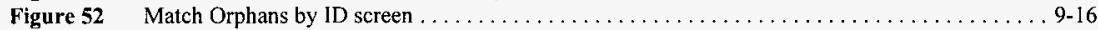

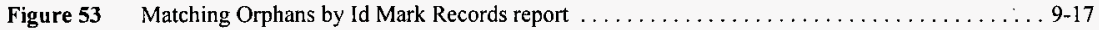

Figure 54 Data Base Administration, Match Orphans by Name screen $\ldots \ldots \ldots \ldots \ldots \ldots \ldots$

Figure 55 Match Orphans by Name - Find Matches screen $\ldots \ldots \ldots \ldots \ldots \ldots \ldots \ldots \ldots$

Figure $56 \quad$ Match Orphans by Name - Link screen $\ldots \ldots \ldots \ldots \ldots \ldots \ldots \ldots \ldots \ldots \ldots \ldots \ldots$

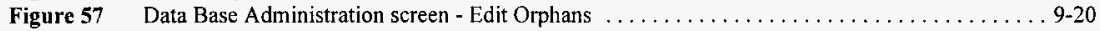

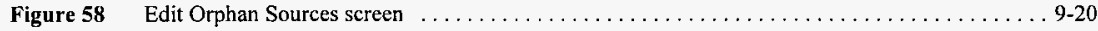

Figure 59 Data Base Administration screen, Query Orphan Sources . . . . . . . . . . . . . . 9 -21

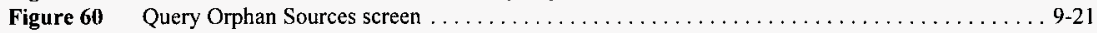

Figure 61 Data Base Administration screen, Map Data Items . . . . . . . . . . . . . . . .

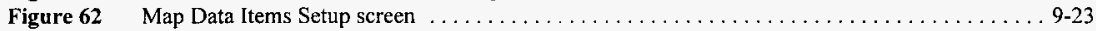

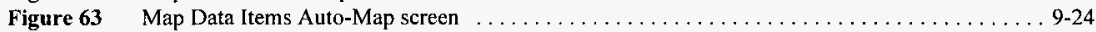

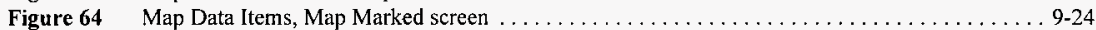

Figure 65 Map Data Items, UnMap Marked screen $\ldots \ldots \ldots \ldots \ldots \ldots \ldots \ldots \ldots \ldots \ldots$

Figure 66 Map Data Items, Commit Changes screen $\ldots \ldots \ldots \ldots \ldots \ldots \ldots \ldots \ldots \ldots$

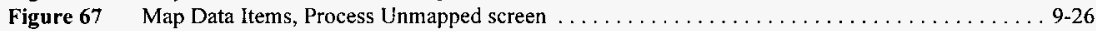

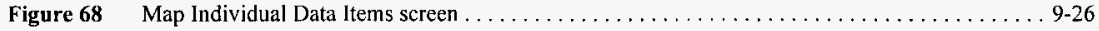

Figure 69 Map Individual Data Items, Map Data Item screen $\ldots \ldots \ldots \ldots \ldots \ldots \ldots \ldots \ldots \ldots$

Figure 70 Map Individual Data Items, Unmap Data Item screen $\ldots \ldots \ldots \ldots \ldots \ldots \ldots \ldots \ldots$

Figure 71 Data Base Administration screen, Edit Class Tables . . . . . . . . . . . . . . . . .

Figure $72 \quad$ Class Table Maintenance Screen $\ldots \ldots \ldots \ldots \ldots \ldots \ldots \ldots \ldots \ldots \ldots \ldots \ldots \ldots \ldots \ldots$

Figure 73 Data Base Administrator screen, Change Password $\ldots \ldots \ldots \ldots \ldots \ldots \ldots$

Figure 74 Change System Administrator Password screen $\ldots \ldots \ldots \ldots \ldots \ldots \ldots \ldots \ldots \ldots$

Figure 75 Data Base Administration, Check Data Base Integrity $\ldots \ldots \ldots \ldots \ldots$

Figure 76 Data Base Administration, Pack and Reindex Data Base . . . . . . . . . . . . . . 91

Figure 77 Data Base Administration, Update User's Data Base $\ldots \ldots \ldots \ldots \ldots \ldots \ldots \ldots$

Figure $78 \quad$ ILD Manual Install, Paradox Runtime Installation Screen $\ldots \ldots \ldots \ldots \ldots \ldots$

Figure $79 \quad$ ILD Manual Install, Paradox Installation Complete Screen $\ldots \ldots \ldots \ldots \ldots \ldots \ldots$

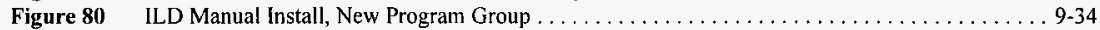

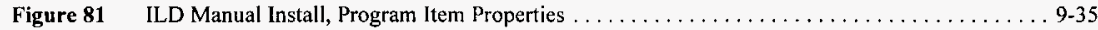

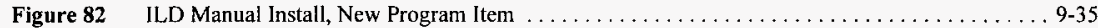

Figure $83 \quad$ ILD Manual Install, Program Group Properties $\ldots \ldots \ldots \ldots \ldots \ldots \ldots \ldots$ 


\subsection{Introduction}

The purpose of the Tank Waste Remediation System (TWRS) Information Locator Database (ILD) system is to provide a directory of information sources and source attribute information supporting the TWRS Technical Baseline that is available to Site personnel through network resources. The TWRS ILD system supports the management of information necessary for defining and maintaining the TWRS Technical Baseline. It includes information mapping features that show information relationships between TWRS functional or program management hierarchies. The database provides an orderly cataloging of information used to support the TWRS Systems Engineering process. This catalogue, or inventory, contains descriptive attributes of each data item including its identification, source, use, applicability to the TWRS Systems Engineering process, and certain technical information regarding its preparation and handling to facilitate its identification and acquisition by a potential user. The inventory is maintained in the form of a relational database developed in Paradox 4.5.

\subsection{Purpose}

The purpose of this manual is to provide the system administrator sufficient information about the TWRS ILD System to allow for system and data maintenance. This manual is for that person who is responsible for maintaining the system and data.

\subsection{Scope}

This document will provide the system administrator with information relevant to data entry procedures and maintenance, system maintenance and backup, and general setup information. It is not intended to be a technical description of the data base structure or the software that controls and accesses the data base. For a further discussion of these technical aspects, please refer to the TWRS ILD System Design Description (WHC-SD-WMADP-024).

\subsection{Definitions}

The following acronyms and definitions are referenced within this document:

Data Item

Drains

HLAN

Orphan Sources

Shared Area

Sources
An identifiable piece of information that is generated, used, (or both) by the TWRS Systems Engineering Process, and is retained as a permanent record.

Drains are one or more data items to which the particular data item being classified contribute. Every drain data item must be, itself, a TWRS Information Locator Data Item. However, a particular data item need not, itself, be listed as a drain of another data item.

Hanford Local Area Network

Orphan sources and drains are those items that have been identified as being sources to data items that were previously entered into the database but have not yet had their information collected and entered.

The area on an HLAN server set aside to contain data relating to a specific function or individual.

Sources are one or more data items which contribute to the development of the particular data item being classified. Every source data item must be, itself, a TWRS 
Information Locator Data Item. However, a particular data item need not, itself, be listed as a source for another data item.

Template

The data collection form which is used to record attribute information about data items during interviews with personnel.

Working Directory The directory in the server shared area that contains the ILD system.

For further definitions, please refer to the TWRS Information Locator System Description document.

\subsection{Overview}

This document has been prepared using the guidelines set forth in document "Software Practices, System User Documentation", WHC-3-10, Appendix I, Rev. 2.

Below is a listing of the sections contained within this document:

- Section 1 - Introduction, describes the purpose and specifies the intended audience.

- Section 2 - System Environment, describes the hardware, software, and general operating environment.

- Section 3 - System Operation, guidance in operating the system.

- Section 4 - Input, detailed explanations of the procedures, forms, menus, and screens used in the input process.

- Section 5 - Output, explanations of the reports available to the system administrator and their use.

- Section 6 - Error Messages, a description of possible error messages that may be encountered while using the system.

- Section 7 - System Recovery, a description of steps needed to recover from abnormal system shutdown.

- Section 8 - References, a listing of all documents referenced in this documentation.

- Section 9 - Appendix, examples. 


\subsection{System Environment}

\subsection{Hardware}

Each workstation must have the following minimum configuration in order to install and use ILD effectively:

IBM PC compatible

486-33 CPU

$6 \mathrm{Mb}$ RAM

$10 \mathrm{Mb}$ hard drive space for installation

$5 \mathrm{Mb}$ hard drive space for using the system (queries and admin. functions)

Physical connection to the HLAN

\subsection{Software}

The system (data base and software) was developed, and is implemented, using Paradox for Windows 4.5 running under Windows 3.11 for Workgroups.

\subsection{Performance}

Major factors that influence system performance are:

- $\quad$ Speed of the workstation (CPU, hard disk access, etc.)

- Amount of RAM on the workstation

- Amount of free hard drive space on the workstation

- Speed of the workstation-HLAN network connection

- Speed of the server that hosts ILD system

- Number of users accessing ILD

Users of the system who wish to increase the response time can fine tune their workstations (other than upgrading the components listed above) in the following manner:

- Go into Windows Control Panel (usually in the Main Program Group)

- Double-click on the 386 Enhanced icon

- Click on the Virtual Memory button

- Check the swap-file setting. If it is "Temporary", change it to "Permanent". This may help speed up Windows performance in general. Refer to the Microsoft Windows User's Guide for further information

Another method of speeding things up is to reduce the resolution of the workstation. Too high a resolution may affect Windows performance. To check the resolution:

- From the Windows Program Manager, double-click the Main Program Group

- Double-click the Windows Setup icon

- The resolution is listed next to Display:. If this is too high, reducing it may increase Windows performance Refer to the Microsoft Windows User's Guide for further information on changing the Display settings

\subsection{Security}

All tables used in the ILD system are password protected. This password, "ILD-TWRS-ILD", is issued when the user starts the system in the STARTUP.SSL script. Any table that is opened during the session then uses this 
password for access to the data. Additionally, if a user tries to open the table using Paradox interactive, the password must be issued before the data can be accessed.

Access to the data base functions in the system software is controlled through password protection to the system administrator functions. These functions are the only way that users can change the data in the data base while in the system.

The password, which is stored in the CFG.DB table, is maintained by the system administrator and can be changed only by accessing the system administrator functions.

\subsection{Workstation-HLAN Connection}

The workstation connected to the HLAN must be configured so as to be able to access the HLAN server and shared area which contains the ILD system. This connection is established at HLAN log on time through each user's U:AAUTOUSER.BAT file. In this file, a line of the form

\section{NET USE J: IISERVERISHARED-AREA PASSWORD}

must exist. This establishes drive J: to point to the shared area that contains the ILD system.

Once this connection is made, another important connection is ensured through the following setup. This is the connection to the J:PDOXDATA PDDOXUSRS.NET file, or the Paradox Network Control File.

The purpose of this file is to control multi-user Paradox table access from multiple workstations. Each workstation must be using the same network control file when accessing common Paradox tables located on a network server (please see the Borland Paradox Users Guide for more details).

The method of ensuring that each workstation is using the same network control file is as follows:

- at system startup, the command line option -o (see "Section 3.1 - Installation" below) ensures that each workstation starts up using the same ODAPI.CFG file (in this case, the J:IODAPI \ODAPI.CFG file).

- the ODAPI.CFG file tells Paradox the directory location of the PDOXUSRS.NET file (in this case, J:(PDOXDATA).

Using the command line method to point to a common ODAPI.CFG file ensures that each workstation is using the same network control file.

\subsection{HLAN Directory Layout}

The system is contained in a shared area on an HLAN server. Within this shared area are a number of directories that contain the software and data base of the system.

There are two directories in the shared area that contain basically two ILD systems, with a few differeneces. The TWRSINV directory contains the ILD system that the general user accesses and will only allow read access to the data through the system software. Only queries can be done on the data through this directories.

The WORKING directory is accessed by the system administrator and is used to perform data base maintainence and updates. The data base is then periodically copied over to the TWRINV directory. 
Please see Section 2.7 below for a further explanation of the function of these two directories.

Below is a listing of the directories and their purpose (assume that drive J: points to the shared area):

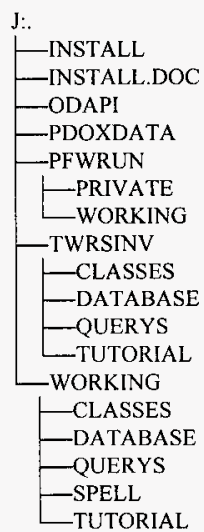

J:

J:IINSTALL

J:INSTALL.DOC

J:XODAPI

J:PDOXDATA

J:IPFWRUN

J:APFWRUNIPRIVATE

J:PFWRUN\WORKING

J:\TWRSINV
This is the root directory of the shared area that contains the ILD system and related data.

Contains the installation files that allow for manual installation of Paradox for Windows 4.5 Runtime.

Contains Windows write files describing the manual installation process.

This directory contains the ODAPI.CFG file.

Contains the PDOXUSRS.NET network control file.

The already installed Paradox for Windows 4.5 Runtime software.

A directory Paradox would use as the default Private directory (the ILD system uses another directory as the Private directory, namely C:IWINDOWSITEMP).

A directory Paradox would use as the default Working directory (the ILD system uses another directory as the Working directory, namely J:ITWRSINV).

This is the working directory of the ILD system that is accessible to the general ILD user. The files and subdirectories contained within are the parts of the ILD system that were developed in Paradox. 
$J: \backslash T$ TRSINVICLASSES Contains the class tables used in the system. Please refer to document "ILD System Design Description" for a further explanation of class tables.

J:TWRSINVDATABASE This contains the entire ILD database.

J:ITWRSINVIQUERYS This subdirectory contains the files pertaining to the query functions available in the system (see documents "ILD System Design Description" and "ILD User Guide" for a description of the query side of the system.

J:\TWRSINVITUTORIAL The files used in the tutorial module of the ILD system are contained here. Please refer to document "ILD System Design Description" for a further explanation of the tutorial.

J:IWORKING

J: WORKING $\backslash C L A S S E S$

J: WWORKING DATABASE This contains the entire ILD database.

J:IWORKINGIQUERYS

J:WORKING\TUTORIAL

J:IWORKINGISPELL explanation of the tutorial.
This is the working directory of the ILD system that is only accessible by the system administrator. It is used by the administrator to maintain and update the data base. The files and subdirectories contained within are the parts of the ILD system that were developed in Paradox.

Contains the class tables used in the system. Please refer to document "ILD System Design Description" for a further explanation of class tables.

This subdirectory contains the files pertaining to the query functions available in the system (see documents "ILD System Design Description" and "ILD User Guide" for a description of the query side of the system.

The files used in the tutorial module of the ILD system are contained here. Please refer to document "ILD System Design Description" for a further

This contains the spell checker used in data entry.

\subsection{Function of the TWRSINV and WORKING Directories.}

The two directories, TWRSINV and WORKING, are used in slightly different manners. The TWRSINV directory is accessed by the general ILD user and contains the data base for viewing only. No edit access of the data base is allowed for the general user in this directory. The querying capability allows for read-only access of the data.

The WORKING directory is accessed by the system administrator and contains the data base that is being updated. The data contained in this directory is periodically copied over to the TWRINV directory for general use. The system administrator functions allow for data editing and general system maintenance. This directory is where all of the system administrator functions are applied.

These two directories are split this way in order to allow general users faster access to queries, etc. as the system administrator process can sometimes be processor intensive and would slow down the overall performance of the system. 
Access to the two directories is controlled in the command line parameter -w which is descibed in further detail in Section 3.1.3. Please refer to this section for a further explanation of the command line used to start the ILD system. 


\subsection{System Operation}

This section provides guidance and explanation on the installation, configuration, and operation of the ILD system.

\subsection{Installation}

Each workstation must go through an installation process in order to configure the workstation to allow access to the ILD system. There are two ways to install the system on a workstation:

- Using WinInstall

- Manual Installation

\subsubsection{Win Install}

WinInstall is an HLAN option that is only available to workstations that have been ESOEd (please refer to "ESOE Information" under the "Hanford User Help-n-Hints" Windows Icon, or call Computer Technical Support for more information regarding ESOEing a workstation). Use of this option eliminates the need for tedious and sometimes troublesome steps in configuring the workstation.

However, at this time, WinInstall will not allow for ILD system installation on a drive other than C.: In order to do this, a manual installation must be done.

Note: WinInstall will install ILD as a general user system and does not allow access to the system administrator functions. Please read Section 3.1.3 (command line description) for instructions on how to set up a workstation for access to the system administrator functions (contained in the J:IWORKING directory).

\subsubsection{Manual Installation}

This process requires the user to install the ILD system through a manual step-by-step process. By using this method the user can install the ILD system on their D: drive, or other workstation drive, if they so desire:

- Install Paradox for Windows 4.5 Runtime on the workstation.

- Manually edit file C: $\quad$ AUTOEXEC.BAT.

- Manually edit file U:AUTOUSER.BAT.

- Exit windows and reboot the workstation.

- Create a Windows icon with the proper command line.

Please see the Appendix for a step-by-step example of a manual installation.

\subsubsection{Configuration}

Once the installation process is complete, the workstation will have the following configuration which is needed in order to properly access the ILD system.

- Paradox for Windows Runtime will have been installed in two directories on the workstation's hard drive: 
C:PFWRUN Contains the Paradox Runtime software.

C:IODAPI Contains the Paradox Open Database Architecture Programming Interface files.

Please refer to Borland's "Paradox for Windows User's Guide" for further information regarding Paradox software.

- The file C:IAUTOEXEC.BAT will have C:IODAPI added to the path statement (or D:IODAPI if the installation is to the D: drive). This is needed so that Paradox can find the ODAPI files it needs in order to execute properly.

- The file U:IAUTOUSER.BAT will have a line added to it that at HLAN $\log$ on time will connect to the ILD system shared area. See Section 2.5 for further information.

- A windows icon will have been created that when double-clicked will start the ILD system. The command line for this icon contains command line options that provide Paradox with information about file locations, along with the file that starts the ILD system. Below is the command line along with a brief explanation of each command line option:

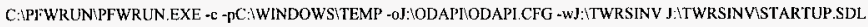

-c starts Paradox with a clean desktop

-p use this directory as the Private Directory (location of temporary files)

$-0 \quad$ use this file as the ODAPI configuration file

-w use this directory as the Working Directory (location of the ILD system)

Startup file this file starts the ILD system

(Please refer to the "Borland Paradox for Windows User's Guide for a further explanation of command line options.)

Note: This command line allows entry to the TWRSINV directory. This directory is for use by the general user and does not allow access to any of the system administrator functions. A different command line is used to access the WORKING directory, which is the directory where all of the administrator functions are applied.

The work station that is used by the system administrator should use the following command line in order to gain access to the administrator functions:

C:IPFWRUN\PFWRUN.EXE -c -pC:IWINDOWS\TEMP -oJ:LODAPIIODAPI.CFG -wJ:IWORKING $\mathrm{J}:$ WORKINGISTARTUP.SDL

\subsection{Operation}

Operation of the ILD system is done totally through the Windows operating system. Following is an explanation of the major functions of the system administrator module.

\subsubsection{Starting the system}

Once the ILD system has been installed on a workstation, it is started by double-clicking on the Windows icon at right. At this point, Paradox is loaded, the startup file is executed, and the main menu screen is displayed. The user must then hit the $<$ F $9>$ key and enter the system administrator password in upper case (the workstation is required to have a minimum

TWRS ILD

Figure 1 ILD ICON 
of $5 \mathrm{Mb}$ of free hard drive space before access is granted). The administrator screen is then displayed.

Please refer to Section 9.1.1 for an example of this procedure.

\subsubsection{Data Control, Data Checking, Data Entry}

Data entry is controlled by using temporary tables to hold the data until the user specifies that they wish to save the data item to the data base. By holding the data in temporary space, the data base will not be affected by an abnormal shutdown. All that is lost is the data in the temporary tables.

All temporary tables are stored in the Private Directory (the location of this directory is specified on the command line, normally in C:IWINDOWSITEMP). Each table is created when it is needed, and deleted when exiting the system. Temporary tables are also deleted at system startup in case of an abnormal shutdown the previous session.

Data entry consists of entering textual data, and choosing from a pop up menu of classes for those attributes that have classes. E.g., the data item type has six classes (Computer Program, Document, Data base, Image, Line Drawing, Report, and Video). When the user needs to enter the data item type, a pop up menu is presents the user with these choices. The choices in the pop up menu are what is contained in the class table for the data item type (TYPECLAS.DB).

Presenting the user with the current classes contained in the data base for an attribute ensures that the data base is clean. This method is employed for all those attributes that have classes associated with them.

For textual data entry, a spell checking feature is available for any attribute that requires textual input, e.g., data item name.

\subsubsection{Backup and Recovery}

The data base and software are backed up on a daily basis in the event of data loss or corruption. Since the data and the software reside on an HLAN server, this backup is done by the network personnel responsible for the server which hosts the ILD system. For further information regarding the backup procedure for the server, please call Customer Technical Support at 376-1234.

Restoration of data base and/or software files from a backup are also handled by Customer Technical Support. In the event that the system administrator wishes to restore specific files, he/she needs to call CTS at 376-1234 and give them a list of files to be restored.

\subsubsection{Password Maintenance}

The system administrator maintains the password that allows access to the system administrator functions of the system. In order to change the password, follow this procedure:

- Start the ILD system

- $\quad$ Press $<$ F9>

- Enter the system administrator password

- Click $\mathrm{OK}$

- Click on the "Change Password" button

- Enter the new password (remember that the password is UPPER CASE)

- Click OK 
The new password will now be in affect the next time the system administrator module is started. Remember to write it down somewhere.

Note: In the event that the administrator does not remember the password, it can be found by looking in the CFG.DB table in the ILD system working directory. There is only one record in this table, and it contains the system administrator password.

\subsubsection{Administration}

Administration of the ILD system consists of these functions:

\section{- Processing Orphan Sources}

This process consists of reconciling the records in the Orphan Source file. This file is a repository of data items that were identified as sources to parent items, but at the time of saving the parent item, the source could not be found in the data base (the name, id, and revision number of the source must be found in the data base in order to a link to be done between the source and the parent). Therefore, a record of the data item name, id and revision number of this orphan is stored in the orphan source table, along with a reference to the parent item.

The administrator's job in reconciling this file is to use the forms "Query Orphan Sources", "Edit Orphan Sources", "Orphan Sources Matched by 1D", and "Orphan Source Matched by Name" to determine what to do with each record in the orphan source file.

Sometimes, a source's name or id was mistyped, and that is why it is in the orphan file. In this case just correcting the name and/or id and relinking will take care of the orphan.

Or the source had not yet been entered into the data base. In this case the orphan needs to be entered as a new data item.

The idea is to keep on top of the orphan source file as it can, and does, grow to be a very large file.

- Processing new System Engineering Functions

The main job of the administrator here is to maintain the TWRS System Engineering Functions based on changes received from the RDD-100 system. This ensures that the user is referencing the latest version of these functions.

Please refer to Section 9.1.10 for a complete explanation of this process.

- Adjustment of the interview template

Anytime that an attribute has their classes adjusted or changed the interview template should be changed to reflect this. Since this template is the mechanism for recording and entering data item attribute information it is important that it reflect the current status of the class tables.

Section 9.4 contains the TWRS ILD Interview Template.

- Tracking user's comments/suggestions and problems 
User's of the ILD system have to option to enter comments/suggestions and/or problems that they encounter while using the system. The administrator should keep track of these using the "ILD User Information" "ILD User Followup Information" forms. Use of these allow the administrator to track and reconcile problems that user's may have had while using the system. It is also the mechanism by which user's can request that new data items be added into the system.

- Packing and reindexing the data base

On a periodic basis it is a good idea for the administrator to pack and reindex the data base. Paradox will leave blank "holes" in a table when a record is deleted. These "holes" end up using space. By packing and reindexing the data base these holes are deleted and the space is freed up thereby increasing overall system performance. Please see the description for the "Data Base Administrator Screen" for instructions on how to pack the data base

- Check data base integrity

Also, on a periodic basis, the administrator should run this to check the links in the data base and delete those records in tables that are not linked to anything else. There is the possibility that during data entry, if the workstation freezes up, that records will be in the data base that are not linked to anything else. This option deletes those records and cleans up the data base links. Please see the description for the "Data Base Administrator Screen" for instructions on how to check the data base integrity.

- Update the General User data base

The administrator must periodically update the general user ILD data base (contained in directory J:ITWRSINVIDATABASE) by copying the data base from the J:IWORKINGIDATABASE working directory. This is accomplished by using the Update DB button on the "Data Base Administrator Screen". Please see the description for the "Data Base Administrator Screen" for instructions on how to update the general user data base.

\subsubsection{Exiting the System}

Exiting the ILD system is important in two ways. Temporary tables are cleared out of the private directory thereby clearing up hard disk space on the workstation, and Paradox is properly closed which in turn properly releases locks on tables and directories.

To exit the ILD system correctly, choose the File | Exit main menu option if it exists, or close all open windows until the main ILD screen is displayed and choose Exit from the main menu. 


\subsection{Input}

\subsection{Data Collection Forms}

The data collection form listed in Section 9.4 is the mechanism by which data item attributes are collected and entered into the data base. It is to be used as a guide in conducting interviews with personnel involved in the TWRS Systems Engineering Process, and to record attribute information about the data items that they use.

The subject matter of the Template are the attributes of these data items. It is to be used to obtain information about each Data Item that will be retained in the Data Inventory. While much of the information contained in the Template may be obtained through accessing existing Site data repositories, other information will require direct interviews with personnel involved in the TWRS Systems Engineering process. Use of the Template will help ensure the conduct of an orderly and complete interview.

A complete interview template is listed in Section 9.4.

\subsection{Screens and Menus}

Below are the screens that comprise the ILD system administrator's module. Each screen is printed along with a brief explanation of it's function, it's layout, the menu options available, a list of the buttons available, and a brief description of their function.

The layout common to each screen is:

- The name of a screen is contained on the top line.

- The second line of a screen contains the main menu.

- The body of the screen.

- The bottom line of the screen, to the left, is the message area and can contain various messages and information about the screen.

Each screen contains a variety of objects. These objects either display information or perform actions. Below is a list of these objects:

- $\quad$ Text objects
- Ruttons
- $\quad$ Radio buttons
- Tables

- Text objects

- Buttons

- Fields

The screens that makeup the ILD system administrator's module are:

\author{
display of information \\ performs and actions when clicked with the mouse \\ performs and actions when clicked with the mouse \\ allows for display and/or input of data \\ allows for display and/or input of data
}

- $\quad$ All Data Items screen

- About TWRS Information Locator

- Class Table Maintenance screen

- Comments

- Data Base Administration screen

- Data Item Entry/Edit screen

- Edit Orphan Sources screen

- Enter Password screen

- ILD System Startup screen 
- ILD User Follow Up Information

- ILD User Information

- Map Data Items to New System Engineering Functions screen

- Map Individual Data Items screen

- Orphan Sources Matched by ID screen

- Orphan Sources Matched by NAME screen

- Progress Meter

- Query Orphan Sources

- TWRS Information Locator Cleanup 


\subsubsection{About TWRS Information Locator}

The purpose of this screen is to provide information about the TWRS Information Locator System to the online user. The version number and version date are provided.

This screen is displayed when the user selects Help | About IL.D... from any of the main menus on any of the ILD screens.

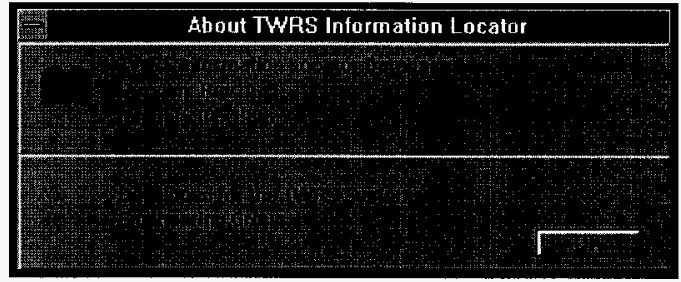

Figure 2 About TWRS Information Locator screen 


\subsubsection{All Data Items Sereen}

The purpose of this screen is to allow the user to choose from a list of data items that are currently in the data base. In this way it can eliminate unnecessary typing of the data item name, id, and revision number of a source if it has already been entered into the data base. It can also eliminate typing mistakes.

This screen is used during data entry of sources and drains of a data item. When the user is entering data item sources and drains, this screen can be displayed by selecting the "List Data Items" menu option in the Data Item Entry/Edit main menu. This displays all of the data item's name, id, and revision numbers that are currently in the data base. The data entry person can then choose a data item to use as the source. Figure 3 All Data Items Screen

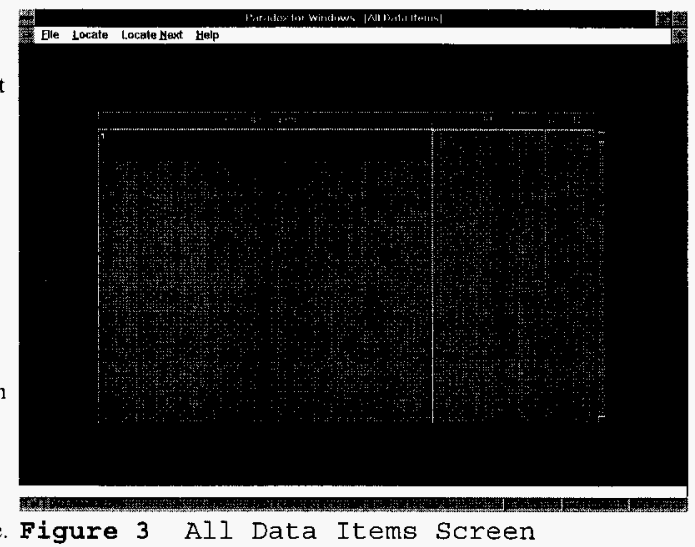

The table in the middle of the screen contains all of the data items. The user can scroll down using the vertical scroll bar on the table, or page down using the keyboard, or use the Locate and Locate Next menu options to locate and highlight a data item. Once this is done, the File $\mid$ Ok menu option will use the selected data item as the source. If File $\mid$ Cancel is selected, this screen is closed and control returns to the previous screen.

Below is the main menu of this form. Each line is an option in the menu. Those options that are bolded signify lower level options to choose from.

Main menu:

File

Locate

Locate Next

Help

file menu (described below)

allows the user to enter a search string to locate a data item name, id, or rev. number

locate the next data item containing the search string

useful information

File menu:

Ok

Cancel

accept the highlighted data item and return to the previous screen

do not accept the highlighted data item and return to the previous screen 


\subsubsection{Class Table Maintenance Screen}

The purpose of the Class Table Maintenance form is to allow the system. administrator to add, change, and/or delete classes of data item attributes. It also allows for the reassignment of data items from one attribute class to another.

The body of the screen contains a list of the attributes as radio buttons. When an attribute is clicked, the classes of that attribute are displayed thereby allowing the administrator to manipulate them.

The screen to the right is an example of what is displayed when the Data Item Type radio buttion is clicked.

The administrator should then select a class to work with.

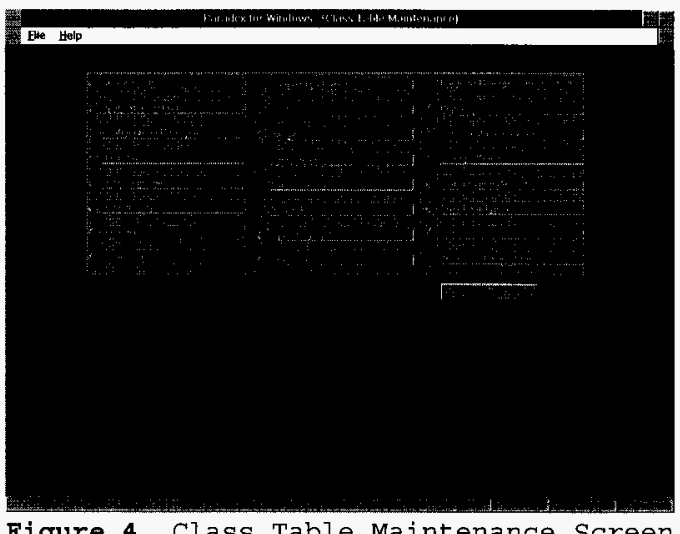

Once this is selected, the following buttons perform the following function:

- Reassign

Reassigns all data items assigned this class to another class. The administrator will be prompted to select another class and then prompted to do the reassignment.

- Add

- Delete Add a new class Delete an existing class. This is not allowed until all data items classified under this class are reassigned to

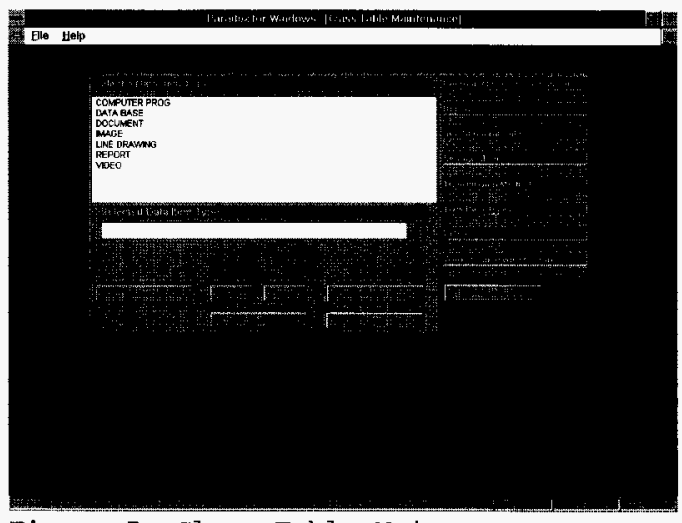

Figure 5 Class Table Maintenance Screen, Process Classes another.

- Edit

Edit a class (e.g., change the spelling)

- Reset Reset the screen

- Close

Return to the previous screen

Below is the main menu of this form. Each line is an option in the menu. Those options that are bolded signify lower level options to choose from. 
Main Menu:
File
File menu (described below)
Help
Help menu (described below)

File menu:
Classes
Classes menu (described below)
Close
Return to the previous screen

Help menu:

Index

Allows for viewing definitions of ILD terms

ILD System

Info Information about the ILD system

How to

Use Help How to use the help system

About ILD... A screen indicating various information (revision number, developer, etc.)

Classes menu: Allows access to the various attributes.

Access Control

Application Software

Configuration Management

Data Base

Data Confidence

Data Item Type

Data Use

Document

Frequency of lssue

Host

Image

Interviewer

Line Drawing

Network

Operating System

Processor

Program Management Function

Report

Site Standard Software

Storage Media

Transmission Method

TWRS Data Types

Video

Work Breakdown Structure 


\subsubsection{Comments}

This screen allows the user to enter comments and/or suggestions regarding the usability of the ILD system. It also allows them to report any errors that they may have encountered. The system administrator can use this information to diagnose any problems and/or user input to further enhance the system.

The first part of the screen displays the network name of the user, the data and time, and the ILD version number and date.

The second part displays information about the user's workstation such as windows version, number of active tasks, network type, CPU type, amount of ram, and amount of free disk space (note: a user is required to have a minimum of $5 \mathrm{MB}$ of free disk space before using the ILD

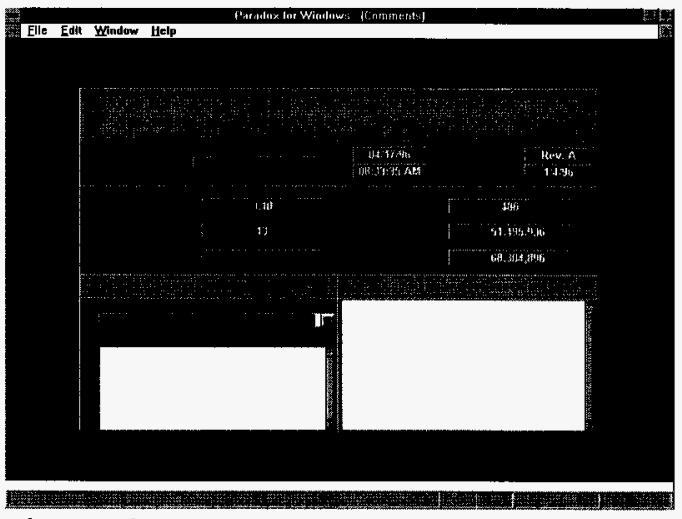
Figure 6 Comments screen system).

The bottom part of the screen allows the user to enter information about any problems that they may encounter by selecting from a list of problem severity, and then entering in free format a problem description. The list of problem severity to choose from is:

- Error in Data

- Error in Documentation

- Limitation Encountered

- Peculiar or irritating problem encountered

- Problem causes loss of efficiency

- Problem causes work to be lost

- Product lacks feature

In order to report a problem the user should select from the list of problem severity a choice that best describes the problem encountered. They should then describe the problem in the 'Brief Description of the Problem' field.

The user can also enter any comments and/or suggestions in the 'Comments and/or Suggestions' field.

All of the above information is saved in the COMMENTS.DB table when the user exits the system. By using the 'ILD User Information' and the 'ILD User Follow Up Information' screens the system administrator can diagnose and follow up general user input.

Please refer to the sections on these two screens for further information regarding general user input and follow up. 


\subsubsection{Data Base Administration Sereen}

The purpose of the Data Base

Administration form is to allow the system administrator to perform various administrative functions to the data base, e.g., add new data items, delete data items, pack and reindex the data base, etc.

The speed bar of buttons at the top of the screen allow access to the various functions. Holding the cursor on a button for one second will display a help line of the function of the button. Also a message is displayed at the bottom left of the screen when the cursor is moved over a button.

The table in the body of the screen contains all of the data items that are currently in the data base.

There are 25 buttons on the speed bar.

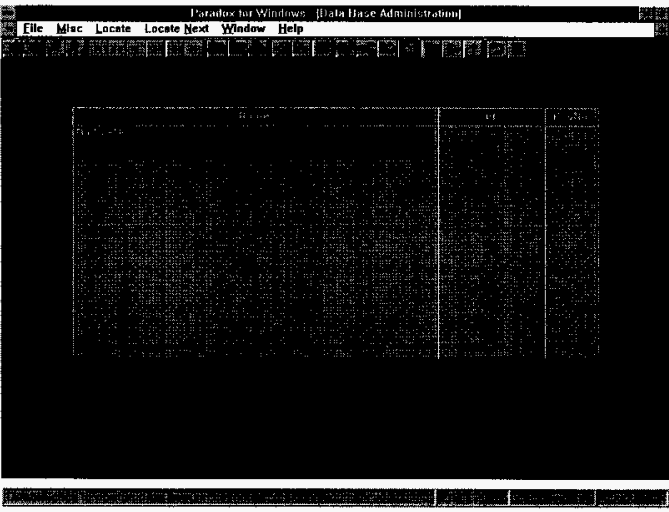

\section{Figure 7 Data Base Administration Screen}

Starting from the left hand side as button 1 , and the right hand button as button 25 , following is a brief description of the function of each button:

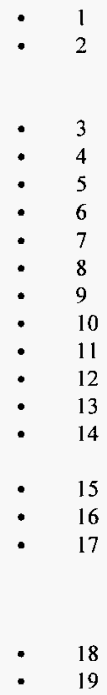

Enter a new data item.

Enter a new data item like another data item. Allows the user to choose the other data item that has similar attributes thereby eliminating the need to reenter these attributes.

Locate a data item.

Locate the next data item.

Display the first data item.

Display the next set of data items.

Display the next data item.

Display the previous data item.

Display the previous set of data items.

Display the last data item.

Edit the attributes of a data item.

Delete a data item from the data base.

View/print the attributes of the selected data item.

Process orphan sources by matching orphans to data items in the data base by name or id.

Edit the orphan source file.

Query the orphan source file and run the Orphan Query report.

Allows the administrator to incorporate the TWRS System Engineering changes that have been received from RDD-100. The system will automatically signal the administrator when there are updates. The administrator must then determine the affect of these updates by using this option to act on them.

Make changes to the attributes and their classes.

Change the system administrator's password. 
- 20
- 21
- 22
- 23
- 24
- 25

Process and track follow up of user's comments, suggestions and/or problems. Check the integrity of the data base.

Pack and reindex the data base.

Update the general user's data base with the working version. Return to the previous screen.

Exit the ILD system.

Below is the main menu of this form (most of the menu options perform the same function as a speed bar button). Each line is an option in the menu. Those options that are bolded signify lower level options to choose from.

Main menu:

File

Misc

Lowate

Locate Next

Window

Help

File menu:

New Empty

New Like

Open

Delete

Attributes

Return

Exit
File menu (described below).

Misc menu (described below).

Allows the user to enter a search string to locate a data item name, id, or rev. number.

Locate the next data item containing the search string. Window menu (described below).

Help menu (described below).

Window menu:

This will display all open screens. Use of this screen can facilitate hopping back and forth between open screens.

Help menu:

Index

ILD System Info

How to Use Help

About ILD...

Misc meru

Match Orphan

Sources

Edit Orphan

Sources

Query Orphan

Sources

Map Functions
Enter a new data item.

Enter a new data item like another data item. Allows the user to choose the other data item that has similar attributes thereby eliminating the need to reenter these attributes.

Open a data item for editing.

Delete a data item.

View/print the attributes of a data item.

Return to the previous screen.

Exit the ILD system. 
affect of these updates by using this option to act on them.

Change Password Change the system administrator's password.

Class Table

Maintenance

Work with the attributes and their classes.

User Information

Process and track follow up of user's comments, suggestions and/or problems.

DB Integrity Check

Check the integrity of the data base. Pack DB Pack and reindex the data base.

Update DB to Server

Update the general user's data base with the working version.

Various examples of how to use this screen are listed in Section 9 of this document. Please refer to these sections for further information on how to use the various functions of this screen. 


\subsubsection{Data Item Entry/Edit Screen}

This screen is the main data item entry screen. In it the administrator has access to all of the attributes for a data item. All data on this form is contained in temporary tables until the user chooses File $\mid \mathrm{OK}$ or File | Cancel from the main menu whereby the data item is either stored into the data base, or it is not. The temporary tables are then cleared.

This form consists of 11 pages and allows for two types of data entry: textual entry and class entry.

Textual entry is allowed on those attribute fields that are text. Once the text is entered, it can be spell checked at any time by following this procedure:

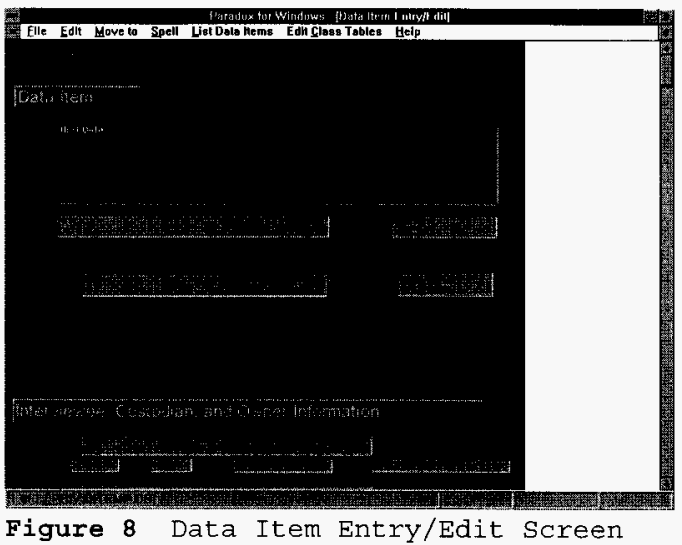

- highlight the text to be spell checked

- $\quad$ use the Edit | Copy menu option to copy the text to the clipboard

- $\quad$ click on the Spell menu option. This starts a spell checker.

- when control is returned from the spell checker, use the Edit | Paste menu option to paste the text in the clipboard back to the text field

All fields that require class entry are designated on the screens by a button containing a down arrow. When this button is clicked, a pop up menu of classes for that attribute appears from which the user can choose. No text entry is allowed in attributes that have classes. Only this method can be used to enter a class for an attribute.

If the administrator wishes to add a class to a class table, using the "Edit Class Tables" main menu option starts up the "Class Table Maintenance" screen. From this screen the administrator can add, delete, or change any of the classes in the data base. Once the change is made, clicking on the class button in this screen will display the changes that were made. Please see the "Class Table Maintenance" screen section for a further description of this process.

Below is the main menu of this form. Each line is an option in the menu. Those options that are bolded signify lower level options to choose from.

Main menu:

File

Edit

MoveTo

Spell

Edit Class Tables

List Data Items
File menu (described below).

Edit menu (described below). MoveTo menu (described below).

Allows the administrator to spell check any text input in this form. The user must first copy the text to the clipboard, click this option. When spell checking is complete, the clipboard should be pasted back to the field. Allows the administrator to add/change any of the classes in the data base. These changes will immediately be reflected in the data entry pop-up class menus. This is only enabled when sources are being input. It allows the user to pick from 
the list of all data items in the system.

Help Help menu (described below).

File menu:

Save

Cancel

Save the data item into the data base then clear the temp tables.

Do not save the data item. Then clear the temp tables.

Help menu:

Index

ILD System Info

Allows for viewing definitions of ILD terms.

How to Use Help

Information about the ILD system.

How to use the help system.

About ILD..

A screen indicating various information (revision number, developer, etc.).

Edit menu:

Undo

Undo the last change in a field.

Cut

Cut text from the field into the clipboard.

Copy

Copy text from the field into the clipboard.

Paste

Paste the clipboard into a field.

MoveTo menu: Allows the user to skip to different sections of the form containing the selected attribute.

Access Control

Application Software

Compliance

Confidence in Data

Configuration Management

Custodian

Data Base

Data Drain(s)

Data Item

Data Source(s)

Description

Document

Frequency of lssue

Host

Image

Interviewee

Line Drawing

Location

Owner

Processor

Report

TWRS Program Management Function

TWRS Data Type

TWRS Work Breakdown Structure

Use of the Data Item

Video

Chapter 9 contains examples of entering/editing data item attributes. Please refer to these examples for a further explanation of using this form.

Note:

A special description is made here for the application software section of the data entry screens. This page allows 
the administrator to input multiple softwares for a data item.

The "Number of " line tells how many application softwares there are for this data item. Clicking on the "+" button will allow for entering another, clicking the "-" will delete the displayed application software, clicking the left arrow will display the previous, and clicking the right arrow will display the next.

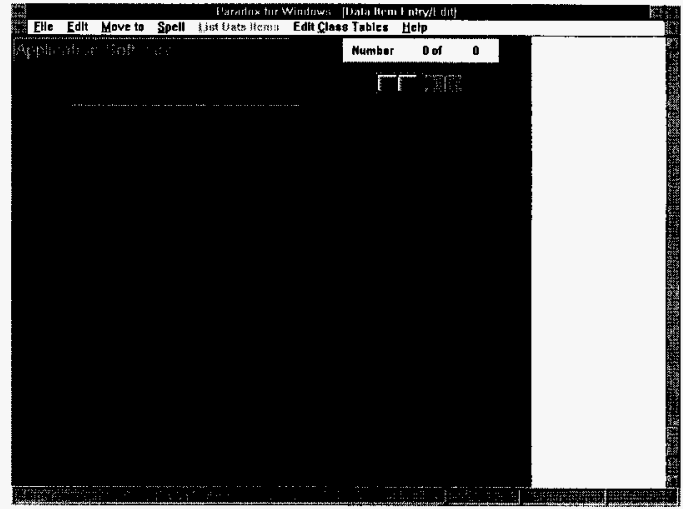

Figure 9 Data Item Entry/Edit, Application Software page. 


\subsubsection{Edit Orphan Sources Screen}

This form allows the administrator to edit the orphan source file. This file contains all of the data items that were entered as sources but could not be found in the data base when the data item was saved. Editing of this file consists of deleting records that contain duplicate sources, correcting typing mistakes, and linking a source to it's parent data item.

The speed bar of buttons at the top of the screen allow the user for process any changes that may be made to the orphan source table. Please see below for a description of the function of each button.

The table on the screen contains all of the orphan sources in the data base. The orphans eventually need to be reconciled, either by identifying that it has already

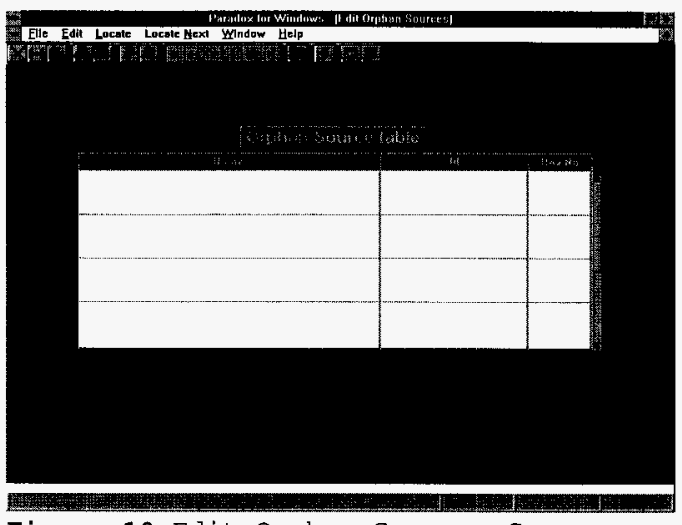
been entered into the data base, or that it needs to be entered.

Note: The reason that it may already be in the data base and was not linked at the time it's parent was saved is that there is a difference between the orphan's name, id, or revision number and the name, id, or revision number of the data item in the data base.

The user can edit the orphan name, id, and/or revision number in case a mistake was found. When a change of this type is made, the link option will again attempt to find the orphan name, id, and revision number in the data base. If it does, then this will be linked as the source to the parent data item of the orphan and the orphan will be deleted from the orphan source file.

Assuming the left hand button of the speed bar is button 1 and the right button is number 17 , following are the functions of each of the buttons:

Cut selected text to the clipboard.

Copy selected text to the clipboard.

Paste from the clipboard.

Display the parent data item of the selected source.

Hide the parent data, if it is displayed.

Allows the user to enter a search string to locate an orphan source name, id, or rev. number.

Locate the next orphan source containing the search string.

Display the first orphan source.

Display the next set of orphan sources.

Display the next orphan source.

Display the previous orphan source.

Display the previous set of orphan sources.

Display the last orphan source. 


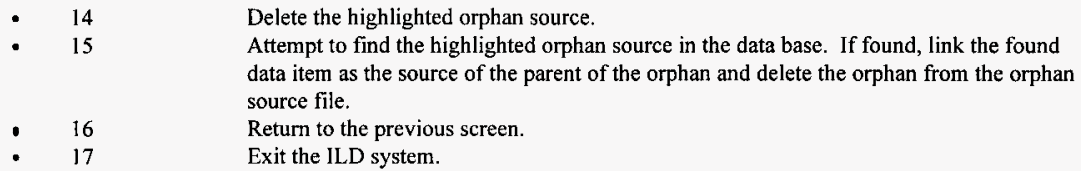

Below is the main menu of this form (each menu item performs the same functions as one of the speed bar buttons). Each line is an option in the menu. Those options that are bolded signify lower level options to choose from.

Main menu:

File $\quad$ File menu (described below).

Edit Edit menu (described below).

Locate Allows the user to enter a search string to locate a data item name, id, or rev. number.

Locate Next Locate the next data item containing the search string.

Window Window menu (described below).

Help Help menu (described below).

File menu:

Delete Delete the highlighted orphan source.

Lirk Attempt to find the highlighted orphan source in the data base. If found, link the found data item as the source of the parent of the orphan and delete the orphan from the orphan source file.

Return Return to the previous screen.

Exit Exit the ILD system.

Edit menu:

Undo Undo the last change in a field.

Cut Cut text from the field into the clipboard.

Copy Copy text from the field into the clipboard.

Paste Paste the clipboard into a field.

Window menu:

This will display all open screens. Use of this screen can facilitate hopping back and forth between open screens.

Help menu:

Index Allows for viewing definitions of ILD terms.

ILD System

Info Information about the ILD system.

How to Use

Help

How to use the help system.

About ILD... A screen indicating various information (revision number, developer, etc.).

Chapter 9 contains an example of editing the orphan source file. Please refer to this section for further explanation on the use of this screen. 


\subsubsection{Enter Password Screen}

This screen allows entry of the system administrator password and access to the administrator functions. The password is case sensitive.

Note that if the password is lost or the administrator cannot remember it, it can be found in the CFG.DB table in the working directory.

There is no main menu for this screen.

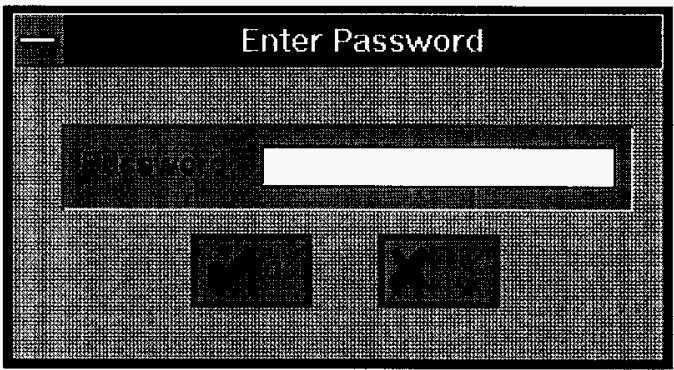

Figure 11 Enter Password Screen 


\subsubsection{ILD System Startup Screen}

This is the first screen that is displayed when the ILD system is started. Through it the user can access all of the ILD modules.

In order to access the system administrator's functions, press $\angle \mathrm{F} 9>$ and enter the password.

Three buttons are on this screen:

- Query

- Tutorial

access the query module access the tutorial module

- Exit exit the ILD system

Below is the main menu of this form. Each line is an option in the menu. Those options that are bolded signify lower level options to choose from.

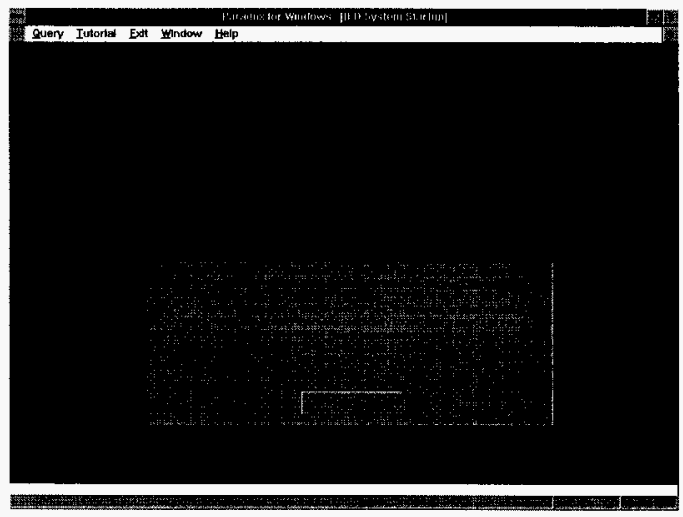

Figure 12 ILD System Startup Screen

Main menu:

Query Access the query module.

Tutorial Access the tutorial module.

Exit $\quad$ Exit the ILD system.

Window Window menu (described below).

Help Help menu (described below).

Window menu:

This will display all open screens. Use of this screen can facilitate hopping back and forth between open screens.

Help meriu:

Index

Allows for viewing definitions of ILD terms.

ILD System

Info

Information about the 1LD system.

How to Use

Help

How to use the help system.

About ILD... A screen indicating various information (revision number, developer, etc.). 


\subsubsection{ILD User Follow Up Information}

This screen displays information that the user's entered in the 'Comments' screen. Whenever.a user enters anything in the 'Problem Severity', 'Brief Description of the Problem', or 'Comments and/or Suggestions' fields in the Comments screen the Follow Up Required flag is set to Yes. This form only displays those records in the COMMENTS.DB table that have this field set to Yes.

The administrator can then go through the list of records and determine what kind of follow up needs to be done.

The screen displays information about the user, when they left the comments and/or problems, what the comments and/or problems were, and the follow up information.

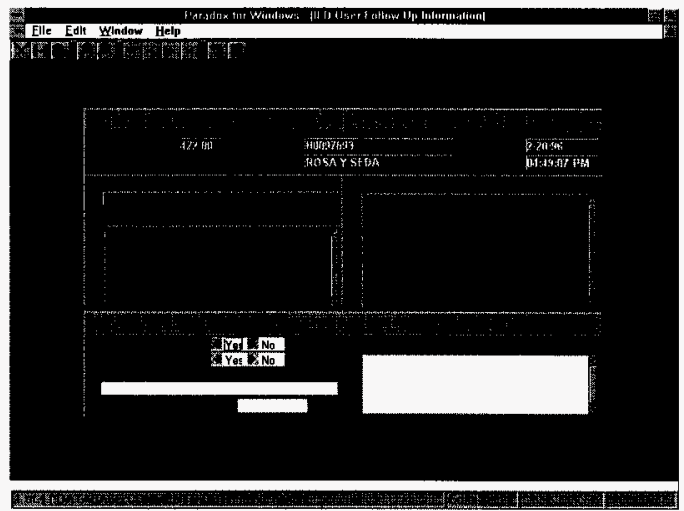

Figure 13 ILD User Follow Up Information screen

The follow up information tells the administrator if a follow up is required, if it has been completed, who completed it, the date completed, and a brief explanation of what was done to complete the follow up.

The administrator can use the 'ILD User Information' to print a report of those follow up records that have not yet been completed and can use it to follow up and fix any problems and/or suggestions that users may leave. When the follow up is completed the administrator should use this screen to mark it as being done.

Assuming the left hand button of the speed bar is button 1 and the right button is number 11 , following are the functions of each of the buttons:

\begin{tabular}{ll} 
- & 1 \\
- & 2 \\
- & 3 \\
- & 4 \\
- & 5 \\
- & 6 \\
- & 7 \\
- & 9 \\
- & 10 \\
\hline & 11
\end{tabular}

Cut selected text to the clipboard.

Copy selected text to the clipboard.

Paste from the clipboard.

Allows the user to enter a search string to locate a particular record.

Locate the next record.

Display the first record.

Display the next record.

Display the previous record.

Display the last record.

Return to the previous screen.

Exit the ILD system.

Below is the main menu of this form (each menu item performs the same functions as one of the speed bar buttons). Each line is an option in the menu. Those options that are bolded signify lower level options to choose from.

Main menu:

File File menu (described below). 


$\begin{array}{ll}\text { Edit } & \text { Edit menu (described below). } \\ \text { Window } & \text { Window menu (described below) } \\ \text { Help } & \text { Help menu (described below) }\end{array}$

File menu:

Return

Return to the previous screen.

Exìt

Exit the ILD system.

Edit menu:

Undo Undo the last change in a field.

Cut

Cut text from the field into the clipboard.

Copy Copy text from the field into the clipboard.

Paste Paste the clipboard into a field.

Window menu:

This will display all open screens. Use of this screen can facilitate hopping back and forth between open screens.

Help meru:

Index

ILD System Info

Allows for viewing definitions of ILD terms.

How to Use Help

Information about the ILD system.

About ILD...

How to use the help system.

A screen indicating various information (revision number, developer, etc.). 


\subsubsection{ILD User Information}

This screen allows the administrator to run reports which display information about ILD user"s. The report is generated from the COMMENTS.DB table which contains information about each ILD user and their comments and/or suggestions, and problems that they may have encountered while using the systern (please refer to the description of the 'Comments' screen for further information about the type of information retained on each ILD user).

Two type of reports can be generated, a Work Station Report, and a Comments/Problems Report.

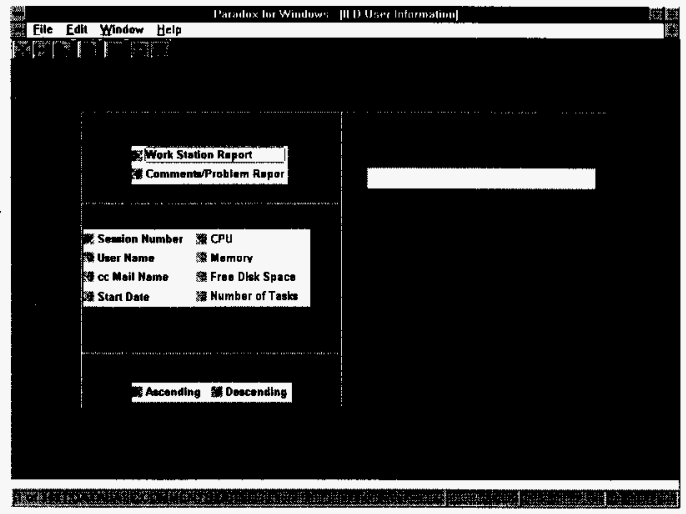

The user can select which type of report they wish to view/print. The list of fields listed on each report is then displayed under the 'Sort On' section of the screen. The

Figure 14 ILD User Information screen user can use this section to sort the report. The can also select a sort order in the 'Sort Order' section, either ascending or descending. And finally, a 'Sort On' field can be entered.

E.g., selecting 'Work Station Report' as the Report Type, 'CPU' as the Sort On selection, and 'Descending' as the Sort Order selection will give a report sorted on CPU in descending order. Entering '386' in the Sort On field will list only those workstation that are 386 s.

The Work Station report contains the following information about ILD usage:

- Sesision Number

- User Name/cc:Mail Name

- Start Date/Time

- End Date/Time

- CPU

- Memory

- Free Disk Space

- Windows Version

- Number of Tasks

- Network Type
ILD Session Number.

ILD Network User Name and cc:Mail Name.

Date and time that the user started ILD.

Date and time that the user exited ILD.

CPU type of the user's workstation.

Amount of RAM in the user's workstation.

Amount of free hard disk space in the user's workstation.

Windows version on the user's workstation.

Number of tasks running on the user's workstation.

Type of network running on the user's workstation.

The Comments/Problem Report contains the following information that user's may have entered:

- Session Number/User Name/cc:Mail Name/Start Date-time/End Date-time

- $\mathrm{CPU} /$ Windows Version/Number of Tasks/Memory/Free Disk Space/Network Type

- Comments

- Problem Severity/Description

- Follow Up Required/Completed/Followed Up By/Follow Up Date

- Follow Up Description

Assuming the left hand button of the speed bar is button 1 and the right button is number 7 , following are the 
functions of each of the buttons:

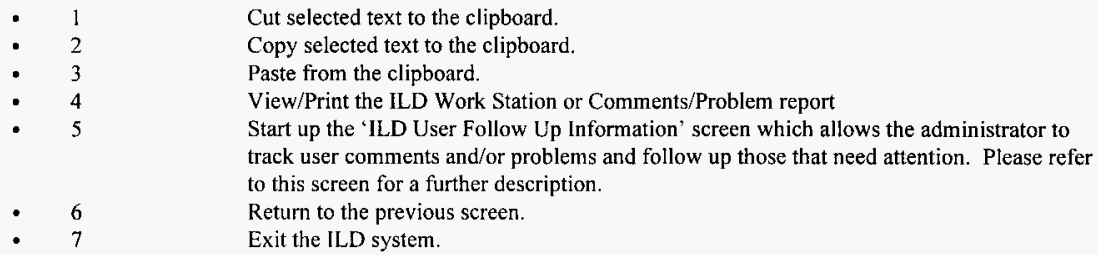

Below is the main menu of this form (each menu item performs the same functions as one of the speed bar buttons). Each line is an option in the menu. Those options that are bolded signify lower level options to choose from.

Main menu:

$\begin{array}{ll}\text { File } & \text { File menu (described below). } \\ \text { Edit } & \text { Edit menu (described below). } \\ \text { Window } & \text { Window menu (described below). } \\ \text { Help } & \text { Help menu (described below). }\end{array}$

File menu:

View/Print Report View/Print the ILD Work Station or Comments/Problem report.

Follow Up Info

Start up the 'ILD User Follow Up Information' screen which allows the administrator to track user comments and/or problems and follow up those that need attention. Please refer to this screen for a further description.

Printer Setup

Return

Allows to change printer setup.

Exit

Return to the previous screen.

Exit the ILD system.

Edit menu:

Undo Undo the last change in a field.

Cut Cut text from the field into the clipboard.

Copy Copy text from the field into the clipboard.

Paste Paste the clipboard into a field.

Window menu:

This will display all open screens. Use of this screen can facilitate hopping back and forth between open screens.

Help menu:

Indlex

ILD System Info

How to Use Help

About ILD...

Allows for viewing definitions of ILD terms.

Information about the ILD system.

How to use the help system.

A screen indicating various information (revision number, developer, etc.). 


\subsubsection{Map Data Items to New System Engineering Functions Screen}

This screen allows the administrator to incorporate changes to the TWRS System Engineering Function's name and/or definition. These changes come from the RDD-100 system (please see Section 9.1.10 for further information regarding this transfer of data). When these functions are updated, the system notifies the administrator when the Data Base Administrator screen is started. They should then start this form to determine if there are changes to the system engineering functions, and if so, if they should be implemented.

If the changes are significant enough the administrator may have to map the data items from the old functions to the new ones. This screen also allows for this process.

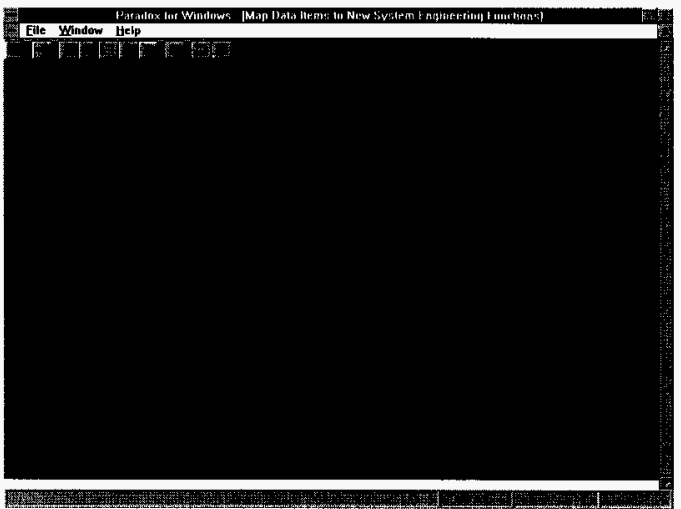

Figure 15 Map Data Items to New System Engineering Function Screen

Please refer to Section 9.1.10 for a further explanation of this screen, the processes within, and it's use.

Assuming the left button of the speed bar is button 1 and the right is button 10 , following is a brief description of the function of each (Section 9.1.10 describes these buttons in more detail):

- 1 Sets up the new functions and old functions for processing by extracting the new functions from the BASELINE.MDB file (this contains the up-to-date RDD-100 information used by the Browser). Creates the temp tables used in this process.

- 2 Automatically map like functions. This compares the old and new functions, and automatically maps all data items to the new function for those functions that have not changed.

- 3 View/print a list of the old or new functions and their definitions.

- 4 Map the data items under the highlighted old function into the highlighted new function.

- 5 Map individual data items. This allows the administrator to view a list of those data items that have not yet been mapped. The data items can then be mapped on an individual basis.

- 6 all data items have been mapped to new functions. Commit the new functions and data item assignments to the data base.

- 7 Only applies to an old function that has been previously mapped. Will unmap that function thereby resetting all of the data items under it back to the old function.

- 8 Throw away all mapping that has been done and start completely over. All temporary tables are deleted and everything is reset to before the setup process was started.

- 9 Return to the previous screen

- 10 Exit the ILD system

Below is the main menu of this form (each menu item performs the same function as a speed bar button). Each line is an option in the menu. Those options that are bolded signify lower level options to choose from.

Main menu: 
File

Window

Help

File menu:

Setup

Auto-Map Functions

View/Print

Functions

Map Marked

Process Unmapped

Commit Mapping

Unmap Marked

Start Over

Printer Setup

Return

Exit
File menu (described below).

Window menu (described below).

Help menu (described below).

Sets up the new functions and old functions for processing by extracting the new functions from the the file which contains the up-to-date RDD-100 information used by the Browser. Creates the temp tables used in this process.

Automatically map like functions. This compares the old and new functions, and automatically maps all data items to the new function for those functions that have not changed.

View/print a list of the old or new functions and their definitions.

Map the data items under the highlighted old function into the highlighted new function.

Map individual data items. This allows the administrator to view a list of those data items that have not yet been mapped. The data items can then be mapped on an individual basis.

All data items have been mapped to new functions. Commit the new functions and data item assignments to the data base.

Only applies to an old function that has been previously mapped. Will unmap that function thereby resetting all of the data items under it back to the old function.

Throw away all mapping that has been done and start completely over. All temporary tables are deleted and everything is reset to before the setup process was started.

Allows to change printer setup.

Return to the previous screen.

Exit the ILD system

Window menu:

This will display all open screens. Use of this screen can facilitate hopping back and forth between open screens.

Help menu:

Index

ILD System Info

How to Use Help

About ILD...

Allows for viewing definitions of ILD terms.

Information about the ILD system.

How to use the help system.

A screen indicating various information (revision number, developer, etc.) 


\subsubsection{Map Individual Data Items Screen}

This screen allows the user to map individual data items to a new function. The functions listed on the left side of the screen are the old system engineering functions. Clicking on any of the function names will display a list of those data items in that function that have not yet been mapped to a new function.

The table on the right side of the screen lists all of the data items that have not yet been mapped to a new system engineering function. By selecting a data item and clicking the map button, the administrator can complete the mapping process.

Please refer to Section 9.1.10 for a further explanation of this screen, the processes within, and it's use.

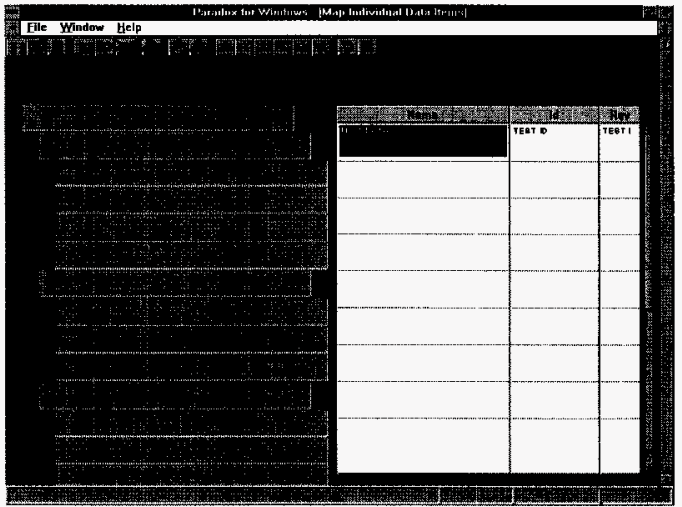

Figure 16 Map Individual Data Items screen

Assuming the left button of the speed bar is button 1 and the right is button 17, following is a brief description of the function of each (Section 9.1.10 describes these buttons in more detail):

- 1 Display all of the unmapped data items in the table on the screen.

- 2 Map the selected data item to a new function.

- 3 Print a report of the displayed data items.

- 4 Show all data items that have already been mapped to a new function.

- 5 Display the new function that the selected data item has been mapped to.

- 6 Unmap the selected data item thereby making it available to be remapped to another new function.

- 7 View data item attribute information of the selected data item.

- 8 Locate a data item in the displayed table.

- 9 Locate the next data item.

- 10 Display the first data item.

- 11 Display the next set of data items.

- 12 Display the next data item.

- 13 Display the previous data item.

- 14 Display the previous set of data items.

- 15 Display the last data item.

- 16 Return to the previous screen.

- 17 Exit the ILD system.

Below is the main menu of this form (each menu item performs the same function as a speed bar button). Each line is an option in the menu. Those options that are bolded signify lower level options to choose from.

Main menu:

File File menu (described below).

Window Window menu (described below). 
Help Help menu (described below).

File menu:

Show Unmapped

Display all of the unmapped data items in the table on the screen.

Map Data Item Map the selected data item to a new function.

Print UnMapped

Print a report of the displayed data items.

Printer Setup

Allows to change printer setup.

Show Mapped

Show Function

Show all data items that have already been mapped to a new function.

Unmap Data Item

Display the new function that the selected data item has been mapped to.

Unmap the selected data item thereby making it available to be remapped to another new function.

View/Print

Attributes View data item attribute information of the selected data item.

Return

Return to the previous screen.

Exit

Exit the ILD system.

Window menu:

This will display all open screens. Use of this screen can facilitate hopping back and forth between open screens.

Help menu:

Index

ILD System Info

How to Use Help

About ILD...

Allows for viewing definitions of ILD terms.

Information about the ILD system.

How to use the help system.

A screen indicating various information (revision number, developer, etc.). 


\subsubsection{Orphan Sources Matched by ID Screen}

The purpose of this screen is to display the orphan sources that have the same ID as data items in the data base. The reports that are created from this can be used to determine that an orphan source is in the data base and can be used in place of the orphan (this may happen because of a typing error in the orphan source name, or the reference to the orphan source name was not exactly equal to the document title).

To use this screen the administrator must first run setup. This will, for each orphan source, find all data items in the data base that have the same ID. When this is done, the reports should be printed to show the orphans and their matching data items from the data base (matched by Id). The administrator must then use the report to identify those orphans that are in the data

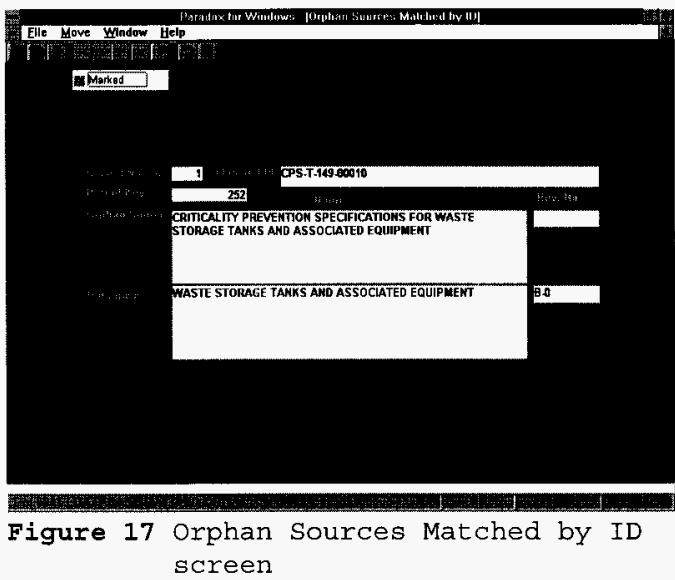
base. Once all orphans have been identified, they should "mark" each orphan by scrolling through the orphans and marking the appropriate records. Once all records have been marked, link will link those marked orphans using the matching data base data item as the source and deleting the orphan from the orphan source file.

Assuming the left button of the speed bar is button 1 and the right is button 10 , following is a brief description of the function of each (Section 9.1.10 describes these buttons in more detail):

- 1 This option runs a query that finds all data items in the data base that have the same ID as orphan

sources.

- 2 View/print a report of the data items and orphan sources that have the same IDs.

- 3 Links the data item that was matched with an orphan source as the source to the parent of the orphan.

- 4 Move to the first record in the table.

- 5 Move to the prior record in the table.

- 6 Move to the next record in the table.

- 7 Move to the last record in the table.

- 8 Move to a specific record in the table.

- 9 Return to the previous screen.

- 10 Exit the ILD system.

Under the speed bar is a field used to mark this record, meaning that the orphan source is actually in the data base and this matched data base data item can be used in place of the orphan as the source to the parent of the orphan.

Below is the main menu of this form (each menu item performs the same function as a speed bar button). Each line is an option in the menu. Those options that are bolded signify lower level options to choose from.

Main menu:

File

File menu (described below). 

Move
Window
Help
Move menu (described below).
Window menu (described below).
Help menu (described below).

File menu:

Setup

Link

View/Print

Return

Exit

Move menu:

Move to Record Number

Home

End

Next Record

Prior Record same ID as orphan sources. the parent of the orphan. IDS.

Return to the previous screen.

Exit the ILD system.

Move to a specific record in the table.

Move to the first record in the table.

Move to the last record in the table.

Move to the next record.

Move to the prior record

This option runs a query that finds all data items in the data base that have the

Links the data item that was matched with an orphan source as the source to

View/print a report of the data items and orphan sources that have the same

Window menu:

This will display all open screens. Use of this screen can facilitate hopping back and forth between open screens.

Help meriu:

Index

ILD System Info

How to Use Help

About ILD...

Allows for viewing definitions of ILD terms. Information about the ILD system.

How to use the help system.

A screen indicating various information (revision number, developer, etc.).

Special note on linking:

A special message may appear when the link is done. If a message appears that says "More that one data item marked. Only one can be marked. Record number xx.." it means that there is more that one record marked where the parent key, matched id, orphan source name and rev. number are the same. Since an orphan source record can only be linked to ONE data item in the data base, and since an orphan source record is uniquely identified in this screen by the parent key, matched id, orphan source name and rev. number, only one of these can be marked. The record number listed tells what the record number of the offending group is. The administrator must go to that record number and determine which data item of the group should be used as the source.

Multiple records in this screen for a given orphan source may occur because there may be multiple data items in the data base that have the same ID as the orphan source. Of these data items only one of them can be the replacement of the orphan source. 


\subsubsection{Orphan Sources Matched by Name Screen}

The purpose of this screen is to display the orphan sources that have the same NAME as data items in the data base. The reports that are created from this can be used to determine that an orphan source is in the data base and can be used in place of the orphan (this may happen because of a typing error in the orphan source id, or the reference to the orphan source id was not exactly equal to the document id).

To use this screen the administrator must first run setup. This will, for each orphan source, find all data items in the data base that have the same Name. When this is done, the reports should be printed to show the orphans and their matching data items from the data base (matched by Name). The administrator must then use the report to identify those orphans that are in the data base. Once all orphans have been

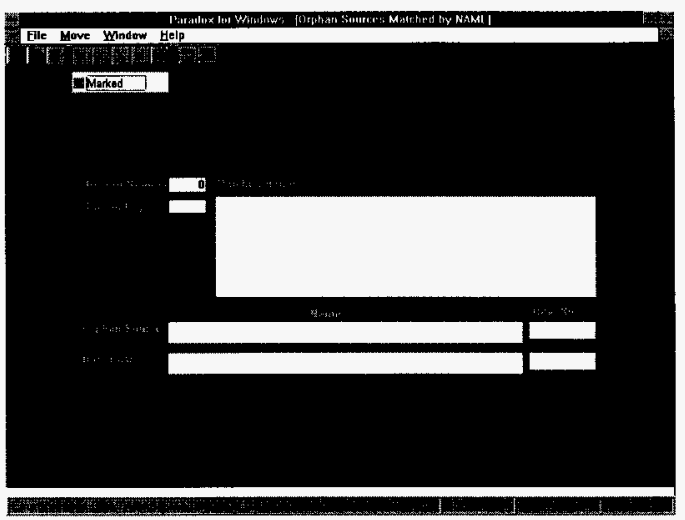

Figure 18 Orphan Sources Matched by Name screen

identified, they should "mark" each orphan by scrolling through the orphans and marking the appropriate records. Once all records have been marked, link will link those marked orphans using the matching data base data item as the source and deleting the orphan from the orphan source file.

Assuming the left button of the speed bar is button 1 and the right is button 10 , following is a brief description of the function of each (Section 9.1.10 describes these buttons in more detail):

- 1 This option runs a query that finds all data items in the data base that have the same NAME as orphan sources.

- 2 View/print a report of the data items and orphan sources that have the same NAME.

- 3 Links the data item that was matched with an orphan source as the source to the parent of the orphan.

- 4 Move to the first record in the table.

- 5 Move to the prior record in the table.

- 6 Move to the next record in the table.

- 7 Move to the last record in the table.

- 8 Move to a specific record in the table.

- 9 Return to the previous screen.

- 10 Exit the ILD system.

Under the speed bar is a field used to mark this record, meaning that the orphan source is actually in the data base and this rnatched data base data item can be used in place of the orphan as the source to the parent of the orphan.

Below is the main menu of this form (each menu item performs the same function as a speed bar button). Each line is an option in the menu. Those options that are bolded signify lower level options to choose from.

Main menu:

File File menu (described below). 
File menul:

Setup

Link

View/Print

Return

Exit

Move menu:

Move to Record Number

Home

End

Next Record

Prior Record
Move menu (described below).

Window menu (described below).

Help menu (described below).

This option runs a query that finds all data items in the data base that have the same NAME as orphan sources.

Links the data item that was matched with an orphan source as the source to the parent of the orphan.

View/print a report of the data items and orphan sources that have the same NAME.

Return to the previous screen.

Exit the ILD system.

Move to a specific record in the table.

Move to the first record in the table.

Move to the last record in the table.

Move to the next record.

Move to the prior record.

Window menu:

This will display all open screens. Use of this screen can facilitate hopping back and forth between open screens.

Help menu:

Index

ILD System Info

How to Use Help

About ILD...

\author{
Allows for viewing definitions of ILD terms. \\ Information about the ILD system. \\ How to use the help system. \\ A screen indicating various information (revision number, developer, etc.).
}

Special note on linking:

A special message may appear when the link is done. If a message appears that says "More that one data item marked. Only one can be marked. Record number xx.." it means that there is more that one record marked where the parent key, matched name, orphan source id and rev. number are the same. Since an orphan source record can only be linked to ONE data item in the data base, and since an orphan source record is uniquely identified in this screen by the parent key, matched name, orphan source id and rev. number, only one of these can be marked. The record number listed tells what the record number of the offending group is. The administrator must go to that record number and determine which data item of the group should be used as the source.

Multiple records in this screen for a given orphan source may occur because there may be multiple data items in the data base that have the same NAME as the orphan source. Of these data items only one of them can be the replacement of the orphan source. 


\subsubsection{Progress Meter}

The purpose of this screen is to provide the user with feedback. Because some of the functions may be processor intensive, this shows the user that something is happening and that their workstation is not frozen.

This screen is used throughout ILD as an informative screen.

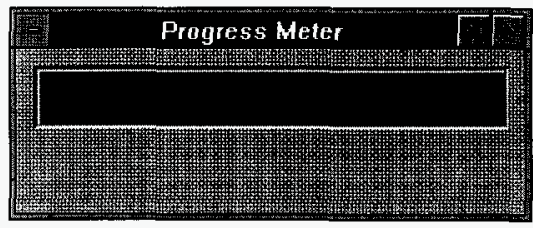

Figure 19 Progress Meter screen 


\subsubsection{Query Orphan Sources}

The purpose of this screen is to allow the administrator to find all orphan sources that have a specific string in their IDS. By using the wildcard ..., strings can be found at the beginning, in the middle, or at the end of the ID.

E.g., entering ..DOE.. in the query string field will find all orphan sources that have DOE anywhere in the ID.

Entering DOE.. will find all orphan sources that begin with DOE.

Once the query is run a report can be viewed and printed which lists the orphan sources that satisfied the query.

Assuming the left button of the speed bar is

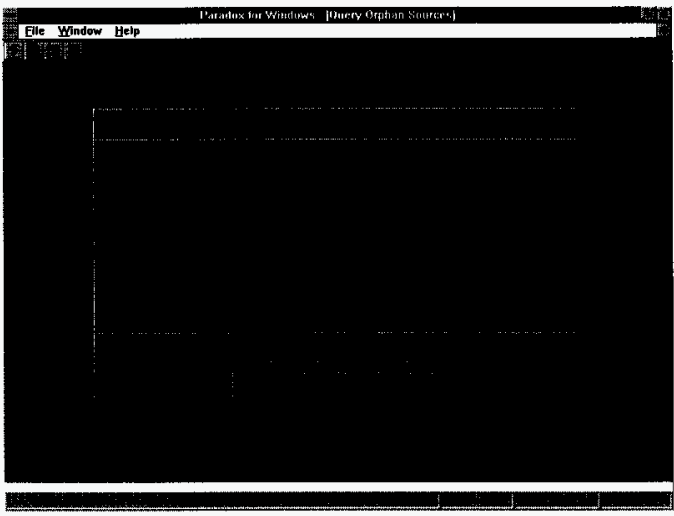

Figure 20 Query Orphan Sources screen button 1 and the right is button 4, following is a brief description of the function of each:

- 1 This option executes the query using the query string.

- 2 View/print the list of orphan sources that satisfied the query.

- 3 Return to the previous screen.

- 4 Exit the ILD system.

Below is the main menu of this form (each menu item performs the same function as a speed bar button). Each line is an option in the menu. Those options that are bolded signify lower level options to choose from.

Main menu:

File

Window

Help

File menu:

Execute Query

View/Print Report

Return

Exit
File menu (described below).

Window menu (described below).

Help menu (described below).

Window menu:

This will display all open screens. Use of this screen can facilitate hopping back and forth between open screens.

Help menu:

Inclex

This option executes the query using the query string.

View/print the list of orphan sources that satisfied the query.

Return to the previous screen.

Exit the ILD system.

ILD System Info

Allows for viewing definitions of ILD terms.

Information about the ILD system. 
How to Use Help

About ILD...

How to use the help system.

A screen indicating various information (revision number, developer, etc.). 


\subsubsection{TWRS Information Locator Cleanup}

This screen is displayed when the user exits the ILD system. When the system is exited various clean up of temporary files, etc. is done. This may sometimes take a little longer. This informs the user that clean up is happening.

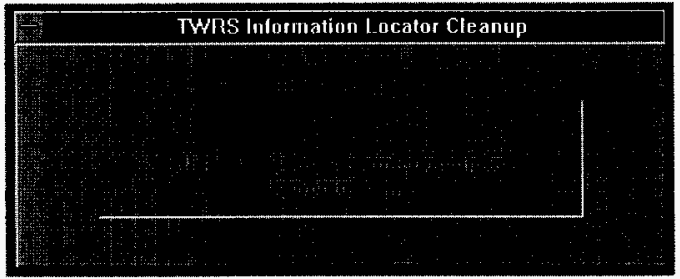

Figure 21 TWRS Information Locator Cleanup screen 


\subsection{Output}

\subsection{Reports}

\subsubsection{ILD User Comments/Problem Report}

This report comes from the "ILD User Information" screen and displays the various information that is retained about each ILD user and their workstation. Any comments/suggestions and/or problems that a user may have entered while using the system are printed in this report. The administrator can use this report to diagnose and follow up on anything that the user may have suggested.

An example copy of the first page of this report is in Section 9

\subsubsection{ILD User Workstation Report}

This report comes from the "ILD User Information" screen and displays the various information that is retained about each ILD user and their workstation. This report lists specific details about the user's workstation as well as who has been using the system and when. Use of this report can help in diagnosing any problems that a user may encounter while using the system.

An example copy of the first page of this report is in Section 9.

\subsubsection{List of Orphan Sources Satisfying Query}

This report comes from the "Query Orphan Sources" screen and lists all of the orphan sources that contain the query string input in this screen. This list of orphans can then be used to gather more attribute information for eventual data entry.

An example copy of the first page of this report is in Section 9.

\subsubsection{Listing of All UnMapped Data Items}

This report comes from the "Map Individual Data Items Screen" and lists all of the data items (name, ID, and revision number) that have not been mapped to a new Systems Engineering function. The purpose of this report is to aide the administrator in deciding which new function a data item should be mapped to. Please refer to Section 9.1.10 for further explanation of the mapping process.

An example copy of the first page of this report is in Section 9.

\subsubsection{Listing of All UnMapped Data ltems for Function ...}

This report comes from the "Map Individual Data Items Screen" and lists all of the data items (name, ID, and revision number) classified under a particular TWRS System Engineering function that have not been mapped to a new Systems Engineering function. The purpose of this report is to aide the administrator in deciding which new function a data item should be mapped to. Please refer to Section 9.1 .10 for further explanation of the mapping process.

An example copy of the first page of this report is in Section 9. 


\subsubsection{NEW TWRS System Engineering Functions}

This repoit comes from the "Map Data Items to New System Engineering Functions screen" and lists the new TWRS System Engineering functions (name and definition) when new functions have been received from the RDD100 system. This report, in conjunction with report "OLD TWRS System Engineering Functions" is used to determine which old functions can be directly mapped to a new function. This process, described in greater detail in Section 9.1.10, reduces the amount of time needed to map data items to the new functions. Please refer to Section 9.1.10 for further explanation of the mapping process.

An example copy of the first page of this report is in Section 9.

\subsubsection{OLD TWRS System Engineering Functions}

This report comes from the "Map Data Items to New System Engineering Functions screen" and lists the old TWRS System Engineering functions (name and definition), i.e., the functions that are currently in use in the data base. This report, in conjunction with report "NEW TWRS System Engineering Functions" is used to determine which old functions can be directly mapped to a new function. This process, described in greater detail in Section 9.1.10, reduces the amount of time needed to map data items to the new functions. Please refer to Section 9.1.10 for further explanation of the mapping process.

An example copy of the first page of this report is in Section 9.

\subsubsection{Parent Item, Orphan Source, and Data Base ID Match - Entire Report}

This report comes from the "Orphan Sources Matched by ID screen" and displays all of the matches that were found when the Setup query from this screen was executed. This query found all orphan sources that have the same ID as a data item in the data base. This report lists each match in a three line section of the report.

An example three line section of the report follows:

$\begin{array}{cllc}\text { DiUnique } & \text { Name } & \text { ID } & \text { Rev No } \\ 1 & \text { PARENT ITEM TITLE } & \text { WHC-XXX3 } & \\ & \text { ORPHAN SOURCE TITLE } & \text { WHC-XXX1 } & \\ 3 & \text { DATA BASE ITEM TITLE } & \text { WHC-XXX1 }\end{array}$

This three line section says that there is a record in the orphan source file with the Name "ORPHAN SOURCE TITLE" and ID "WHC-XXX1". The query found a data item in the data base with the same ID, "DATA BASE ITEM TITLE". The parent item of the orphan source is "PARENT ITEM TITLE". At the time that "PARENT ITEM TITLE" was entered, one of its sources was entered as "ORPHAN SOURCE TITLE" and when it was saved, the link process could not find "ORPHAN SOURCE TITLE" in the data base. That is why it is in the orphan source file.

The administrator must now make the determination if "ORPHAN SOURCE TITLE" and "DATA BASE ITEM TITLE" refer to the same data item. If so, the mark button in the "Orphan Sources Matched by ID screen" can be used to mark this record. When the link button is executed, "DATA BASE ITEM TITLE" will be linked to "PARENT ITEM TITLE" and "ORPHAN SOURCE TITLE" will be deleted from the orphan source file.

An example copy of the first page of this report is in Section 9. 


\subsubsection{Parent Item, Orphan Source, and Data Base ID Match - Mark Records Report}

This report comes from the "Orphan Sources Matched by ID screen" and displays all of the records that were marked in the process described in the "Parent Item, Orphan Source, and Data Base ID Match - Entire Report" above. This report can be used to double-check the records to be linked before executing the link "Orphan Sources Matched by ID screen".

An example copy of the first page of this report is in Section 9.

\subsubsection{Parent Item, Orphan Source, and Data Base Name Match - Entire Report}

This report comes from the "Orphan Sources Matched by Name screen" and displays all of the matches that were found when the Setup query from this screen was executed. This query found all orphan sources that have the same Name as a data item in the data base. This report lists each match in a three line section of the report.

An example three line section of the report follows:

\begin{tabular}{cllc} 
DiUnique & Name & \multicolumn{1}{c}{ ID } & RevNo \\
1 & PARENT ITEM TITLE & WHC-XXX3 & \\
& ORPHAN/DATA ITEM TITLE & WHC-XXX2 & \\
3 & ORPHAN/DATA ITEM TITLE & WHC-XXX1
\end{tabular}

This three line section says that there is a record in the orphan source file with the Name "ORPHAN/DATA ITEM TITLE" and ID "WHC-XXX2". The query found a data item in the data base with the same Name. The parent item of the orphan source is "PARENT ITEM TITLE". At the time that "PARENT ITEM TITLE" was entered, one of its sources was entered as "ORPHAN/DATA ITEM TITLE" ID "WHC-XXX2" and when it was saved, the link process could not find "ORPHAN/DATA ITEM TITLE" ID "WHC-XXX2" in the data base. That is why it is in the orphan source file.

The administrator must now make the determination if the reference to "ORPHAN/DATA ITEM TITLE" in the orphan scurce file and the data base data item refer to the same data item. If so, the mark button in the "Orphan Sources Matched by Name screen" can be used to mark this record. When the link button is executed, "ORPHAN/DATA ITEM TITLE" ID "WHC-XXX1" will be linked to "PARENT ITEM TITLE" and "ORPHAN/DATA JTEM TITLE" ID "WHC-XXX2" will be deleted from the orphan source file.

An example copy of the first page of this report is in Section 9.

\subsubsection{Parent Item, Orphan Source, and Data Base Name Match - Mark Records Report}

This report comes from the "Orphan Sources Matched by Name screen" and displays all of the records that were marked in the process described in the "Parent Item, Orphan Source, and Data Base Name Match - Entire Report" above. This report can be used to double-check the records to be linked before executing the link "Orphan Sources Matched by Name screen".

An example copy of the first page of this report is in Section 9. 


\subsubsection{TWRS Information Locator Data Item Attributes}

This report lists all of the attributes for a data item in a multi-page report, except for the sources and drains. In order to view the sources and drains for a data item, the administrator can:

- Open the data item and move to the sources and drains section of the input form

- From the query module, the Query Results screen, select the Sources/Drains button.

An example copy of the first page of this report is in Section 9. 


\subsection{Troubleshooting}

\subsection{General Protection Faults (GPF)}

Note: This Section (6.1) is taken from the Borland Technical Information Bulletin T12775. This bulletin, and all bulletins referenced within can be found on Borland's Technical Support WWW Homepage or FTP site.

Understanding how Microsoft Windows uses memory helps you to troubleshoot memory problems and protection faults that may arise in Windows when running multiple applications, such as Paradox for Windows and another application.

Protection faults occur when Windows or a Windows application attempts to use memory that has not been allocated to it or attempts to write to a memory address to which it does not have access. This may corrupt any other data that already occupies that memory space.

The first section describes the different types of memory available to the computer. The second section describes Windows system resources and how this affects memory. The third section uses this information to provide suggestions for troubleshooting a protection fault.

\subsubsection{An Overview of Memory}

Applications are loaded into Random Access Memory (RAM) while you are using them. Device drivers and terminate-and-stay-resident (TSR) software programs are also loaded into RAM and will remain in RAM until uninstalled from memory or the system is rebooted. Examples of device drivers include video, mouse, and printer drivers. Types of TSR programs include a network shell, disk caching program, virus protection software, and screen savers. Examples of TSRs are SmartDrive, Norton Anti-Virus, and After Dark.

Your computer has three types of RAM: conventional memory, extended memory, and expanded memory. Conventional memory is the first $640 \mathrm{~K}$ of RAM available on your system. Extended memory is the memory above $1,024 \mathrm{~K}$ ( I Megabyte). Expanded memory was provided in 286 and prior computers by a physical add-in memory card (similar to extended memory). To access expanded memory on a 386 or higher system, you must run an expanded memory manager (such as EMM386 or QEMM) which will simulate expanded memory by using extended memory and provide access to the upper memory area. Expanded memory is accessed through a window in the upper memory area (the area above $640 \mathrm{~K}$ and below $1,024 \mathrm{~K}$ ).

Because the upper memory area is used by hardware devices and Windows in addition to memory managers, memory conflicts are more likely to occur in the upper memory area than in any other area of memory. Although Windows and Windows applications do not use expanded memory, your system may have a memory manager that creates expanded memory and accesses the upper memory area.

When you are running Windows in 386 Enhanced mode, Windows can create a fourth type of memory called virtual memory (commonly known as a swap file). Virtual memory is an extension to physical RAM which uses free disk space on the hard disk as if it were RAM. Virtual memory can be related to memory problems or protection faults when Windows has trouble reading from or writing to the hard drive. A lack of disk space, for example, may prevent virtual memory from operating correctly. Because virtual memory is much slower than RAM memory, problems may arise when an application expects a memory access to take a specific amount of time.

Note: Manufacturers of disk compression software (such as Stacker or Microsoft DoubleSpace) recommend that the drive used for the virtual memory swap file be uncompressed. 


\subsubsection{Memory and Windows System Resources}

System resources are another specific area of memory that Windows users need to be concerned about. The memory that is used by the core Windows internal structure makes up the system resources. There are three files that make up the part of Windows that runs Windows applications: KRNL386.EXE, GDI.EXE, and USER.EXE.

KRNL3815.EXE, the kernel file, loads and executes Windows applications and handles their memory management. GDI.EXE manages graphics and printing. USER.EXE controls user input and output. Both GDI and USER have $64 \mathrm{~K}$ memory areas called heaps. GDI has a local heap. USER has a menu heap and a user heap. Each window opened consumes resources from some of the memory heaps. The amount of available system resources displayed under Help $\mid$ About Program Manager reflect the remaining free percentage after combining these three heaps. There are third- party utilities that can provide more detailed information.

\subsubsection{Protection Faults}

To handle the possibility of memory conflicts between programs, Windows relies on cooperative memory usage. The memory used by Windows or a Windows application is not protected by Windows. Windows relies on each application to stay within its allocated space, using only the amount and location of memory allocated for its use. If any application writes outside its bounds, a protection fault will occur. Protection faults are most likely to occur when you are starting a program, loading a file, working with reports, or printing.

You can find important information for troubleshooting protection faults from the Program Manager by choosing Help $\mid$ About Program Manager. The dialog box that appears shows which version of Windows is running, in which mode Windows is running, how much memory is free, and the percentage of free system resources.

\subsubsection{Troubleshooting Steps}

Note: All steps that reference DOS commands are to be executed with Windows closed, not from a DOS shell.

1. Verify HIMEM.SYS is loaded in the CONFIG.SYS file. HIMEM.SYS is needed for Windows to access extended memory. Make sure the version of HIMEM.SYS being used is appropriate for the version of DOS and Windows being used.

2. If you get a protection fault while installing Paradox, simplify your Windows system to reduce the possibility of a conflict with a terminate-and-stay-resident program (TSR) or device driver. More information on how to do this is available from the Technical Information Sheets on the Borland WWW Homepage:

1283 Simplifying Your Windows System

1277 Alternate Installation Instructions $(1.0-4.5)$

1838 Network Installation Guidelines (4.5)

2032 Installing on a LANtastic Network (4.5)

1251 Installing Paradox 1.0 for Windows on a Network

2705 Paradox 5.0 Alternate Installation Instructions

2734 Paradox 5.0 Installation Questions and Answers

3. Check the amount of free system resources (from Windows Program Manager, choose Help | About Program Manager). Although Windows allows many applications to be run simultaneously, every window and sub-window requires USER and GDI local heap space (see discussion on Windows system resources above). The system resources can be exhausted if too many objects are created in one session. If system resources are low, exiting Windows and restarting it will reallocate system resources and resolve the protection fault issue 
until resources become exhausted again.

4. If the message: "PDOXWIN has caused a General Protection Fault in module [see below]" appears, follow the steps specific to troubleshooting that module.

GDI.EXE: $\quad$ The primary cause for a protection fault in GDI.EXE is low system resources. Exit and restart Windows to correct this fault.

KRNL386.EXE: The primary cause for a protection fault in KRNL386.EXE is a conflict within expanded memory. To determine whether or not this is the case, start Windows with: WIN /D:X. If this corrects the problem, put the statement EMMExclude $=A 000-F F F F$ in the [386Enh] section of the SYSTEM.INI file to exclude all of the upper memory (or find out which area of memory is causing the conflict and exclude it).

USER.EXE: $\quad$ One cause for a protection fault in USER.EXE is a corrupt PDOXWIN.INI file. Delete this file from the Windows directory to fix this problem. Paradox for Windows will create a new PDOXWIN.INI with the default settings the next time it is launched.

PXSRV.DLL: $\quad$ This protection fault primarily occurs with respect to printer driver problems. Delete the current printer driver from the WINDOWSISYSTEM directory and then reinstall the printer driver from your original disks. If this does not correct the fault, change the default printer or update to the latest version of the printer driver.

Some other possible solutions for a fault in this area include verifying that Norton Desktop for Windows is not running, verifying that SHARE.EXE is loaded with the parameters /F:4096/L:400, and verifying that the Network Control File Directory in ODAPI.CFG or IDAPI.CFG points to a drive where you have full read/write access.

Other .DRV or .DLL file:

This protection fault is most often caused by use of the third-party driver referenced in the error message, such as SFSOUND.DRV or a third party video driver. For complete compatibility, install the Windows version of the driver.

A corrupt VAL file may also cause this protection fault. Delete the VAL file associated with the table that is causing the problem to resolve this fault. Note: If you delete the VAL file, you will need to recreate any table lookups, pictures, etc.

A corrupt PXTOOLS.FT file may also cause a protection fault. Delete PXTOOLS.FT from the working directory to resolve this fault.

Printer driver: If the protection fault is occurring within a specific printer driver file, consult Microsoft or your printer manufacturer for information on upgrading to the latest version of the printer driver. In some situations, changing the printer setup (such as the Dithering setting or Graphics Resolution) by choosing File | Printer Setup in Paradox resolves the conflict.

5. If the protection fault is occurring with a specific file, a specific application, or a specific module, exit Windows (Do not use the DOS shell. Close Windows completely.) and execute CHKDSK (or use another file 
checking and fixing utility) to check for possible file corruption. Consult the DOS manual for more information on the CHKDSK command. If any cross-linked files or lost clusters are encountered, consider executing CHKDSK $/ \mathrm{F} / \mathrm{V}$. The $/ \mathrm{V}$ parameters show which files were corrupted and the $/ \mathrm{F}$ parameter may fix the problem. If you are a DOS 6 or above user, consider using SCANDISK instead of CHKDSK. After checking the disk for errors and correcting any problems, reboot the computer. If the protection faults continue, you may need to reinstall Windows and Paradox, depending on which files are corrupted.

6. Try to reproduce the problem with Windows running in Standard mode. When running Windows in Standard mode, no expanded memory or virtual memory is used for applications. Windows in Standard mode treats the total free conventional memory and extended memory as one contiguous memory block. Standard mode is useful for determining whether an upper memory area conflict or a lack of hard disk space may be causing the problem in your system (see "An Overview of Memory" above.)

To start Windows in Standard mode, type WIN/S at the DOS prompt. If you get an error message while attempting to start Windows in Standard mode, concentrate on Windows specific issues to resolve this problem. Consult the Windows documentation for more information.

If you are able to start Windows in Standard mode, attempt to re-create the protection fault in Paradox. If the problem is not encountered at this time, it may be related to running Windows in 386 Enhanced mode. To determine whether the problem is related to an upper memory area conflict, start Windows using WIN /D:X.

If at this point in time the protection faults do not continue, edit the SYSTEM.INI file and add this parameter to the [386Enh] section: EMMExclude-A000-FFFF. This parameter specifies a range of memory in the upper memory area that Windows and Windows applications will be excluded from using.

If the protection faults continue to occur in 386 Enhanced mode, the problem may be related to a shortage of hard disk space. Because virtual memory is not activated when Windows is running in Standard mode, the amount of available disk space may be higher in Standard mode if your virtual memory type is temporary. If you are using a temporary swap file, Windows creates a file called WIN386.SWP in your Windows directory when Windows is loaded and deletes the file when Windows is closed. This means that the amount of available disk space may be significantly reduced once Windows is loaded.

To determine the amount of disk space available after Windows is loaded in 386 Enhanced mode when your virtual memory type is temporary, subtract the size of your swap file from the amount of disk space available before Windows is loaded.

To find the amount of disk space available before Windows is loaded, exit Windows and run CHKDSK from the Windows directory and note the "bytes available on disk".

To determine the size (and type) of your swap file, start Windows in 386 Enhanced mode and then, from the Program Manager, open the Main group, start Control Panel, double-click 386 Enhanced, and choose the Virtual Memory button.

If the Type is set to temporary, subtract the amount listed under Size from the bytes available on disk. If the Type is set to permanent, the amount of disk space available before Windows is loaded will not change. A permanent swap file is not deleted when Windows is closed.

As a rule of thumb, the amount of disk space available in the Windows temporary directory after Windows is loaded should be greater than 5 megabytes. The location of the Windows temporary directory is specified in the AUTOEXEC.BAT file with a statement that will resemble "SET TEMP=path", where path points to a 
valid directory on an uncompressed drive.

7. Simplify your Windows system to reduce the possibility of a conflict with terminate-and-stay-resident (TSR) programs or device drivers. For more information on this procedure, see Tech Info $\# 1283$, Simplifying your Windows System. You should follow these steps in this order:

a. CHKDSK /F / (before loading Windows).

b. Start Windows.

c. Simplify the AUTOEXEC.BAT and CONFIG.SYS (see Tech Info \#1283 for more information).

d. Simplify the WIN.INI (put a semicolon before RUN=, LOAD=).

e. Simplify the SYSTEM.INI (verify SHELL=PROGMAN.EXE).

f. For complete compatibility, install Windows versions of all device drivers (such as video drivers).

g. Exit Windows, then reboot the computer.

h. Start Windows in Standard mode (WIN/S).

8. If protection faults continue at this point, the problem may be related to file corruption or hardware incompatibility. If the problem is related to file corruption, you may need to reinstall Windows and Paradox. Consult the Windows documentation for information on how to reinstall Windows without losing your current settings. Reinstall Paradox under the simplified Windows system configuration mentioned previously and explained in Technical Information Sheet \#1283, "Simplifying your Windows System."

If the problem is related to hardware incompatibility, a potential issue is the computer's BIOS. To determine the BIOS manufacturer and version, change into the Windows directory and run MSD.EXE (e.g., C:IWINDOWSIMSD.EXE). If you suspect any problems with the BIOS, contact the computer manufacturer to find out if there are any known problems with that version of the BIOS, particularly if the BIOS date is prior to 1990 .

Verify if the protection fault occurs on other machines. If it doesn't, note the differences between the machines.

\subsection{Index-out-of-Date}

This error message means that the index files for one or more tables has been corrupted. The data base needs to be packed and reindexed. Run the Pack/Reindex from the Data Base Administrator's screen. This will pack and reindex all data base tables which will clear this condition.

\subsection{System Error - Unable to access drive J:}

This has been found to be caused by a slower machine accessing the network and the behind-the-scenes processing of Paradox. The usual cause is the server incorrectly responds to the Windows for Workgroups request to share the file. The server responds with a message that is too long, resulting in an error from NetBios. 
Ensure that the workstation has been updated with the most recent ESOE update. Also ensure that the workstation is running $\mathrm{LAN}$ Manager version 2.2B. 


\subsection{System Recovery}

Normally, when the system is abnormally shutdown, either because of a power failure, or the workstation was rebooted, no special steps need to be take to restart the system. If there was any data in the temporary tables because of data entry/edit of a data item, this is lost. The next time that the system is started the temporary tables will be. Eiut nothing in the database should be affected.

However, if when a restart is attempted and the user is unable to start Paradox 4.5 for Windows Runtime, the following may help to solve the problem:

- Exit Windows and try to restart ILD

If that doesn't work, check the following:

- Check the command line that starts the system (described in Section 3.1) and make sure all command line options point to the right directories. Especially the -o option which controls the location of the network control file.

- Check to make sure that the ODAPI directory is in the workstation's path (usually C:IODAPI). This should be set in AUTOEXEC.BAT.

- Check to make sure that the workstation is connected to the server shared area that contains the ILD system and that it is connected as drive $\mathrm{J}$. . This should be set in the U:LAUTOUSER.BAT file.

- Check to make sure that the PFWRUN and ODAPI directories exist on the workstation (usually C:IPFWRUN and $C:(O D A P I)$ and contain the proper files.

- Check to see if there are any extraneous ODAPI files (possibly left over from Paradox 4.0 if it was on the workstation) in the WINDOWS and the WINDOWSISYSTEM directories. Since these directories are looked in first when Windows wants a file, any older ODAPI files that are in these may cause an incompatibility problem (especially ODAPI.DLL).

If you still can't load Paradox Runtime, try using the File $\mid$ Run option from Windows Program Manager and run file C:IPFWRUN\PFWRUN.EXE. This should start up Paradox Runtime. 


\subsection{References}

"Borland Paradox 4.5 for Windows User's Guide", Borland International

"Borland Technical Information Bulletin \# TI2775", Borland International

"Microsolt Windows for Workgroups \& MS-DOS 6.22 User's Guide"

"TWRS Information Locator Database System Design Description," WHC-SD-WM-ADP-024.

"TWRS Information Locator Database System User's Guide," WHC-SD-WM-UM-032. 


\subsection{Appendix}

\subsection{Examples}

\subsubsection{Starting ILD and Accessing System Administrator Functions}

Once the ILD system has been installed on a workstation, double-click the TWRS ILD icon.

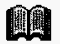

TWRS ILD

Paradox is loaded and the Main Menu screen.

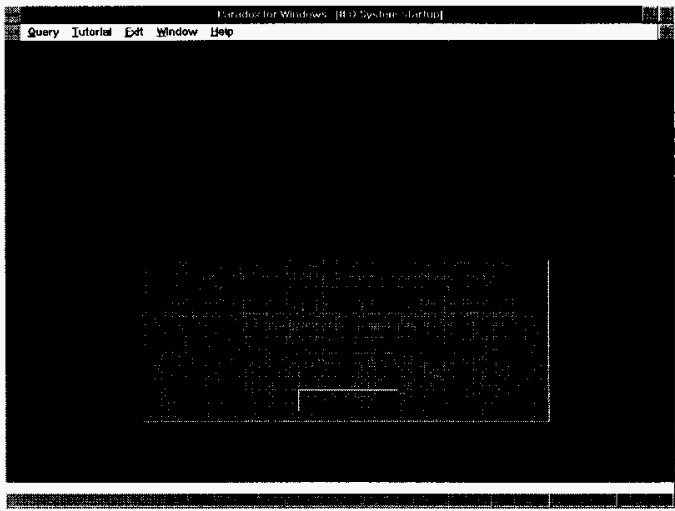

To access the System Administrator module:

Figure 23 ILD System Startup Screen

- $\quad$ hit the <F9> key

- enter the administrator password (upper case)

- click the OK button.

The System Administrator's screen is now displayed.

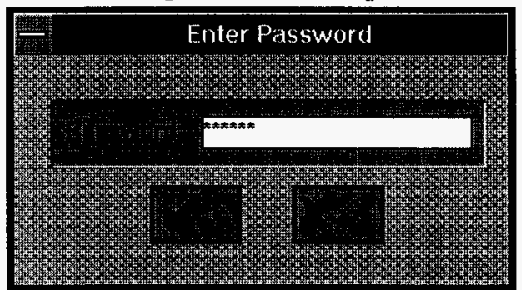

$$
\begin{gathered}
\text { Figure } 24 \text { Enter Password } \\
\text { Screen }
\end{gathered}
$$




\subsubsection{Entering a New Data Item}

- Start up the System Administrator section of the ILD system (see Section 3.2.1 or 9.1.1). The System Administrator's screen is displayed.

- Select either the "New Empty" (first button at the top left of the screen) or "New Like" button (second button). This causes the Data Entry/Edit form to start. See Section 4 for a description of this form and the type of data required for each field.

On this page, enter the following information:

- data item name (text).

- data item id (text).

- data item revision number.

- interviewer (click on the down arrow to display a list of interviewers).

- the date of the interview.

Note: moving from field to field is done by using the mouse, $\langle$ enter $\rangle,\langle\mathrm{tab}\rangle$, or the $<\mathrm{F} 3>$ and $\langle\mathrm{F} 4>$ keys.

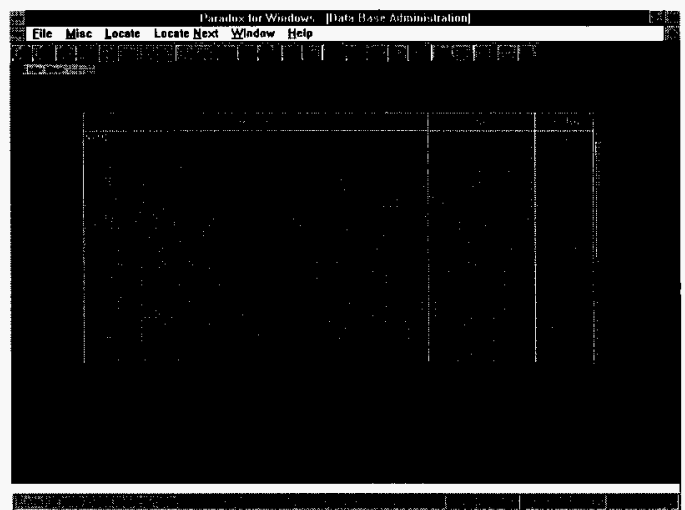

Figure 25 Data Base Administration screen - Enter New

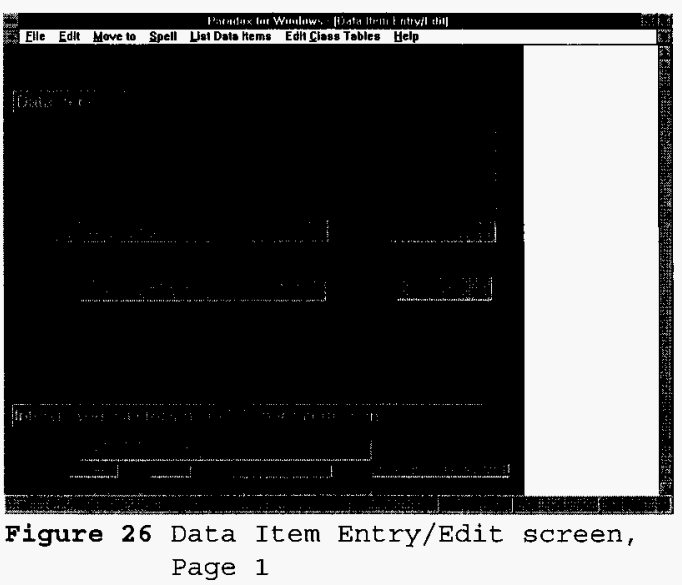


Page 2 allows for entry of the following:

- interviewee - the person who was interviewed.

- custodian of the data item.

- owner of the data item.

By entering the last name of the person in each of the fields, the table will move to that name. Then, double-clicking on the line in the table will select that person as the intervieweee, custodian, or owner.

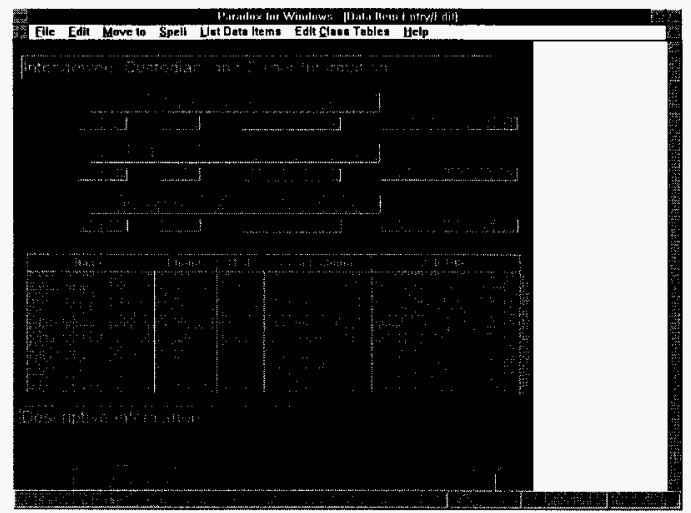

Figure 27 Data Item Entry/Edit screen, page 2

Page 3 allows for entry of the following:

- Data item description. This is a memo field. Formatting of the text in this can be done by hitting <shift>F2. This will put the field in memo view thereby allowing $\langle$ returns $\rangle,\langle$ tabs $\rangle$, etc. to be entered. Hitting $<$ shift $>$ F2 again will exit memo view.

- Data item acronym.

- Data item aliases. Multiple aliases can be entered by clicking on a new line in the table and entering the alias. Use the mouse or $\langle\mathrm{F} 3\rangle|<\mathrm{F} 4\rangle$ keys to exit the table.

- Data item type. Click on the down arrow object to display a list of types.

Note: depending on which type is chosen will affect the next pages. Only the information relating to the data item

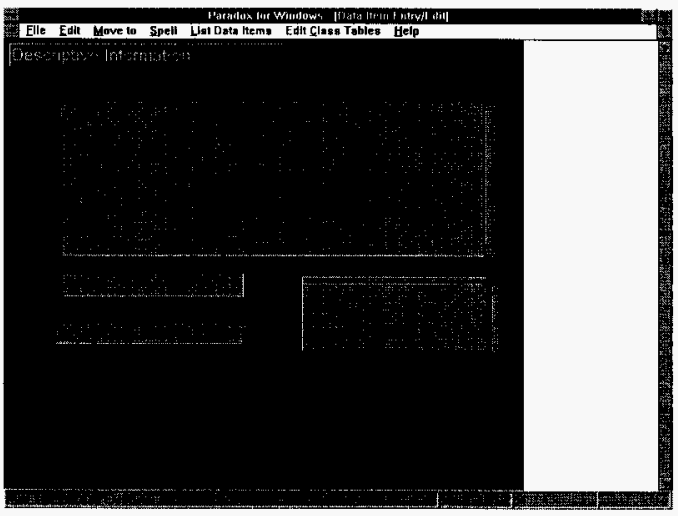

Figure 28 Data Item Entry/Edit screen, page 3 type will be displayed in the next pages. E.g., if the data item is a data base, then only the information relating to that type will be displayed on page 4 . If it is a document, only the information relating to this type will be displayed. 
This page is only displayed for a Data Base data item type:

- Data base class. Click on the down arrow to display a list of classes.

- Data base acronym.

- System name.

- Dictionary name.

- Custodian org tracking code.

- Number of records in the data base.

- Record size (in bytes).

- Data base access instructions. This is a memo field. Formatting of the text in this can be done by hitting $<$ shift $>$ F2. This will put the field in memo view thereby allowing $<$ returns $>,\langle$ tabs $>$, etc. to be entered. Hitling < shift $>$ F2 again will exit memo view.

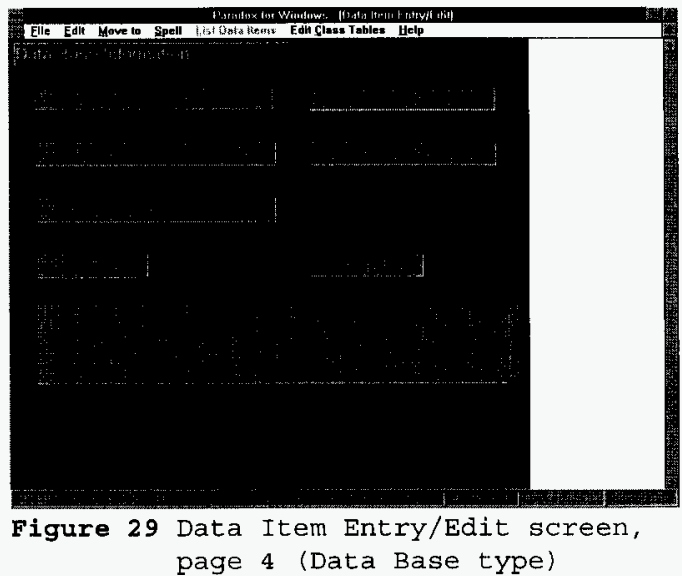

This page is displayed for the rest of the data item types. Enter the following information:

- Class. Click on the down arrow to display a list of classes.

- The date of the data item.

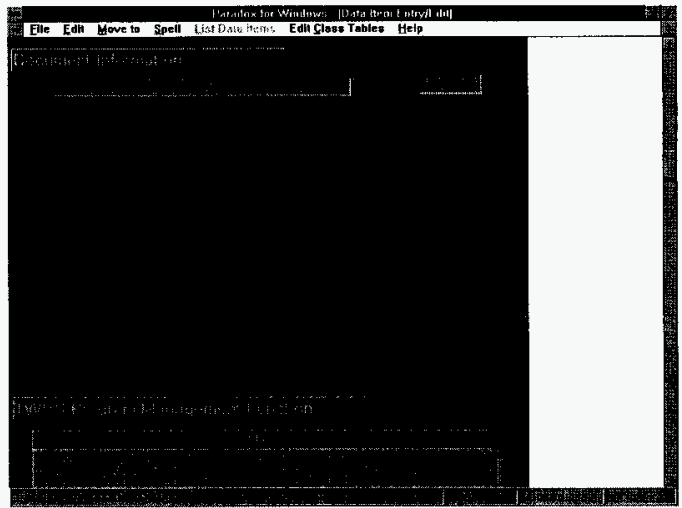

Figure 30 Data Item Entry/Edit screen, page 4 (Document, Image, etc.) 
This page allows for entry of multiple Program Management functions for the data item. To enter a new function:

- Click on an empty line in the table.

- Click on the down arrow to display a list of program management functions.

Repeat the above steps to enter additional functions.

This page allows for entry of the following:

- TWRS Systems Engineering function (data type). Click on the down arrow to display a list of functions.

- TWRS Work Breakdown Structure. Click on the down arrow to display a list of functions.

- Use of the Data Item. Click on an empty line in the table. Click on the down arrow to display a list of data item uses. Repeat the above steps to enter additional uses.
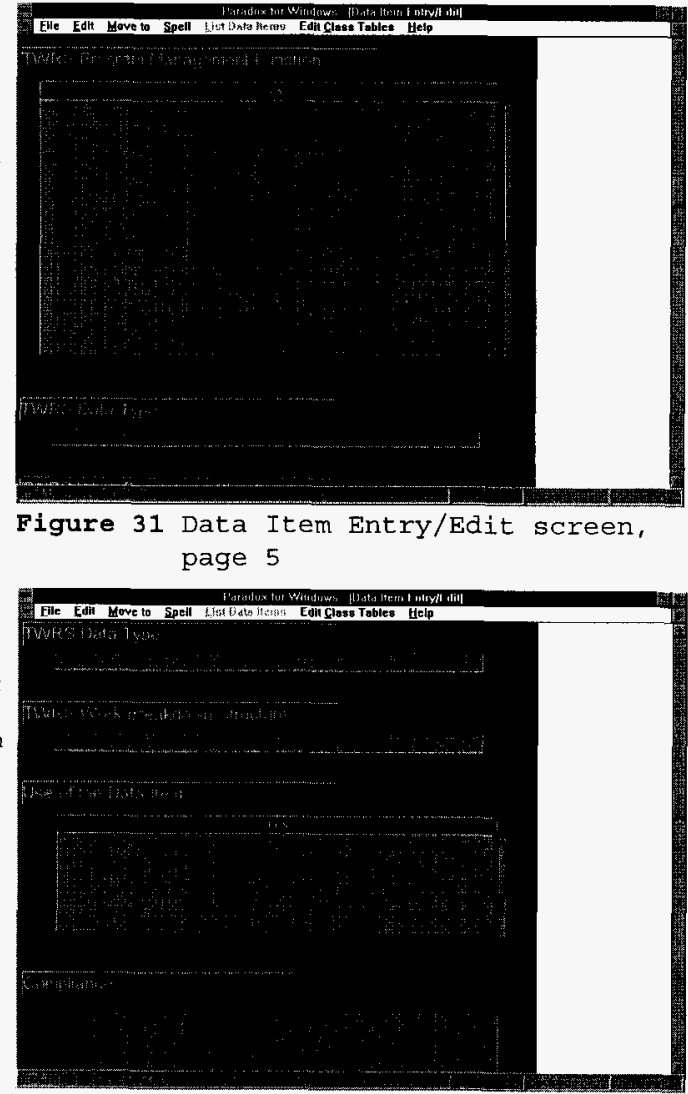

Figure 32 Data Item Entry/Edit screen, page 6 
This page allows for the entry of compliances. This is a memo field. Formatting of the text in this can be done by hitting <shift>F2. This will put the field in memo view thereby allowing <returns>, $<$ tabs $>$, etc. to be entered. Hitting $<$ shift $>$ F2 again will exit memo view.

This page allows for entry of the following attributes:

- Confidence in data. Click on the down arrow to display a list of confidences.

- Configuration management. Click on the down arrow to display a list of classes. If Formal is chosen, enter the standard and authority.

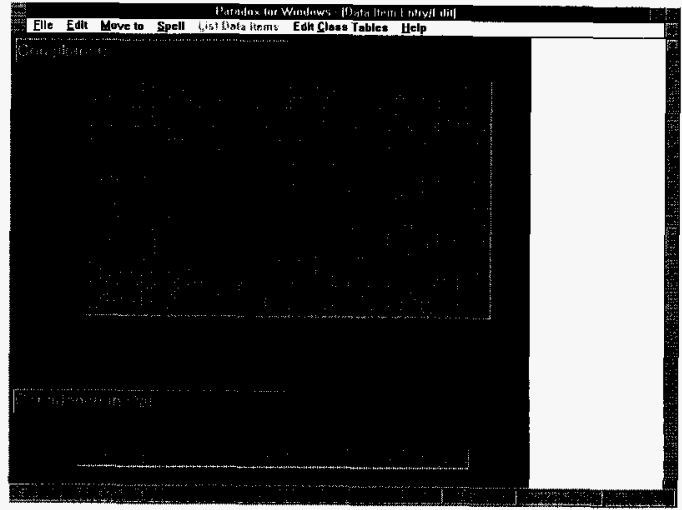

Figure 33 Data Item Entry/Edit screen, page 7

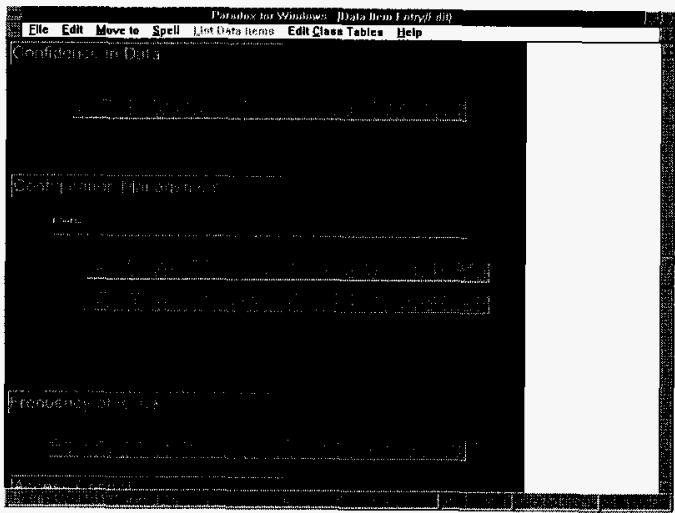

Figure 34 Data Item Entry/Edit screen, page 8 
This page allows for entry of the following attributes:

- Frequency of issue. Click on the down arrow to display a list of classes.

- Access Control. Click on the down arrow to display a list of classes. If Controlled is chosen, enter the Security Level and Control Authority.
This page allows for entry of processor of the data item information:

- Processor class. Click on the down arrow for a list of classes.

- If displayed, enter the processor name, acronym, and description. The description is a memo field.

Formatting of the text in this can be done by hitting $<$ shift $>\mathrm{F} 2$. This will put: the field in memo view thereby allowing $<$ returns $>$, $\langle$ tabs $>$, etc to be entered. Hitting <shift $>\mathrm{F} 2$ again will exit memo view.

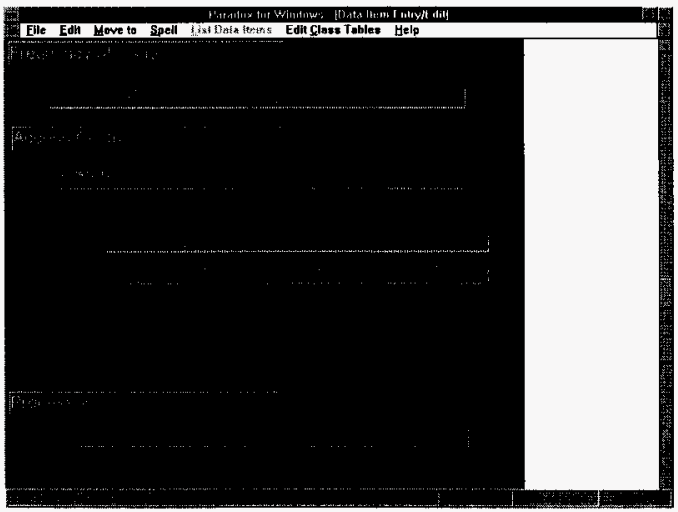

Figure 35 Data Item Entry/Edit screen, page 9

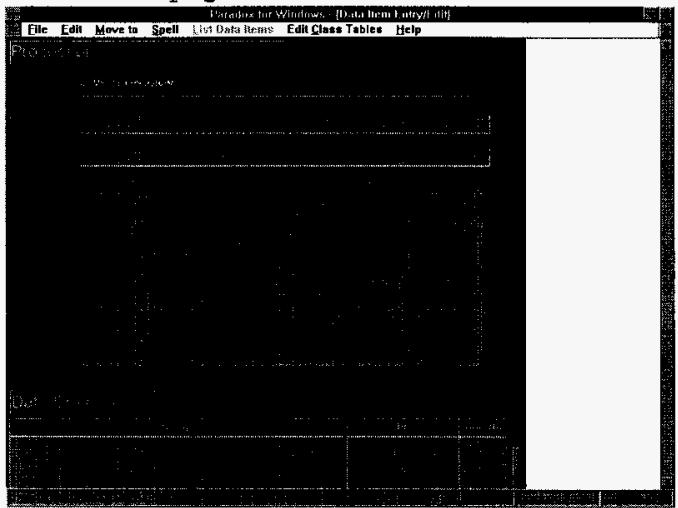

Figure 36 Data Item Entry/Edit screen, page 10 
This page allows for entry of any data item that list this new data item as a source (a drain). Enter the data item name, id, and revision number of these data items here.

Click on a new line in the table to add additional drains.

If the display seems frozen, look at the message at the bottom left of the screen. If it says "Key Violation", use $<$ ctr $1><$ delete $>$ to delete the current line.

To move to the next page, use the $<\mathrm{F} 4>$ key.

This page allows for entry of the sources to the new data item. Enter the following:

- Name of the source data item.

- Id.

- Revision number.

- Transmission method of the source to the new data item. Click on the down arrow for a list of classes.

- Logical requirement.

Click on a new line to enter additional sources.

If the display seems frozen, look at the message at the bottom left of the screen. If it says "Key Violation", use $<$ ctrl $><$ delete $>$ to delete the current line.

\section{$\mathbf{F}$}

To move to the next page, use the $<F 4>$ key.
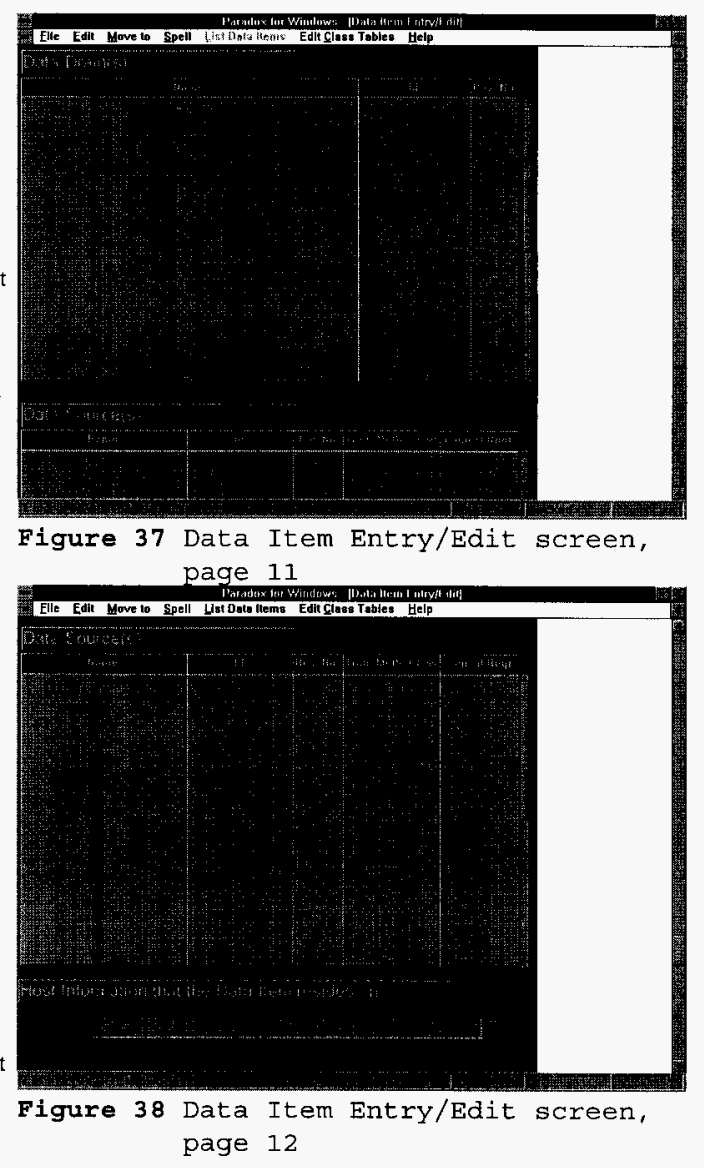
This page allows for entry of information about the host of the data item:

- Host class. Click on the down arrow to display a list of classes.

- Model name.

- Amount of RAM (in MB).

- Storage media and size of the data itern. Click on the down arrow for a list of storage media classes.

- Operating system. Click on the down arrow for a list of operating system classes.

- Network class. Click on the down arrow for a list of network classes.

- Network name and type.

Click on a new line in the table to enter additional information or storage media, operating system, and network.

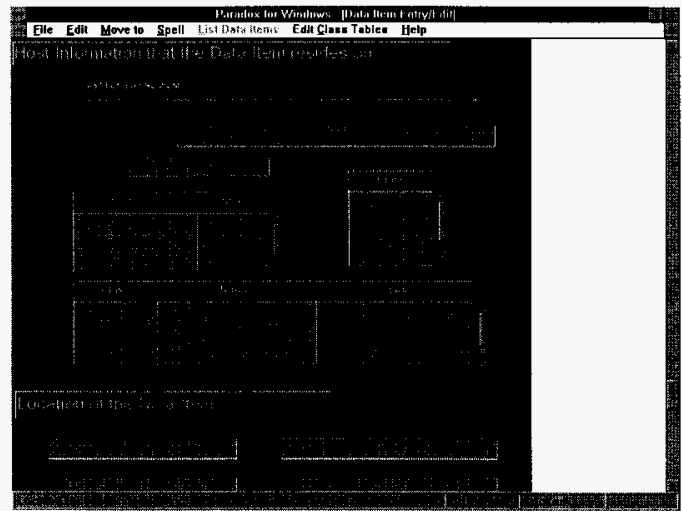

Figure 39 Data Item Entry/Edit screen, page 13

If the display seems frozen, look at the message at the bottom left of the screen. If it says "Key Violation", use $<$ ctrl $><$ delete $>$ to delete the current line.

To move to the next field, use the $<F 4>$ key.

This page allows for entry of the location of the data item:

Note that site, city, state, zip code, and country are initially filled in.

Enter the following:

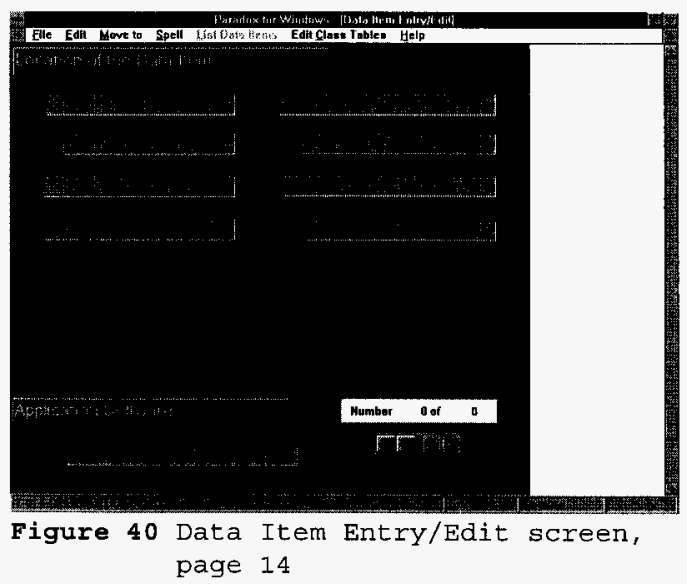

- Area

- Building

- $\quad$ Street address page 14 
This page contains information about the application software of the data item. Enter the application software class by clicking on the down arrow.

If Non-Site is selected, this page allows for entry of non-site standard application software information.

- Application name.

- Commercially available? If so, click to check it yes.

- Version of the software.

- Description. The description is a memo field. Formatting of the text in this can be done by hitting <shift $>\mathrm{F} 2$. This will put the field in memo view thereby allowing <returns $>$, 〈tabs $>$, etc. to be entered. Hitting $<$ shift $>$ F2 again will exit memo view.

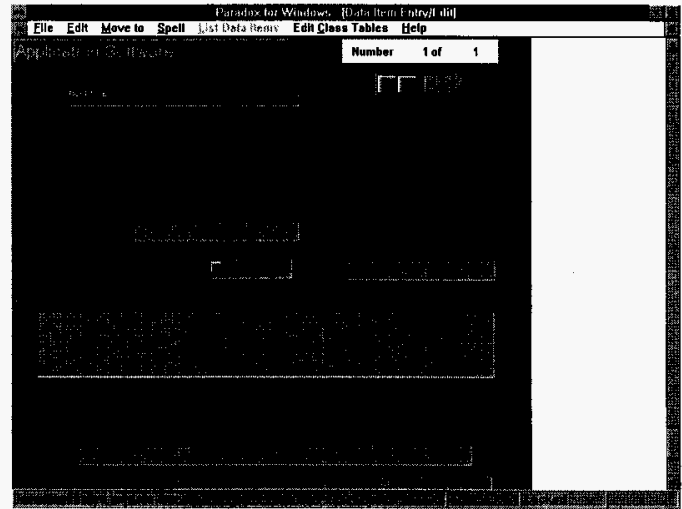

Figure 41 Data Item Entry/Edit screen, page 15 (Non-Site standard)

Note: This page also allows the administrator to input multiple softwares for a data item.

The "Number of " line tells how many application softwares there are for this data item. Clicking on the "+" button will allow for entering another, clicking the "-" will delete the displayed application software, clicking the left arrow will display the previous, and clicking the right arrow will display the next.

If Site is selected as the application software class, this page is displayed. Enter the information about the site standard software.

- Site class. Click on the down arrow to list the site standard software classes.

- Enter the version number of the software.

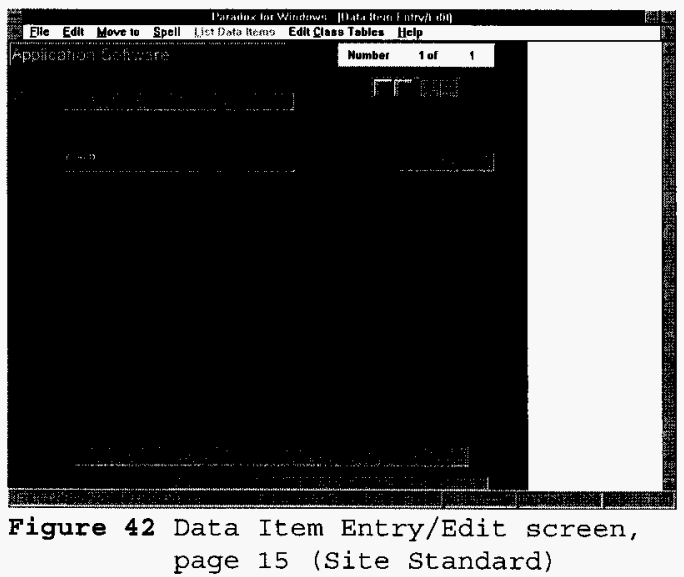


The last page of the data item entry/edit form relates to information on the host of the application software.

- Host class. Click on the down arrow to display a list of classes.

- Model name.

- Amount of RAM (in MB).

- Hard disk size (in MB).

- Storage media. Click on the down arrow for a list of storage media classes.

- Operating system. Click on the down arrow for a list of operating system classes.

- Nerwork class. Click on the down arrow for a list of network classes.

- Network name and type.

Click on a new line in the table to enter additional information or storage media, operating system, and network.

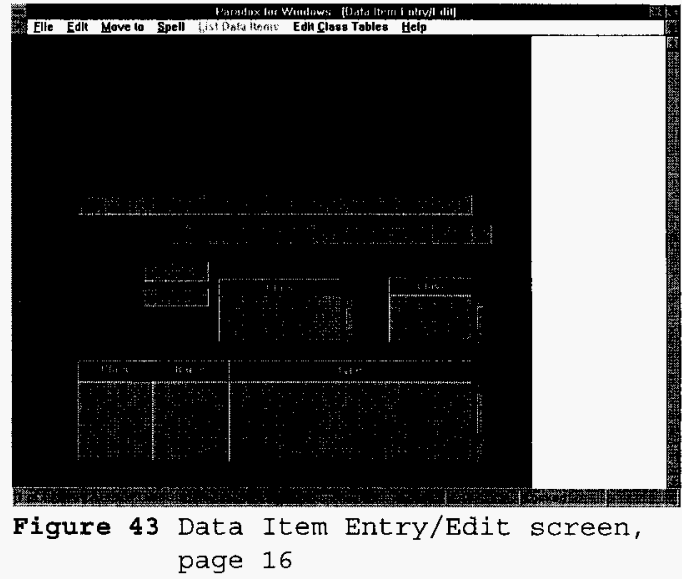

If the display seems frozen, look at the message at the bottom left of the screen. If it says "Key Violation", use $<$ ctrl $><$ delete $>$ to delete the current line.

To move to the next field, use the $<\mathrm{F} 4>$ key.

Once data item entry has been completed, select File | Save from the main menu to save the data item to the data base. Or select File $\mid$ Cancel to cancel data entry. Both options return to the data base administrator screen. 


\subsubsection{Editing a Data Item}

- Start up the System Administrator section of the ILD system.

- Highlight the data item that you want to modify from the table on the Database Administrator screen.

- Select the "Open" button. This causes the Data Entry/Edit form to start. See Section 4 for a description of this form, and Section 9.1.2 for an example of the data entry screens.

- When the edit process is complete select File|Save from the Data Entry/Edit form menu.
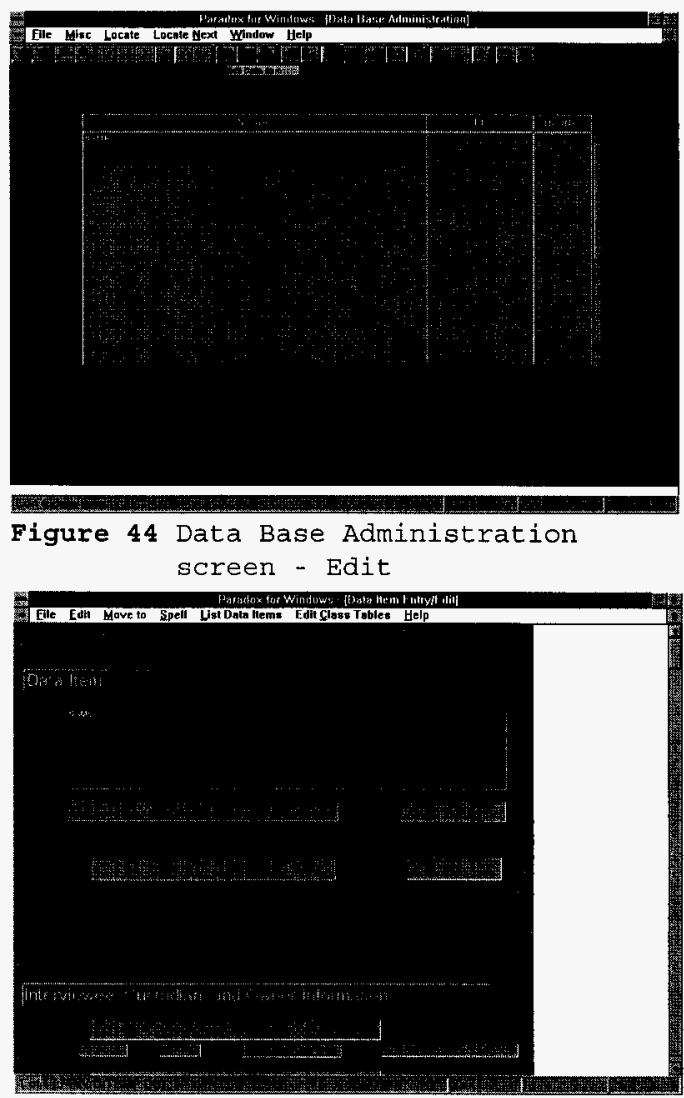

Figure 45 Data Item Entry/Edit screen 


\subsubsection{Deleting a Data Item}

- Start up the System Administrator section of the ILD system (see Section 3.2 .1 or 9.1 .1 ).

- Highlight the data item that you want to delete from the table on the Database Administrator screen.

- Select the "Delete" button.

- A dialog box appears which prompts you to select "Yes" or "No". Select "Yes" if you really want to delete the data item.

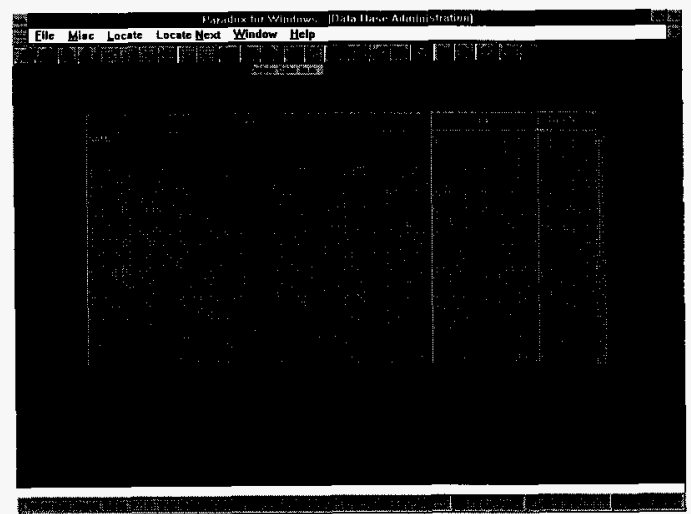

Figure 46 Data Base Administration screen - Delete

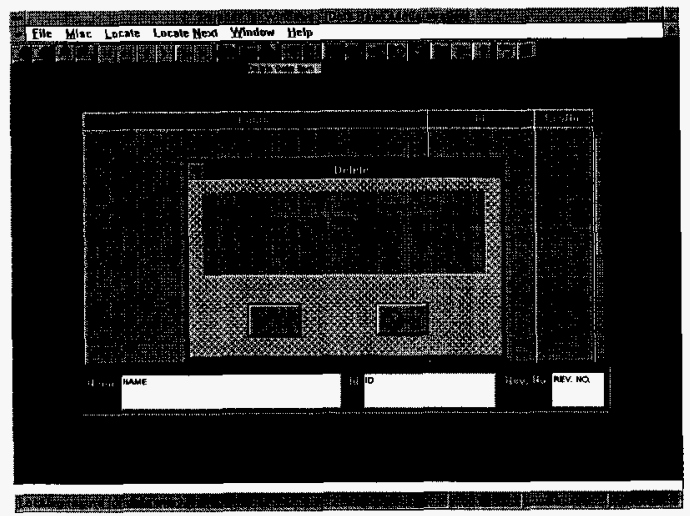

Figure 47 Data Base Administration screen - Delete 


\subsubsection{Printing Data Item Attributes}

- Start up the System Administrator section of the ILD system (see Section 3.2 .1 or 9.1 .1 ).

- Highlight the data item that you want to view/print the attributes from the table on the Database Administrator screen.

- Select the "View/Print Attributes" button. The Data Item Attributes screen is displayed.

This screen contains all of the attributes for

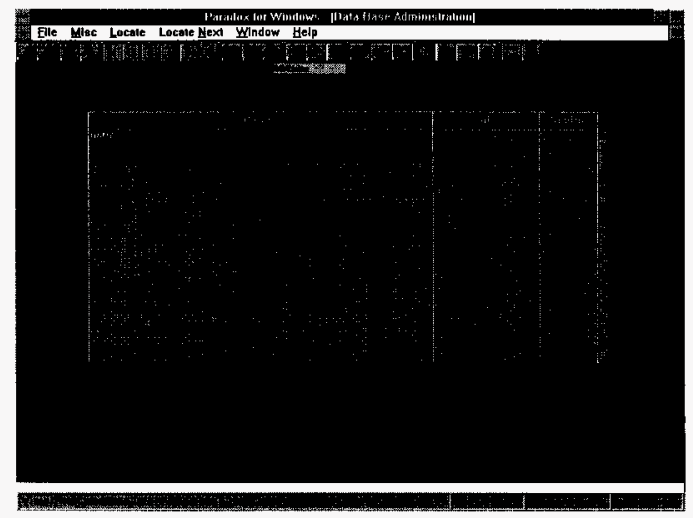

Figure 48 Data Base Administration screen - View/Print

the data item. Clicking on the administrative, applicability, descriptive, heritage, and physical buttons at the bottom of the screen display the attributes contained within that group.

To view/print a report of the data item attributes, click on the Print button.

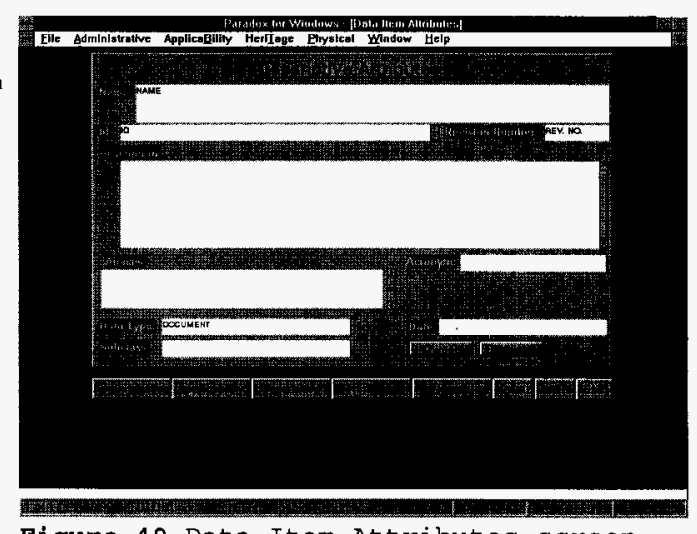

Figure 49 Data Item Attributes screen 
This is a multi-page report of the data item attributes. To print it, click on the print button. Use the arrow buttons to view different pages.

To close this screen, double-click on the Control Menu on the second line.

Note: If when printing the print windows says Page and Printer orientation do not match, close this window and use File | Printer Setup to change the printer orientation from Landscape to Portrait.

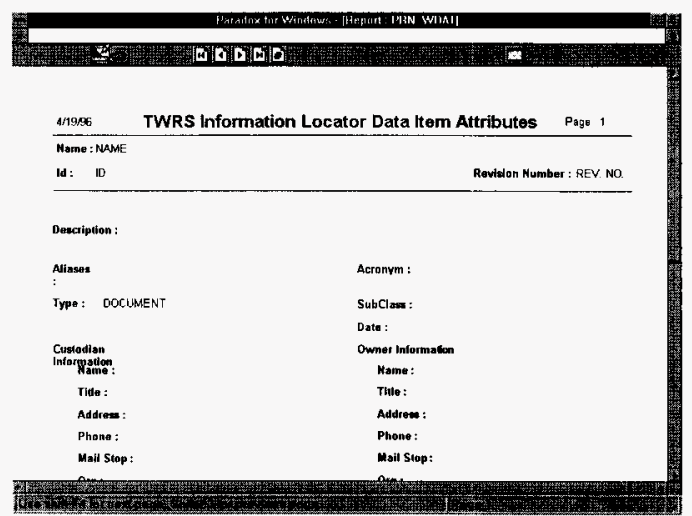

Figure 50 Data Item Attributes report 


\subsubsection{Matching Orphan Sources by ID}

- Start up the System Administrator section of the ILD system (see Section 3.2.1 or 9.1.1).

- Select the "Match Orphans" button from the Database Administrator screen.

- Select the type orphan match - ID. The Orphan Source Mark and Link screen is displayed.
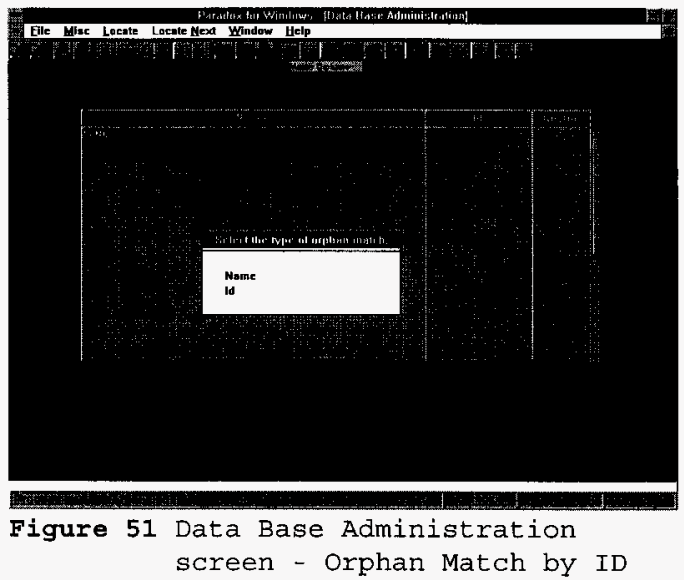

- Select the "Setup" button. This causes all orphan sources that have the same ID as data items in the Database to be placed in a temporary table. The data in the temporary table is what appears on the Orphan Source Mark and Link screen.

Note: The administrator does not have to run setup each time this screen is started. They may leave this screen and come back later to continue working on the orphans.

- Select the "Print Reports" button. You canı print a report which displays all the records that have matching IDs or you can print a report which displays only the records which have been marked.

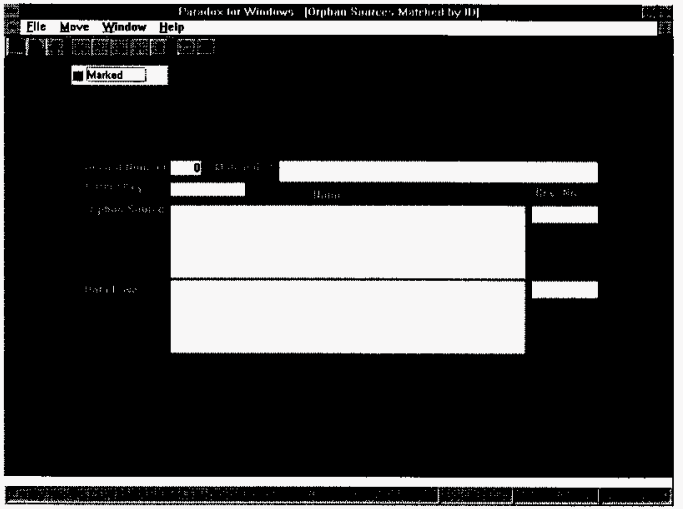

Figure 52 Match Orphans by ID screen

- Use the movement arrow keys and the mark field to mark all records that should be linked (when a record is marked the mark field will turn yellow). Linking means that the orphan source displayed is the same as the data base data item displayed. The reason that the orphan source was not linked originally is because there is a difference in the name and/or revision number of the orphan and the data base data item with the same ID. Marking this record means that the displayed data item from the data base will be linked to the parent of the orphan and the orphan will be deleted from the orphan source file. 
Scrolling through this list there is the possibility of multiple data base data items for a given orphan source. This is signified by subsequent records having the same parent key, matched id, orphan source name and revision number, but the data base name and revision number are different. Only one of these records in this 'group' can be marked because an orphan source record can have only one parent data item. Therefore a check is made when the link process is executed. It checks to make sure that only one data base data item is marked for a given orphan source record. If there is more than one, a message is displayed signifying this and identifying a record number in this 'group'. The administrator should then move to that record nurnber and correct the problem by making sure only one data base data item is marked in this group.

- Select the "Link" button. This makes all marked data base data items become the source to the parent item of the orphan source record. The orphan source record is also deleted. The temporary table is then cleared. 


\subsubsection{Matching Orphan Sources by NAME}

- Start up the System Administrator section of the ILD system (see Section $3.2,1$ or 9.1 .1 ).

- Select the "Match Orphans" button from the Database Administrator screen.

- Select the type orphan match - NAME. The Orphan Source Mark and Link screen is displayed.

- Select the "Setup" button. This causes all orphan sources that have the same NAME as data items in the Database to be placed in a temporary table. The data in the temporary table is what appears on the Orphan Source Mark and Link screen.

Note: The administrator does not have to run setup each time this screen is started. They may leave this screen and come back later to continue working on the orphans.

- Select the "Print Reports" button. You can print a report which displays all the records that have matching NAMEs or you can print a report which displays only the records which have been marked.

- Use the movement arrow keys and the mark field to mark all records that should

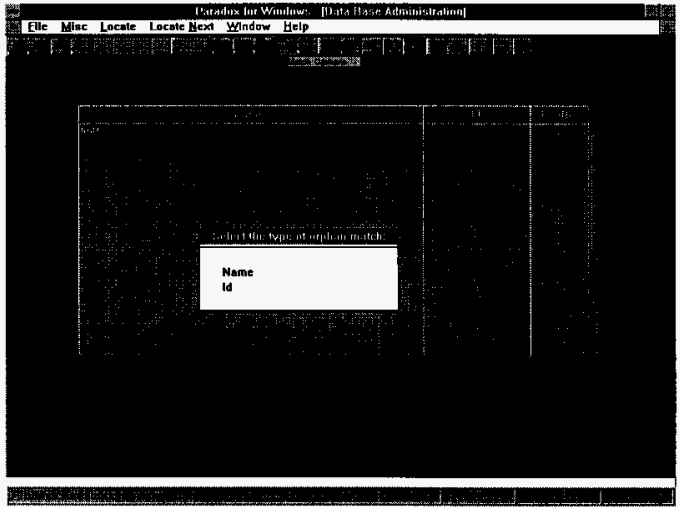

Figure 54 Data Base Administration, Match Orphans by Name screen

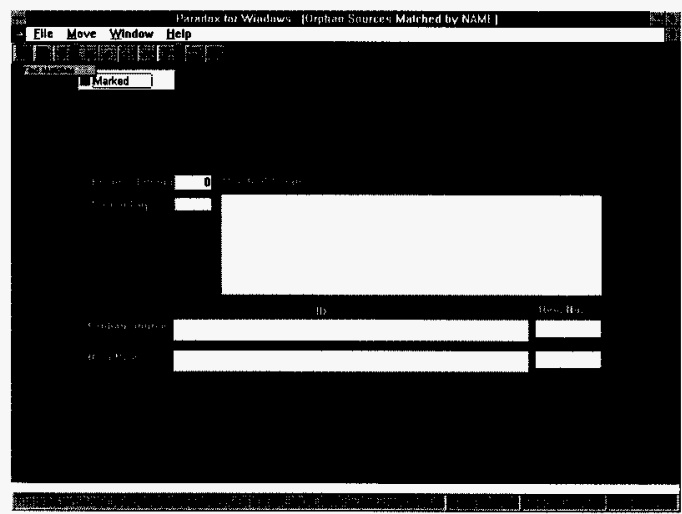

Figure 55 Match Orphans by Name - Find Matches screen be linked (when a record is marked the mark field will turn yellow). Linking means that the orphan source displayed is the same as the data base data item displayed. The reason that the orphan source was not linked originally is because there is a difference in the id and/or revision number of the orphan and the data base data item with the same NAME. Marking this record means that the displayed data item from the data base will be linked to the parent of the orphan and the 
orphan will be deleted from the orphan source file.

Scrolling through this list there is the possibility of multiple data base data items for a given orphan source. This is signified by subsequent records having the same parent key, matched name, orphan source id and revision nurnber, but the data base id and revision nurnber are different. Only one of these records in this 'group' can be marked because an orphan source record can have only one parent data item. Therefore a check is made when the link process is executed. It checks to make sure that only one data base data item is marked for a given orphan source record. If there is more than one, a message is displayed signifying this and identifying a record number in this 'group'. The administrator should then move to that record number and correct the problem by making sure only one data base

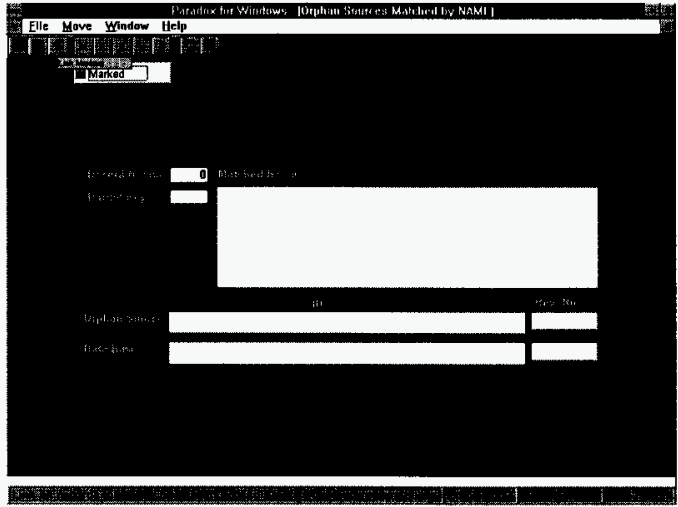

Figure 56 Match Orphans by Name - Link screen data item is marked in this group.

- Select the "Link" button. This makes all marked data base data items become the source to the parent item of the orphan source record. The orphan source record is also deleted. The temporary table is then cleared. 


\subsubsection{Editing Orphan Sources}

- Start up the System Administrator section of the ILD system (see Section 3.2 .1 or 9.1.1).

- Select the "Edit Orphans" button from the Database Administrator screen.

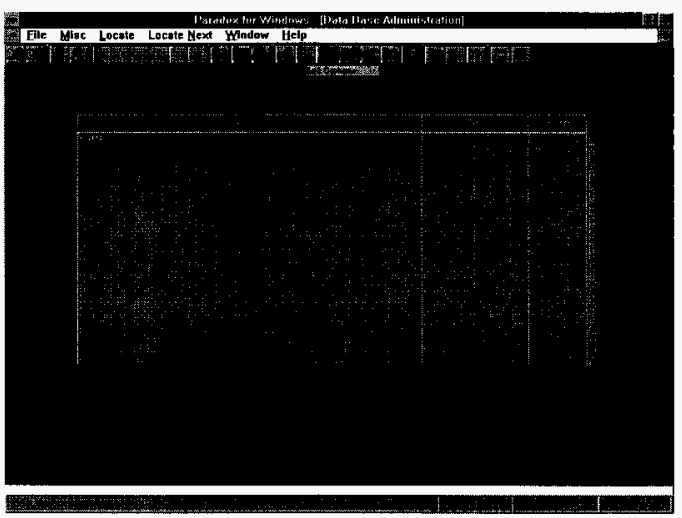

\section{Figure 57 Data Base Administration screen - Edit Orphans

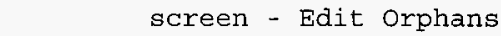

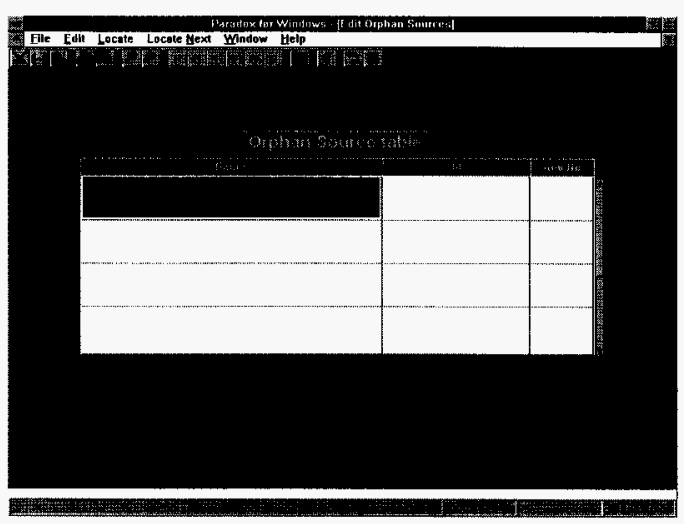

Figure 58 Edit Orphan Sources screen
- Select the "Locate" button to locate an orphan source.

- Make the appropriate modifications.

- Select the "Link" button. This tries to link the modified orphan source to the Database.

\section{Or}

- Select the "Delete" button to delete it from the orphan source table.

- Select the "Return" button when done making modifications. 


\subsubsection{Query Orphan Sources}

- Start up the System Administrator section of the ILD system (see Section 3.2.1 or 9.1.1).

- Select the "Query Orphan Sources" button from the Database Administrator screen.

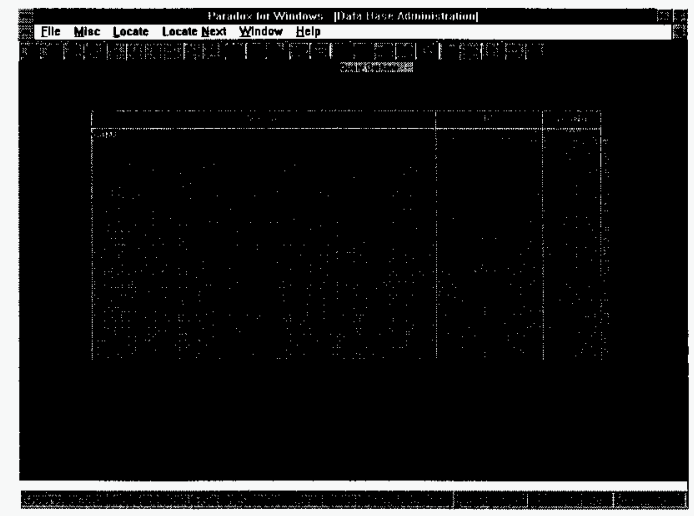

\section{Figure 59 Data Base Administration \\ screen, Query Orphan Sources}

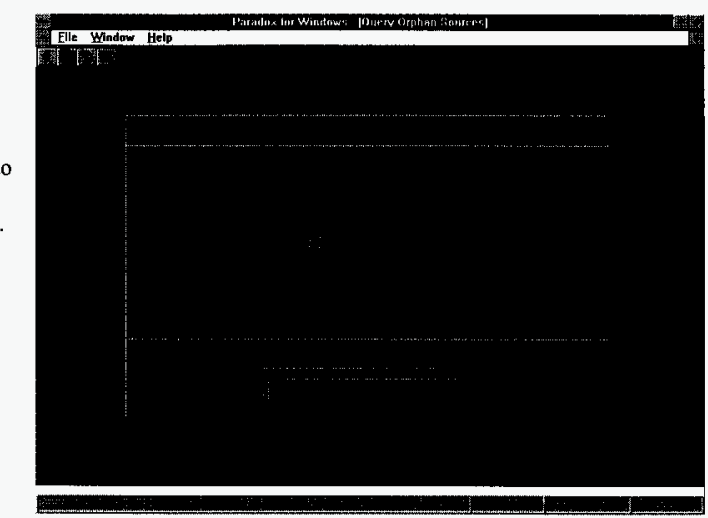

Figure 60 Query Orphan Sources screen
This screen will run a query against the orphan source names.

- Enter the query string to use in the query. The .. operator can be used to match any string. E.g., DOE.. will find all strings that begin with DOE.

- Click on the View/Print button to view/print the report. 


\subsubsection{Mapping Data Items to New System Engineering Functions}

\section{Process for recognizing when new RDD-100 System Engineering Functions are available and incorporating} them into the ILD system.

Currently, the process of updating the RMS TWRS Browser (hereafter referred to as the Browser) with data from RDD-100 is as follows:

The TWRS RDD-100 Administrator informs the RMS TWRS Browser Custodian that there are changes in RDD-100 that need to be reflected in the Browser. She creates an RDT file which contains, in ASCII text format, the RDD-100 commands that describe these changes. This file is stored on the Sun. Contained in this file are the functions and definitions that we are interested in.

The RMS TWRS Browser Custodian then does an FTP of the RDT file which copies it from the Sun to the HLAN.

He then parses the RDT file which extracts the information and creates (or updates) a new RMSB.MDB Access data base file. This is the Access data base file that the browser reads and displays when the browser is used.

When the system administrator starts ILD and opens the Data Base Administrator screen, the system checks the current date of the RMSB.MDB file (the location of this file on the HLAN is located in the ILD.INI file) against the date of the last ILD update. If there is an updated RMSB.MDB file, then a message is displayed telling the administrator that there are possible new functions.

Note: if there is mapping in process then a message displaying this appears. The current mapping must be completed before the updated functions can be examined.

The administrator must then start the Map Data Items to New System Engineering Functions screen.

In order to map data items to new functions, the system administrator must first determine which old functions can be directly classified into a new function. Being able to map all data items classified under an old function into a new one will greatly reduce the amoung of time needed to complete the mapping process. There may, however, be instances where an old function may have been split into two or more new functions. In this case, all of the data items classified under the old function must be looked at individually. This part of the process may take a little more time.

Below are two forms which allow the administrator to accomplish the mapping process. 


\section{Map Data Items to New System Engineering Functions Screen}

- Start up the System Administrator section of the ILD system (see Section 3.2.1 or 9.1.1).

If there is an updated RMSB.MDB file containing possible updated System Engineering functions a message will be displayed informing the administrator to start the Map Data Items screen to process this update.

- Select the "Map Data Items" button from the Database Administrator screen.

The "Setup" button is the only option available at this point. All others are not allowed until setup is complete.

This button will prepare for the data item mapping process by extracting the functions from the RMSB.MDB file and displaying the old and new functions on the screen.

Once the functions have been extracted, a check is made to see if any of the functions have changed. If no changes are found, a message is displayed saying this and the mapping process is terminated. (an updated RMSB.MDB file might or might not contain changes to the functions as other things may have changed in this file)

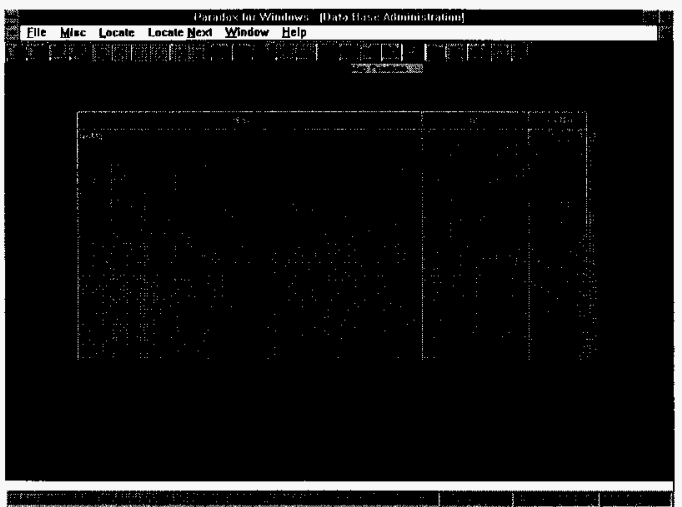

Figure 61 Data Base Administration screen, Map Data Items

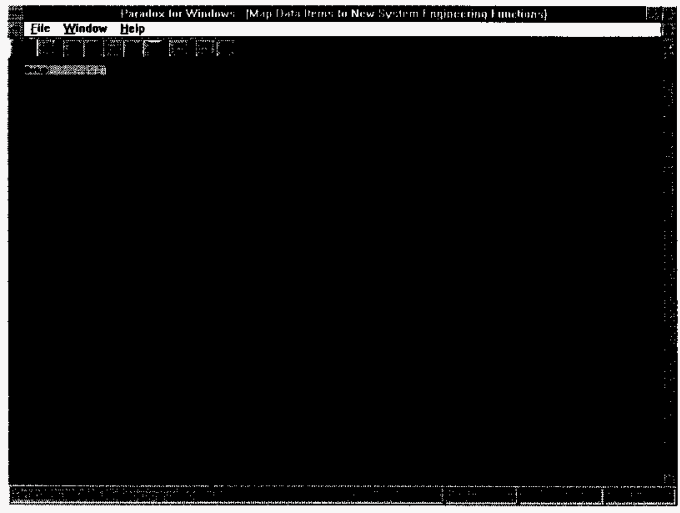

Figure 62 Map Data Items Setup screen 
This screen displays the old functions on the left and the new ones on the right.

The"View/Print" button can be used at any time to view/print a report of the old and new functions.

The "Start Over" button can be used at any time to start the mapping process over.

At this point the administrator can select the Auto-Map button which will scan all the old functions and look for a new function with the same name. If one exists, all data items in the old function will be mapped to the new function.

This allows for easy mapping of functions that have not changed.

The administrator can then map all data items from an old function to a new one by clicking on a function.

- Click on an old function.

- Click on a new function.

Both functions will turn white.

By clicking on the Map Marked button, all data items that are classified in the old function will be mapped to the new function.

Once the mapping process is complete the old function will turn light gray and a red arrow will be drawn to the new function signifying that this function has been mapped.

Note: Clicking on an old function that is light gray will display the new function it was mapped to.

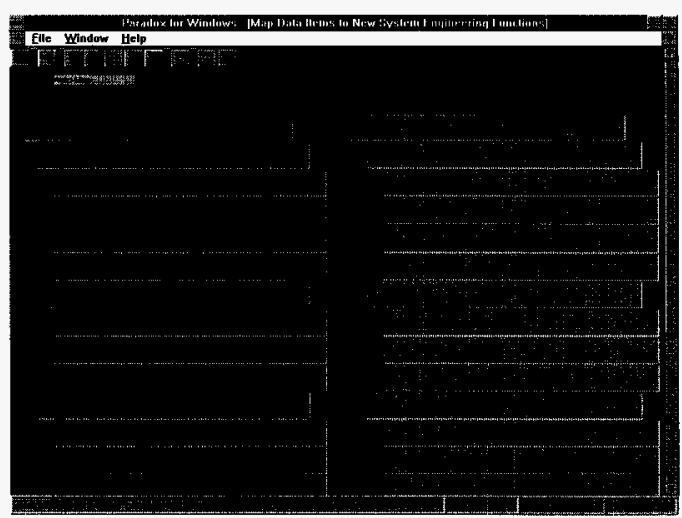

Figure 63 Map Data Items Auto-Map screen

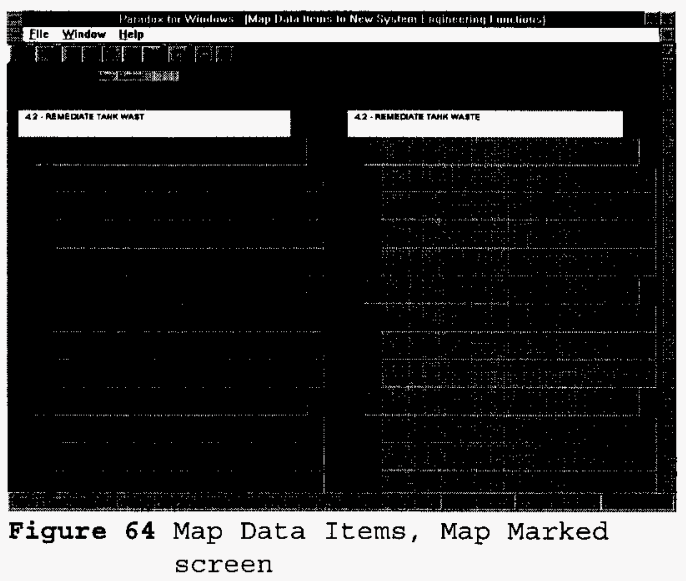


Clicking on the UnMap Marked button wil] undo the mapping of the old function to the new, i.e., all data items that were mapped to the new function will be unmapped.

The old function will return to it's original dark gray color signifying that it can be mapped again to a new function.

When all of the functions have been mapped, and all of the data items have been reassigned to a new function, selecting the Commit Changes button will implement the new functions into the data base.

This will only install the new functions if ALL data items have been mapped. If ALL of them have not, a message is displayed. The data items that have not yet been mapped can be processed using the next button.

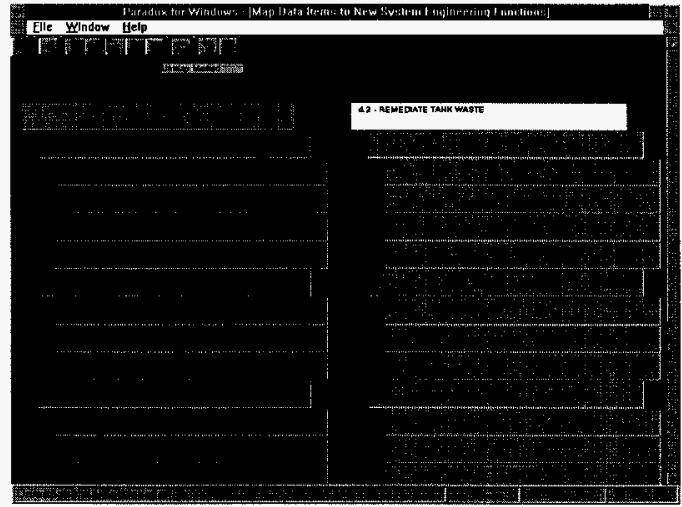

\section{Figure 65 Map Data Items, UnMap Marked} screen

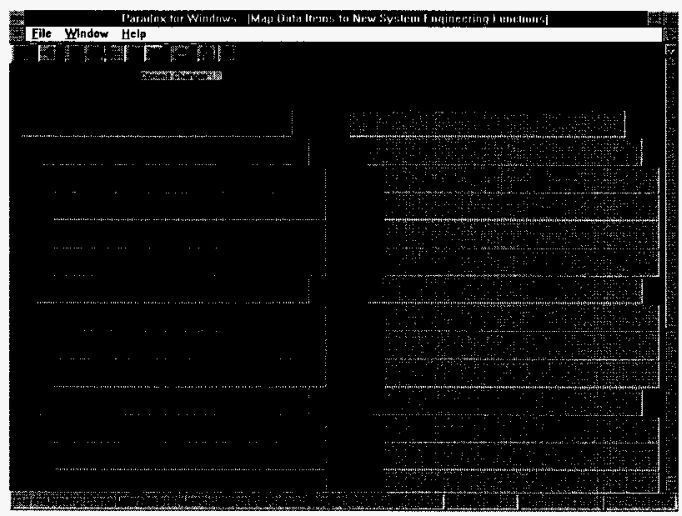

Figure 66 Map Data Items, Commit Changes screen 
The 'Process Unmapped' button allows the administrator to process all those data items that have not yet been mapped. This may be because the data items under an old function have to be reassigned to a new function individually.

Select the 'Process Unmapped' button to map these data items to a new function individually.

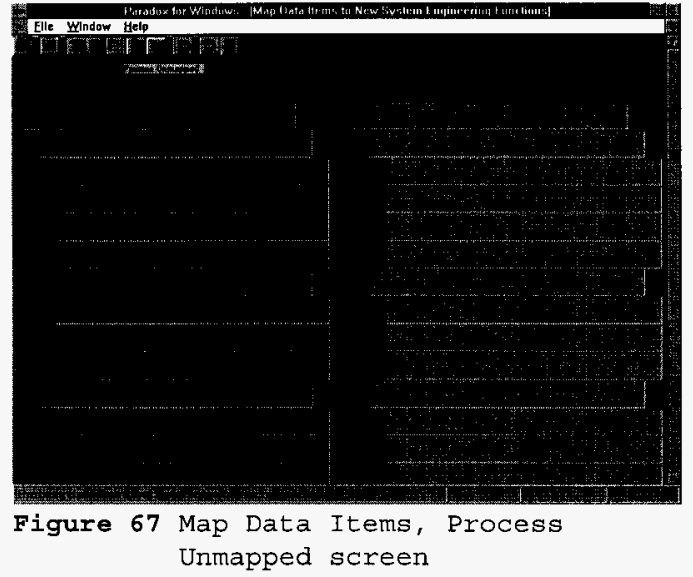

This screen is used to map data items to new functions. The left side of the screen displays all of the old functions. The right table display those data items that have not yet been mapped. Clicking on any of the old functions will display in the table those data items in that function that have not been mapped.

Clicking on the 'Show Unmapped' button will display ALL unmapped data items.

To map a data item, select it in the table and click the 'Map Data Jtem' button.

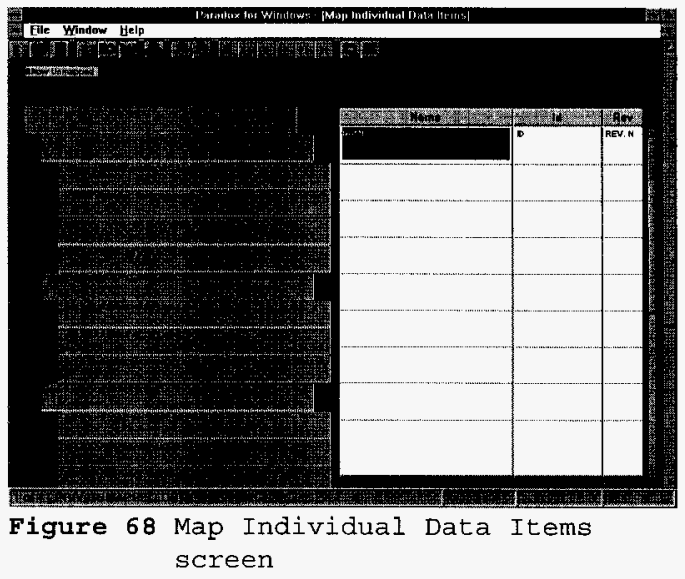


When this button is clicked, a list of new functions is displayed. Select the new function to assign the highlighted data item. The data item will be mapped to the new function and disappear from the table.

The 'Show Unmapped' button will display ALL data items that have been mapped. The administrator can unmap individual data items by highlighting the data item and clicking on the 'Unmap Data Item' button.

Clicking on this button will unmap the highlighted data item. Once the unmapping is done, the data item will disappear from the table.

Using the rest of the buttons the administrator can also print a report of unmapped data items, view/print the attributes of a data item, locate data items, and scroll the table display.

Once all data items have been mapped the commit button from the Map Data Items to New System Engineering Screen' will complete the implementation of new functions.
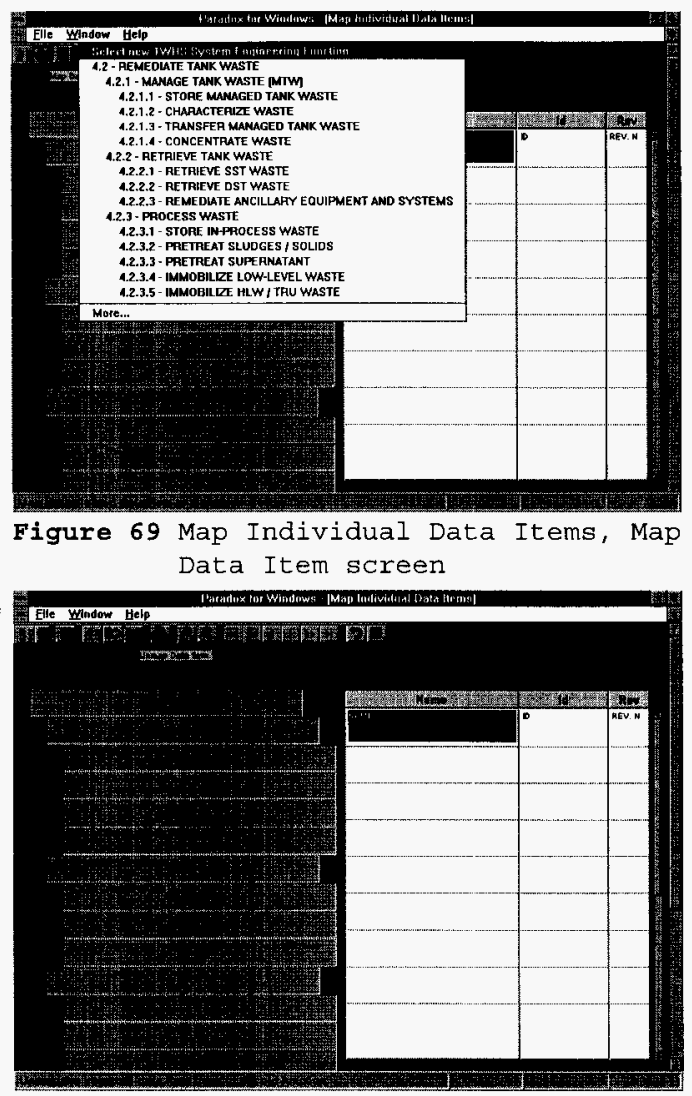

Figure 70 Map Individual Data Items, Unmap Data Item screen 


\subsubsection{Editing Class Tables}

- Start up the System Administrator section of the ILD system (see Section 3.2 .1 or 9.1 .1 ).

- Select the "Class Maint." button from the Database Administrator screen. This causes the Class Table Maintenance screen to be displayed.

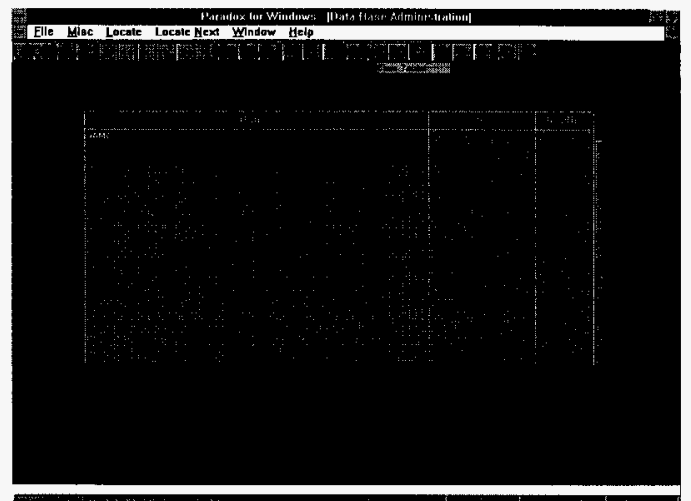

Figure 71 Data Base Administration screen, Edit Class Tables

- Select a Class Table. This displays the classes that comprise the Class Table.

- Highlight the Class that requires modification.

- Choose the button that performs the desired modification. (See Section 4.2.2 for a description of each of the buttons).

- Select the "Close" button when the modifications are complete.

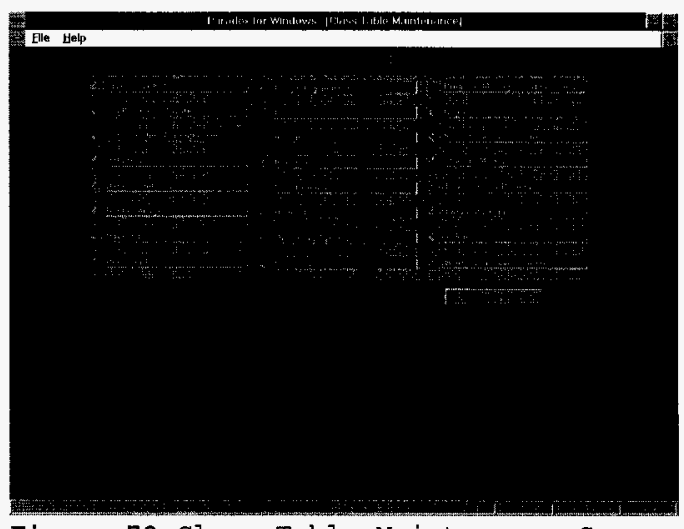




\subsubsection{Change System Administrator Password}

- $\quad$ Start up the System Administrator section of the ILD system (see Section 3.2 .1 or 9.1.1).

- Select the "Change Password" button from the Database Administrator screen. This causes the Class Table Maintenance screen to be displayed.

Enter the new password and click OK. When asked to confirm the password, click OK. The new password is now in effect.

Note: the password is case sensitive.

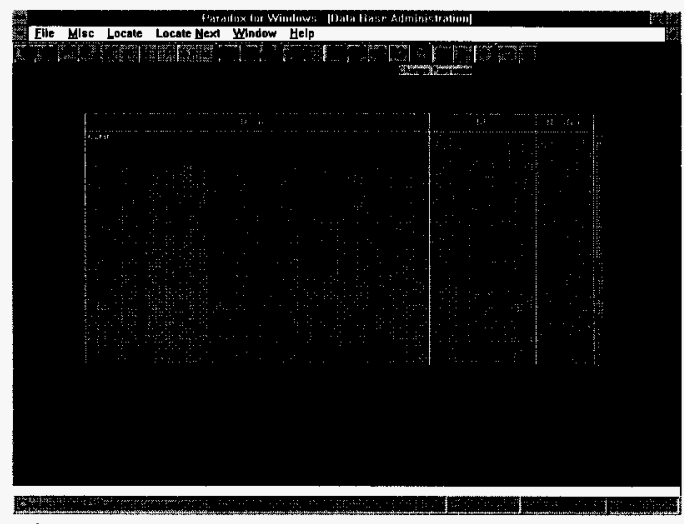

Figure 73 Data Base Administrator screen, Change Password

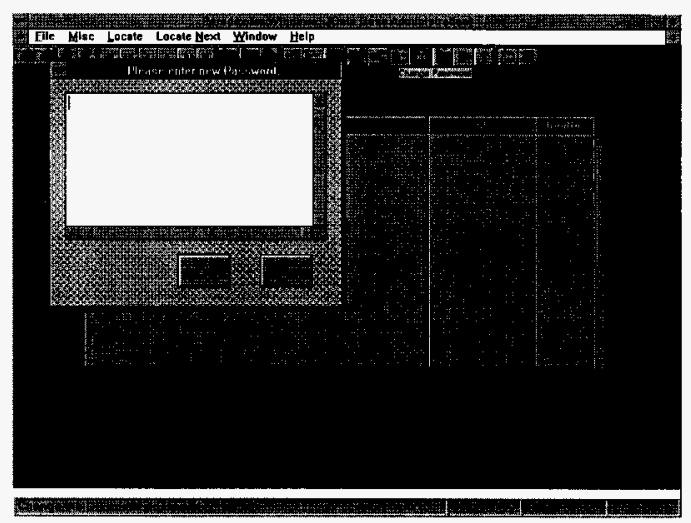

Figure $\mathbf{7 4}$ Change System Administrator Password screen 


\subsubsection{Check the Integrity of the Data Base}

- Start up the System Administrator section of the ILD system (see Section 3.2.1 or 9.1.1).

- Select the "Check Integrity" button from the Database Administrator screen.

The administrator will be asked to confirm this. Select Yes to continue with the data base integrity check.

This check will go through each record in each table in the data base and ensure that it is linked to a data item. If it is not, then that record is deleted.

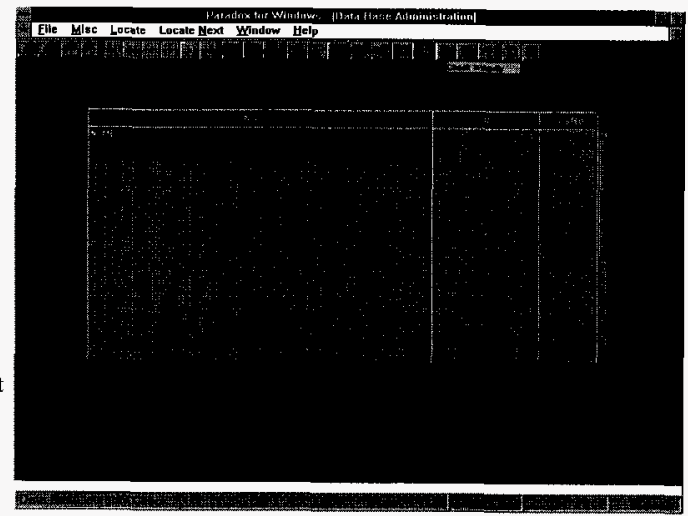

Figure 75 Data Base Administration, Check Data Base Integrity 


\subsubsection{Pack and Reindex the Data Base}

- Start up the System Administrator section of the ILD system (see Section 3.2.1 or 9.1.1).

- Select the "Pack Data Base" button from the Database Administrator scrien.

This option will first check to ensure no one else is using the system. Then it will delete the data item display table in the middle of the screen and backup the data base to a file called PACKBACK.ZIP. Once this is completed, each table in the data base is repacked and reindexed.

Note: this process may take a long time, depending on the speed of the workstation and how busy the network server is.

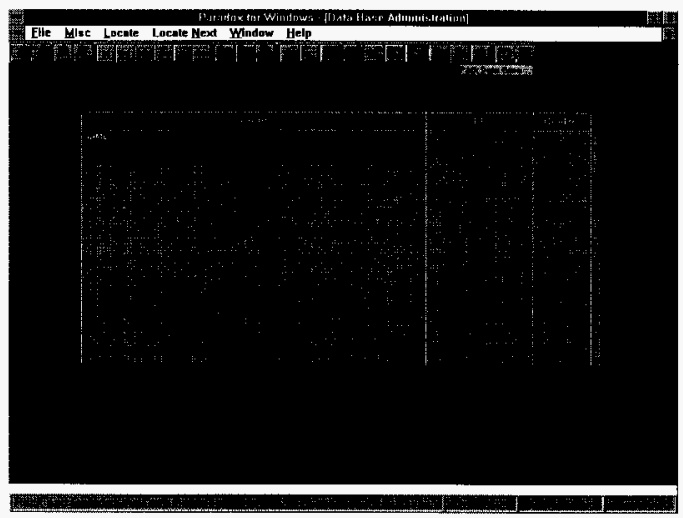

Figure 76 Data Base Administration, Pack and Reindex Data Base 


\subsubsection{Update User's Data Base}

- Start up the System Administrator section of the ILD system (see Section 3.2 .1 or 9.1 .1 ).

- Select the "Update User's DB" button from the Database Administrator screen.

This first determines which drive the data base is orl, then ensures no one else is using the systern. It then makes backup copies of the COMMENTS.DB table in the user's data base (this contains info about who used the system).

It then sets up a message to be displayed in case anyone wants to start the system while this is happening.

Finally, it copies the tables in the IWORKINGIDATABASE and

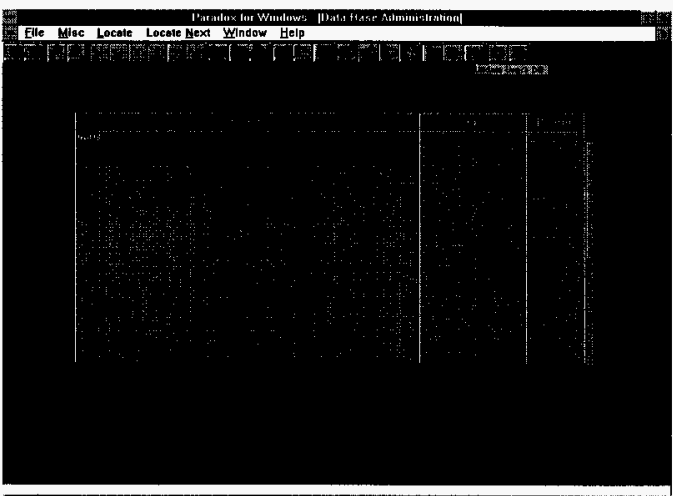

Figure 77 Data Base Administration, Update User's Data Base

IWORKINGICLASSES directories into the ITWRSINVIDATABASE and \TWRSINVICLASSES directories, respectively (IWORKING contains the system constantly being updated. ITWRSINV contains the system that the general user has access to). 


\subsection{Manual installation of the ILD system}

Note: If the user experiences problems, or has any questions about this installation process, please call Patricia $\mathrm{E}$. Porter (376-1987) for assistance.

1. Edit file U:MAUTOUSER.BAT and add the following line:

NET USE J: U"server_name")"shared_area" "password"

where "server_name" is the name of the server where ILD resides "shared_area" is the name of the shared area on the server where ILD resides "password" is the password of the shared area

(e.g. NET USE J: \IWHC336 \TWRSILD OGLEBY)

2. Edit file C:IAUTOEXEC.BAT and make sure C:IODAPI is in the path. Either append ';C:IODAPI' to the path statement if one exists, or add this line:

\section{PATH $=\%$ PATH $\% ; C: I O D A P I$}

(or the drive where ODAPI will be installed, e.g, D:IODAPI)

3. Reboot the machine so that the above changes take effect.

4. Run file JiIINSTALLIINSTALL.EXE. This starts the Paradox Runtime installation.

5. At the installation screen:

Enter the user's name

Enter the user's company

Click off Install Custom Application

Click off Create Windows Group

Click the Install button

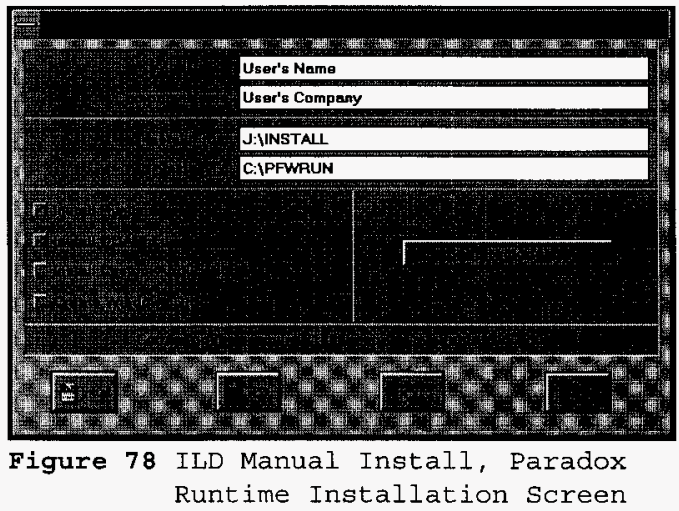

Note: Use $<$ tab $>$ key, or mouse, to move between fields. Pressing <enter $>$ will start the installation.

You can choose 'Cancel' during the installation to return to the above screen. 
6. Close the 'Runtime Readme screen' when it appears.

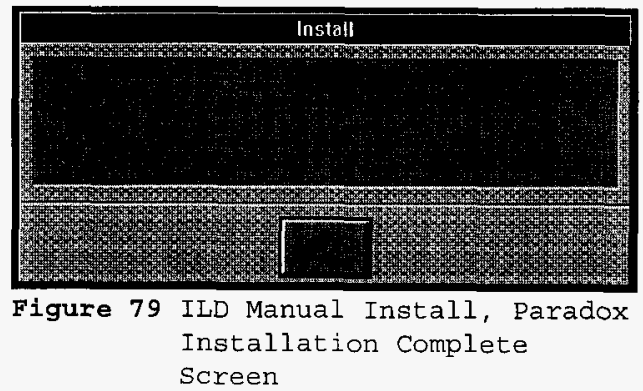

7. Click the OK button at the 'Installation Complete' screen.

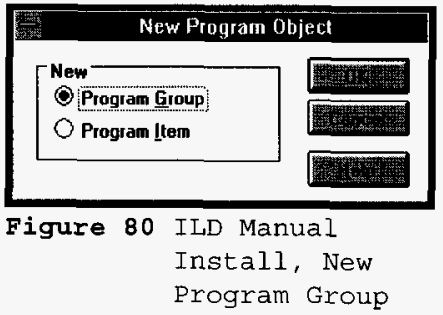

8. Create a new Windows Program Group called 'TWRS Data Inventory'.

From the Windows Program Manager menu: select File select New 
Click on Program Group

\section{Click OK}

\begin{tabular}{|c|c|c|}
\hline 麻形 & Program Item Properti & \\
\hline \multirow{4}{*}{$\begin{array}{l}\text { Description: } \\
\text { Command Line: } \\
\text { Working Directory: } \\
\text { Shortcut Kıy: }\end{array}$} & TwRS Information Localor & \\
\hline & & \\
\hline & C-IPFWRUN & \\
\hline & \multicolumn{2}{|l|}{ None } \\
\hline & $\square$ Rqun Minimized & $(3,4)$ \\
\hline
\end{tabular}

Figure 81 ILD Manual Install, Program Item Properties

\section{Enter the Description} Click OK

9. Create a new Windows Program Item in this group called "TWRS Data Inventory'.

From the Windows Program Manager menu: select File select New

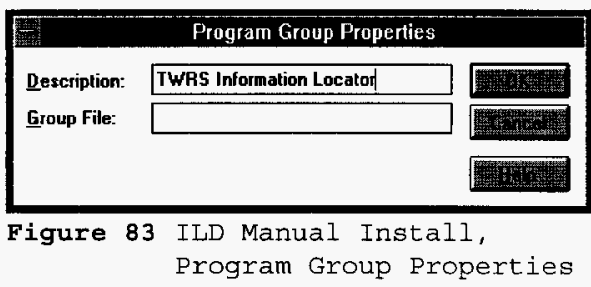

Click on Program Item Click OK
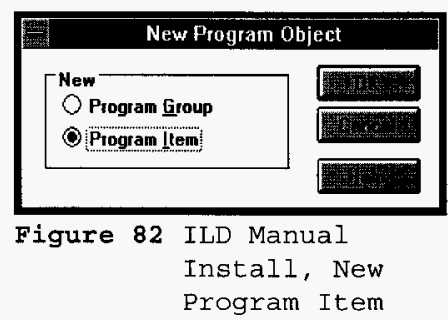
Enter the Description

Enter the Command Line

Enter the Working Directory

Click OK

The command line should read:

\section{C:IPFWRUNIPFWRUN.EXE -C -OJ:IODAPIIODAPI.CFG}

-PC:IWINDOWSITEMP -WJ:ITWRSINV J:ITWRSINVIST ARTUP.SDL

10. The installation is now complete. 


\subsection{Example first pages of System Administrator's Reports}

\subsubsection{ILD User Comments/Problem Report}

This report comes from the "ILD User Information" screen and lists information about the users of the ILD system and their workstations, plus any comments/suggestions and/or problem descriptions that they may have entered while using the system.

Please refer to the next page for an example of this report. 


\subsubsection{ILD User Workstation Report}

This report comes from the "ILD User Information" screen and lists information about the users of the ILD system and their workstations.

Please refer to the next page for an example of this report. 


\subsubsection{List of Orphan Sources Satisfying Query}

This report comes from the "Query Orphan Sources" screen and lists those orphan sources that contain the query string entered in this screen. The example report on the following page was generated using the query string "DOE..".

Please refer to the next page for an example of this report. 


\subsubsection{Listing of All UnMapped Data Items}

This report comes from the "Map Individual Data Items Screen" and lists all of the data items (name, ID, and revision rumber) that have not been mapped to a new Systems Engineering function. The purpose of this report is to aide the administrator in deciding which new function a data item should be mapped to. Please refer to Section 9.1.10 for further explanation of the mapping process.

Please refer to the next page for an example of this report.

\subsubsection{Listing of All UnMapped Data Items for Function ...}

This report comes from the "Map Individual Data Items Screen" and lists all of the data items (name, ID, and revision rumber) classified under a particular TWRS System Engineering function that have not been mapped to a new Systems Engineering function. The purpose of this report is to aide the administrator in deciding which new function a data item should be mapped to. Please refer to Section 9.1.10 for further explanation of the mapping process.

Please refer to the next page for an example of this report. 


\subsubsection{NEW TWRS System Engineering Functions}

This report comes from the "Map Data Items to New System Engineering Functions screen" and lists the new TWRS System Engineering functions (name and definition) when new functions have been received from the RDD100 system. This report, in conjunction with report "OLD TWRS System Engineering Functions" is used to determine which old functions can be directly mapped to a new function. This process, described in greater detail in Section 9.1.10, reduces the amount of time needed to map data items to the new functions. Please refer to Section 9.1.10 for further explanation of the mapping process.

Please refer to the next page for an example of this report.

\subsubsection{OLD TWRS System Engineering Functions}

This report comes from the "Map Data Items to New System Engineering Functions screen" and lists the old TWRS System Engineering functions (name and definition), i.e., the functions that are currently in use in the data base. This report, in conjunction with report "NEW TWRS System Engineering Functions" is used to determine which old functions can be directly mapped to a new function. This process, described in greater detail in Section 9.1.10, reduces the amount of time needed to map data items to the new functions. Please refer to Section 9.1.10 for further explanation of the mapping process.

Please refer to the next page for an example of this report.

\subsubsection{Parent Item, Orphan Source, and Data Base ID Match - Entire Report}

This report comes from the "Orphan Sources Matched by ID screen" and displays all of the matches that were found when the Setup query from this screen was executed. This query found all orphan sources that have the same ID as a data item in the data base. This report lists each match in a three line section of the report.

An example three line section of the report follows:

\begin{tabular}{cclr} 
DiUnique & Name & \multicolumn{1}{l}{ ID } & RevNo \\
1 & PARENT ITEM TITLE & WHC-XXX3 \\
& ORPHAN SOURCE TITLE & WHC-XXXI \\
3 & DATA BASE ITEM TITLE & WHC-XXXI
\end{tabular}

This three line section says that there is a record in the orphan source file with the Name "ORPHAN SOURCE TITLE" and ID "WHC-XXXI". The query found a data item in the data base with the same ID, "DATA BASE ITEM TITLE". The parent item of the orphan source is "PARENT ITEM TITLE". At the time that "PARENT ITEM TITLE" was entered, one of its sources was entered as "ORPHAN SOURCE TITLE" and when it was saved, the link process could not find "ORPHAN SOURCE TITLE" in the data base. That is why it is in the orphan source file.

The administrator must now make the determination if "ORPHAN SOURCE TITLE" and "DATA BASE ITEM TITLE" refer to the same data item. If so, the mark button in the "Orphan Sources Matched by ID screen" can be used to mark this record. When the link button is executed, "DATA BASE ITEM TITLE" will be linked to "PARENT ITEM TITLE" and "ORPHAN SOURCE TITLE" will be deleted from the orphan source file.

Please refer to the next page for an example of this report. 


\subsubsection{Parent Item, Orphan Souree, and Data Base ID Match - Mark Records Report}

This report comes from the "Orphan Sources Matched by ID screen" and displays all of the records that were marked in the process described in the "Parent Item, Orphan Source, and Data Base ID Match - Entire Report" above. This report can be used to double-check the records to be linked before executing the link "Orphan Sources Matched by ID screen".

Please refer to the next page for an example of this report.

\subsubsection{Parent Item, Orphan Source, and Data Base Name Match - Entire Report}

This report comes from the "Orphan Sources Matched by Name screen" and displays all of the matches that were found when the Setup query from this screen was executed. This query found all orphan sources that have the same Name as a data item in the data base. This report lists each match in a three line section of the report.

An example three line section of the report follows:

$\begin{array}{clcl}\text { DiUnique } & \text { Name } & \text { ID } & \text { RevNo } \\ 1 & \text { PARENT ITEM TITLE } & \text { WHC-XXX3 } & \\ & \text { ORPHAN/DATA ITEM TITLE } & \text { WHC-XXX2 } \\ 3 & \text { ORPHAN/DATA ITEM TITLE } & \text { WHC-XXX1 }\end{array}$

This three line section says that there is a record in the orphan source file with the Name "ORPHAN/DATA ITEM TITLE" and ID "WHC-XXX2". The query found a data item in the data base with the same Name. The parent item of the orphan source is "PARENT ITEM TITLE". At the time that "PARENT ITEM TITLE" was entered, one of its sources was entered as "ORPHAN/DATA ITEM TITLE" ID "WHC-XXX2" and when it was saved, the link process could not find "ORPHAN/DATA ITEM TITLE" ID "WHC-XXX2" in the data base. That is why it is in the orphan source file.

The administrator must now make the determination if the reference to "ORPHAN/DATA ITEM TITLE" in the orphan scurce file and the data base data item refer to the same data item. If so, the mark button in the "Orphan Sources Matched by Name screen" can be used to mark this record. When the link button is executed, "ORPHAN/DATA ITEM TITLE" ID "WHC-XXXI" will be linked to "PARENT ITEM TITLE" and "ORPHAN/DATA ITEM TITLE" ID "WHC-XXX2" will be deleted from the orphan source file.

Please refer to the next page for an example of this report.

\subsubsection{Parent Item, Orphan Source, and Data Base Name Match - Mark Records Report}

This report comes from the "Orphan Sources Matched by Name screen" and displays all of the records that were marked in the process described in the "Parent Item, Orphan Source, and Data Base Name Match - Entire Report" above. This report can be used to double-check the records to be linked before executing the link "Orphan Sources Matched by Name screen".

Please refer to the next page for an example of this report.

\subsubsection{TWRS Information Locator Data Item Info}

This report lists all of the attributes for a data item in a two page report, except for the sources and drains. In order to view the sources and drains for a data item, the administrator can: 
- Open the data item and move to the sources and drains section of the input form

- From the query module, the Query Results screen, select the Sources/Drains button.

Please refer to the next page for an example of this report. 


\subsection{TWRS ILD Interview Template}

\section{TWRS Information Locator Database (ILD) DATABASE-ONLY TEMPLATE}

1. Name

2. Document \#/ID (if any)

3. Acronym

4. Description

5. Custodian Information

Name:

Building:

City:

Telephone:

Organization Code:
Title:

Address:

State/Zip:

Mail Stop:

Payroll \#:

6. Data Base Type Information

-Flat File -Hierarchical

-Object Oriented

-Relational

-Sequential

\# of Record/Entries Record Size (in bytes)

7. Regulatory Requirement(s).

8. Confidence in Data (choose one)

-Expert System

Measurement

-Physical Model (Unverified)

-Other
-Physical Model (Verified)

-Professional Judgement
-Quantitative

-Statistical Analysis

9. Configuration Management

-None

-Formal Standard Authority

10. Life Cycle Information

- Operational - Date of Original Version

-In Development - Future Plans

-Inactive - Retired Date

11. Access Control - None Controlled

If Controlled, please specify:

Security Level

Control Authority

Access Instructions 


\section{Processor}

- Collection

- Computer Program

-Math Model

-Other

Name

Alias

Description

\section{Data Source(s)}

Name

ID

If there is a logical connection to the data item, please describe it:

Rev. No.

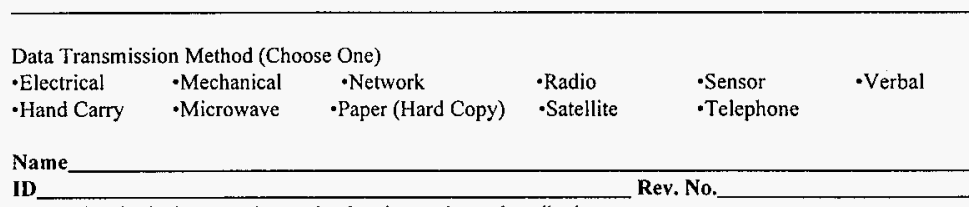

If there is a logical connection to the data item, please describe it:

Data Transmission Method (Choose One)

\begin{tabular}{|c|c|c|c|c|c|}
\hline $\begin{array}{l}\text { - Electrical } \\
\text {-Hand Carry }\end{array}$ & $\begin{array}{l}\text {-Mechanical } \\
\text {-Microwave }\end{array}$ & $\begin{array}{l}\text { - Network } \\
\text {-Paper (Hard Copy) }\end{array}$ & $\begin{array}{l}\text { - Radio } \\
\text {-Satellite }\end{array}$ & $\begin{array}{l}\text { - Sensor } \\
\text { - Telephone }\end{array}$ & -Verbal \\
\hline
\end{tabular}

14. Host In formation that the data resides on

\begin{tabular}{|c|c|c|}
\hline $\begin{array}{l}\text {-Apple MacIntosh } \\
\text {-IBM-PC }\end{array}$ & $\begin{array}{l}\text {-File Server } \\
\text {-Logbook }\end{array}$ & $\begin{array}{l}\text {-Minicomputer Workstation } \\
\text {-Mainframe Computer }\end{array}$ \\
\hline
\end{tabular}

PC Model Name or Nomenclature

RAM Available (in Mb)

Media Storage / Datu Item Size (in bytes) -Floppy Disk /

- Hard Disk (fixed) /

-Hard Disk (removable)/

Network

-LAN -WAN -None

-Other

Network Name

Network Type

\section{Application Software}

- Site Standard Software

- Please specify

- Non-Site Standard Software

- Please specify

- None

\begin{tabular}{|c|c|c|}
\hline \multicolumn{3}{|c|}{-Magnetic Tape / } \\
\hline \multicolumn{3}{|c|}{-Optical Disk/_ } \\
\hline -Other & & $-^{\prime}$ \\
\hline Operati & System & \\
\hline •AOS & -MVS & $\cdot \mathrm{OS} / 2 \quad \cdot$ Unix $\quad \cdot \mathrm{NT}$ \\
\hline$\cdot$ DOS & •PICK & -System $7 \cdot$ VMS \\
\hline Other_ & & \\
\hline
\end{tabular}




\section{TWRS Information Location Database (ILD) DOCUMENT-ONLY TEMPLATE}

1. Name - Highlight in pink

2. ID Rev. No.

3. Description - Highlight in pink

4. Acronym

5. Aliases

6. (Please choose one letter and specify what kind it is)

a. Document - Article - Chart - Specification - Standard - Book - Memo Date

- Spreadsheet - Technical Journal - other

b. Report - Business Management - Technical - other

c. Line Drawing - Architectural - Electric Schematic • Configuration Drawing Date. - Mechanical Drawing • other

d. Image Information - Artist's Renduring - Computer Generated - Photograph Date

- other

e. Video Information $\cdot 1 / 2$ inch $\cdot 3 / 4$ inch $\cdot 8 \mathrm{~mm} \cdot \mathrm{Hi} 8 \cdot \mathrm{VHS} \quad$ Date

- other

7. Functions and definitions are on a separate page.

8. Compliances - Highlight in green

9. Frequency of Issue

- Annually

- Biannually

- Monthly

- Near Real-Time

- Quarterly

- Real-Time

- Weekly

- Aperiodic

- Legacy

10. Data Sources - Highlight in yellow

11. Documents reside in a file cabinet

12. Location of the Data Item (Circle One)

-700 Area (Central Files) $\quad 300$ Area (Report Files) • other

13. Application Software

- Site Standard Software

- AutoCAD - Excel - Lotus -Word Perfect Version.

- cc:Mail Harvard Graphics - Paradox - other

- Non-Site Standard Software (please specify)

- None 


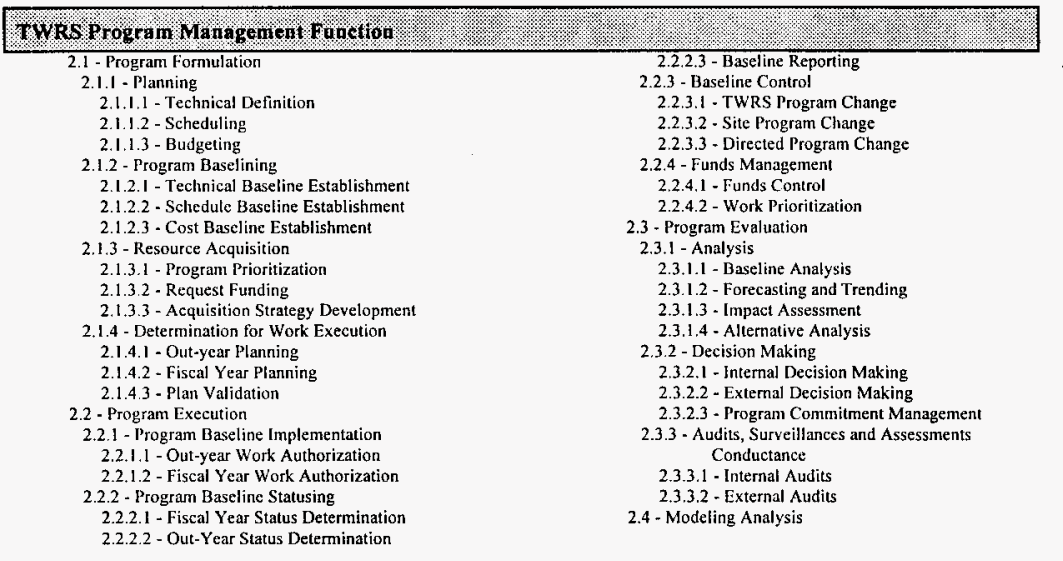

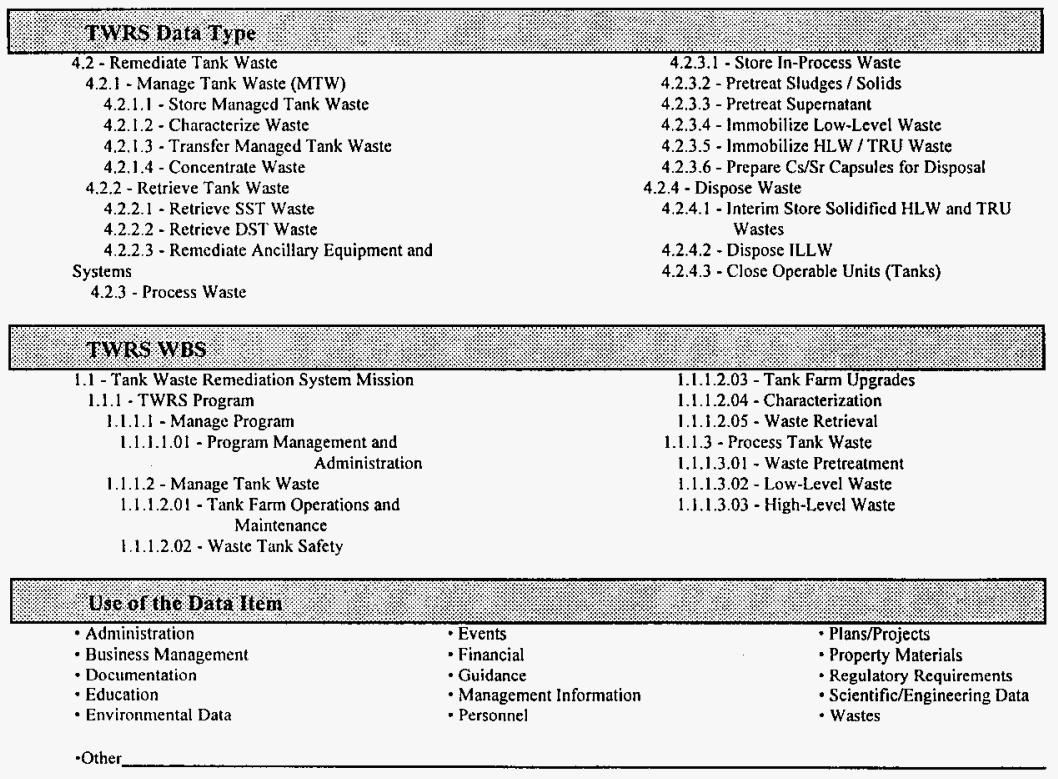

